University of Windsor

Scholarship at UWindsor

\title{
Structural studies of electroless thin Ni-P films grown in an alkaline environment.
}

\author{
Raul. Cortijo \\ University of Windsor
}

Follow this and additional works at: https://scholar.uwindsor.ca/etd

\begin{abstract}
Recommended Citation
Cortijo, Raul., "Structural studies of electroless thin Ni-P films grown in an alkaline environment." (1983). Electronic Theses and Dissertations. 3619.

https://scholar.uwindsor.ca/etd/3619

This online database contains the full-text of PhD dissertations and Masters' theses of University of Windsor students from 1954 forward. These documents are made available for personal study and research purposes only, in accordance with the Canadian Copyright Act and the Creative Commons license-CC BY-NC-ND (Attribution, Non-Commercial, No Derivative Works). Under this license, works must always be attributed to the copyright holder (original author), cannot be used for any commercial purposes, and may not be altered. Any other use would require the permission of the copyright holder. Students may inquire about withdrawing their dissertation and/or thesis from this database. For additional inquiries, please contact the repository administrator via email (scholarship@uwindsor.ca) or by telephone at 519-253-3000ext. 3208.
\end{abstract}


CANADIAN THESES ON MICROFICHE

\section{I.S.B.N.}

\section{THESES CANADIENNES SUR MICROFICHE

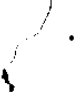

I*

National Library of Canada

Collections Development Branch

Bibliothèque nationale du Canada

Canadian Theses on

Microfiche Service

Direction du développement des collections

Ottawa, Canada

Service des thèses canadiennes

sur microfiche

KIA ON4

\section{NOTICE}

The quality 'of this microfiche is heavily dependent upon the quality of the original thesis submitted for microfilming. Every effort has been made to ensure the highest quality of reproduction possible.

If pages are missing, contact the university which granted the degree.

Some pages may have indistinct print especially if the original pages were typed with a poor typewriter ribbon or if the university sent us a poor photocopy.

$$
\text { (ing }
$$

Previbusly, copyrighted materials (journal articles, published tests, etc.) are not filmed.

Reproduction in full or in part of this film is governed by the Canadian Copyright Act, R.S.C. 1970; c. C-30. Please read. the authorization forms which accompany this thesis.

\section{THIS DISSERTATION \\ HAS BEEN MICROFILMED EXACTLY AS RECEIVED}

La qualité de cette microfiche dépend grandement de la qualité de la thèse soumise au microfilmage. Nous avons tout fait pour assurer une qualité supérieure de reproduction.

S'i! manque des pages, veuillez communiquer avec l'université qui a conféré lè grade.

La qualité d'impression de certaines pages peut laisser à désirer, surtout si les pages originales ont été dactylographiées à l'aịde d'un ruban usé ou si l'univer. sité nous a fait parvenir une photocopie de mauvaise qualité.

Les documents qui font déjà l'objet 'd'un droit d'auteur (articles de revue, examens publiés, etc.) ne sont pas microfilmés.

La reproduction, même partielle, de ce microfilm est soumise à la Loi canadienne, sur le droit d'auteur, SRC 1970, c. C.30. Veuillez prendre connaissance des formules d'autorisation qui accompagnent cette thèse.$$
\text { Canadä }
$$ 


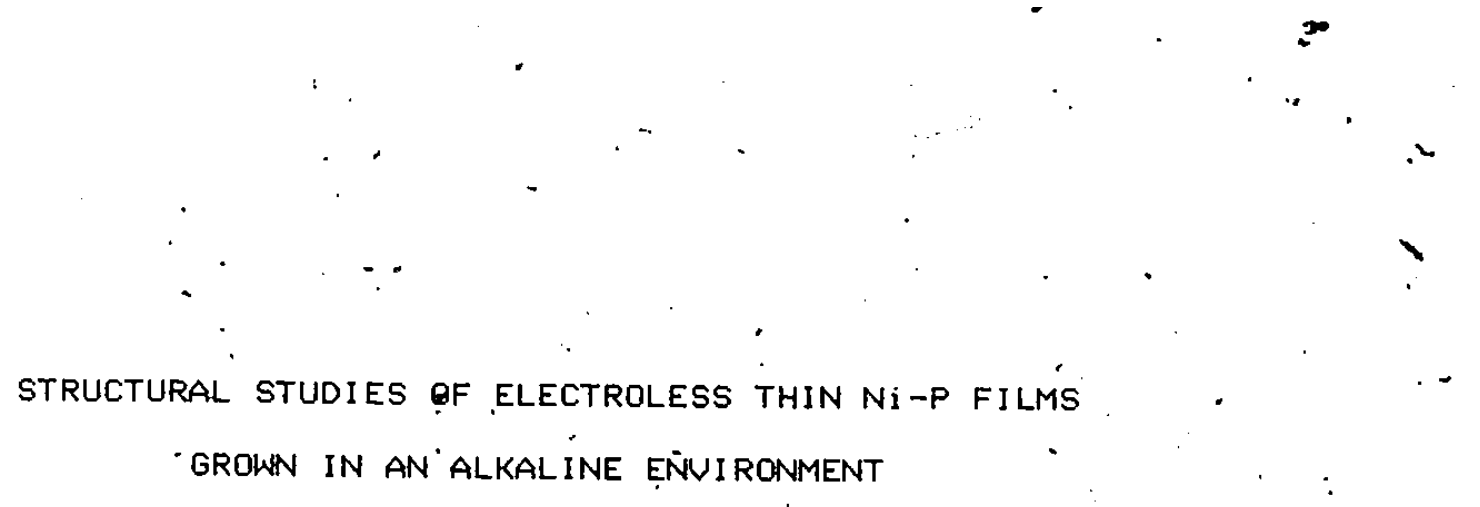
GROWN IN AN ALKALINE ẸNUI RONMENT

ช

-

by

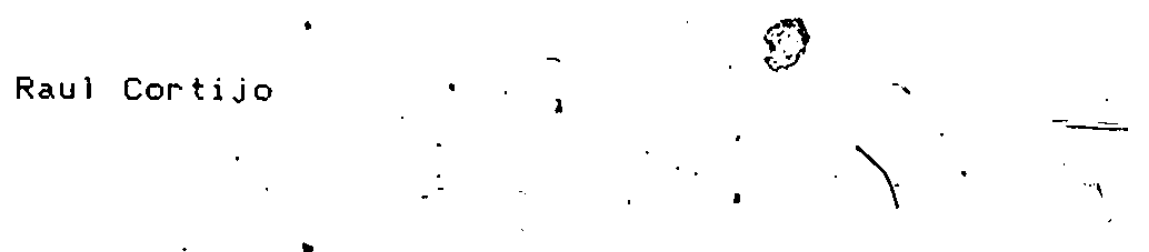

A Thesis

Submitted to the Faculty of Graduate studies through the

Department of Yhysics in Partial Fulfillment of the

Requirements for the Degree of Master of Science

at the University of Windsor

Windsor, Ontario

1983 


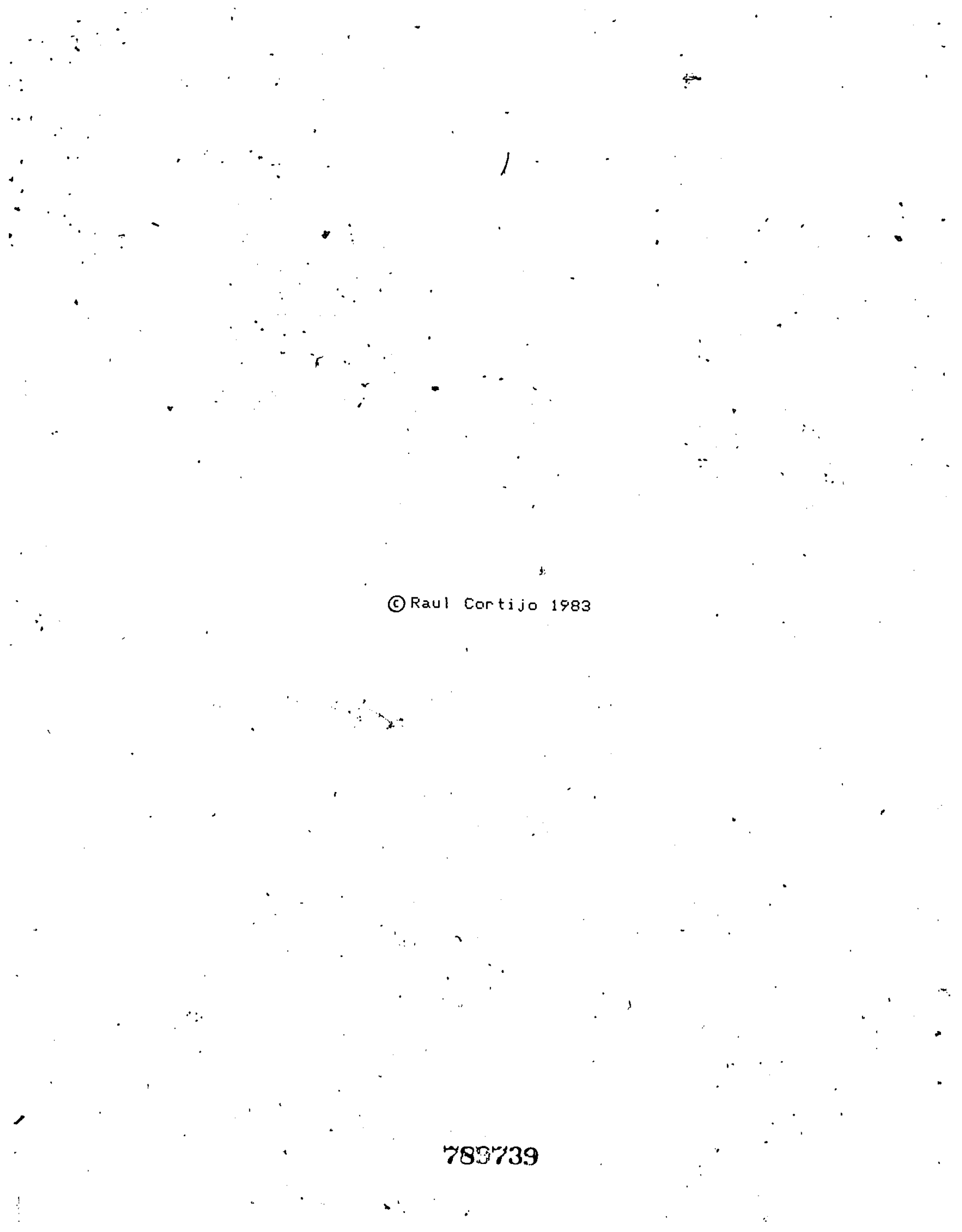


Abstract

A comparative study of the microstructure of electrolessry deposited NiP thin films grown from an alkaline bath with different $\mathrm{pH}$ values was performed. Using Radial Distribution Function (RDF) analysis of the diffraction patterns a model for the structure is given and it is concluded that the films differ mainly by the sizes of their component crystallites. The crystallitas while retaining a high degree of order, exhibit ad liquid like character due to their large surface to volume ratio. 
Ackrioun 1 edgement

I would like to express my sincere thanks to Dr. M. Schlesinger. for his supervision and continual guidance in.' this project. I also wi sh to thank Dr. R. Helping for kindly letting

- me use his computer facilities to get this thesis printed, to Mr.'

- J. Robinson for his technical help in areas dealing with. the electron microscope and last' but not least I would like to thank - my wife Melissa for providing moral support. 


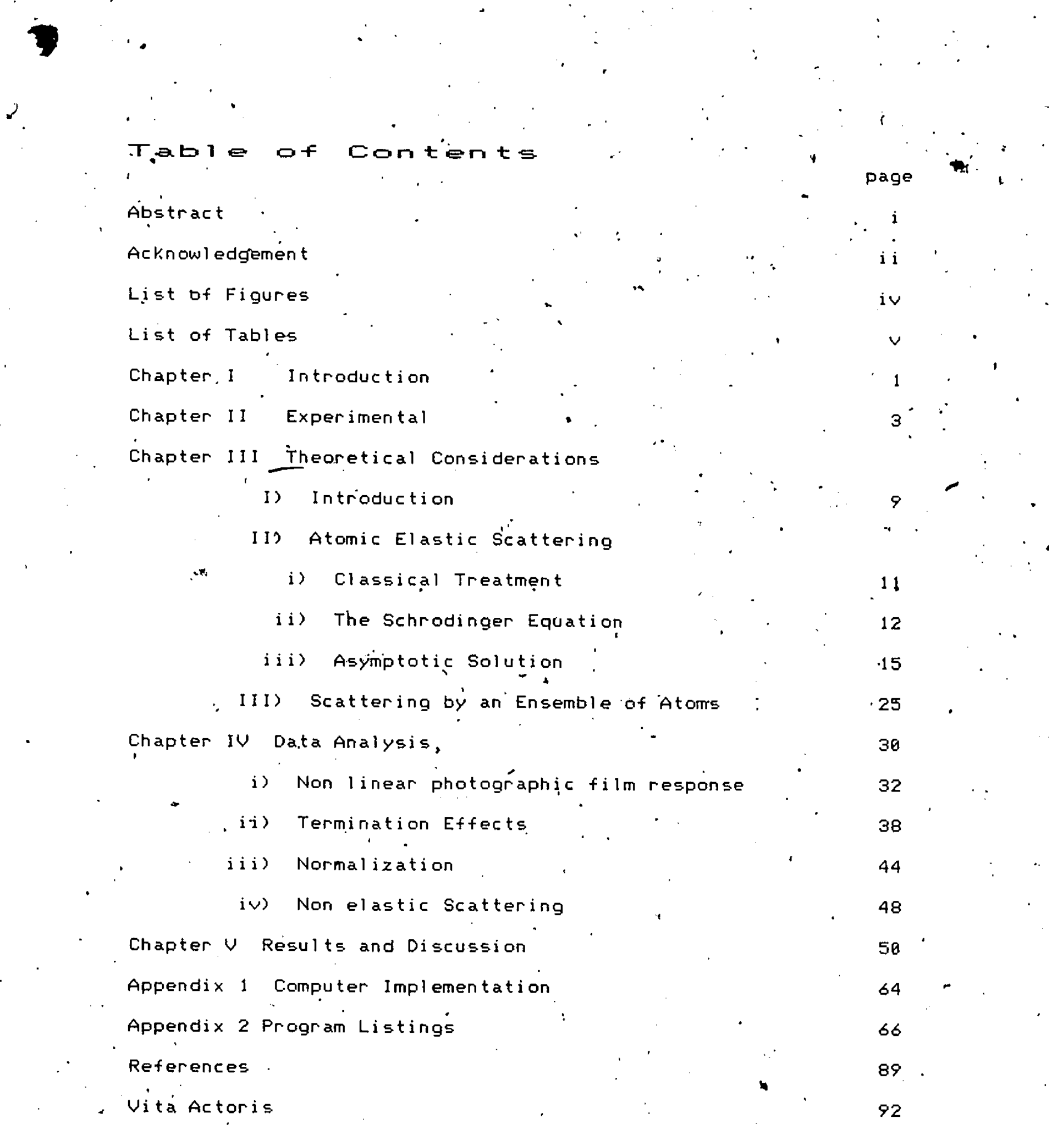


List of Figires

Figure IV-1 Typical characteristic curve for photographic

Figures IU-2 Series of diffraction pattern curves of the and IV-3 same sample taken wi th varying exposure'time.

Figure IV-4 Plot of diffuse density vs. exposure time for the different well defined peaks present in

- figures $I V-2$ and $I V-3$

Figure IV-5 Square wave pulse truncating function and corresponding Fourier transform

Fiqure IU-6. Triangular truncating and corresponding

Fourier transform

Figurel IV-7 Hanning truncating and corresponding

Fourier transform

Figure $I V-8 \quad I(s) / N$, and $f^{2}(s)$ curves for typical sample

Figure U-1 Transmission electron micrographs of electro- lessly deposited Ni-P. films from an alkaline solution grown at different pH values

Figure $U-2$ Diffraction pattern curves corresponding to. the films shown in figure $V-1$

Figures $\mathrm{V}-3$

$i(s)$ curves obtained after the correction and. $v-4$ procedures 


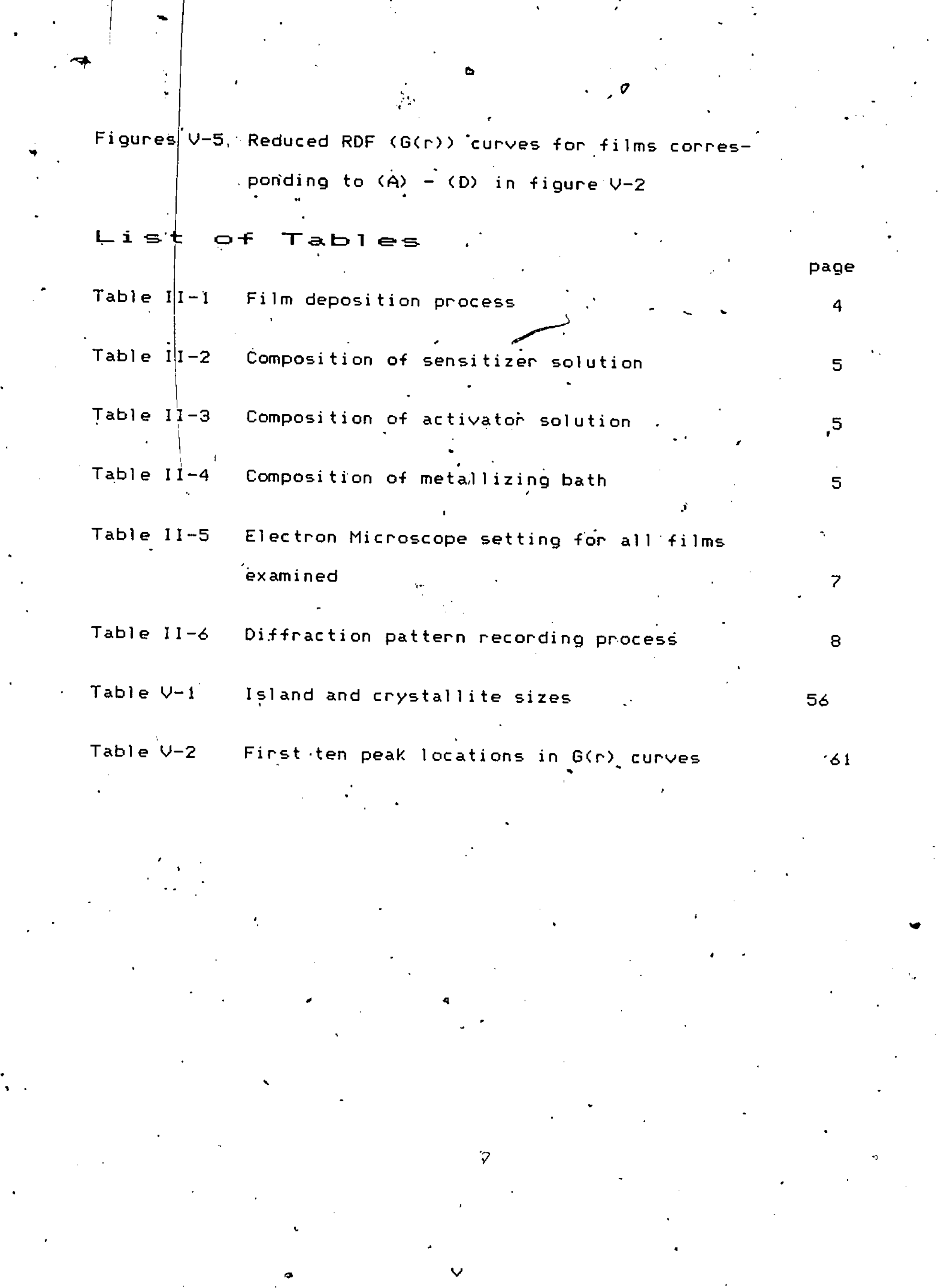




\section{Introduct ion.}

The electrolessly deposited films continue to attract a great deal of attention in both scientific and industrial fields. From an industrial point of view electroless films provide a relatively cheap method to plate non conductive materials. Using the photo-selective properties of the deposition of these films one can create negative or positive images. This fact has been widely used in the printed board industry. As a matter of fact, all PC boards in the new generation IBM computers have been electrolessly deposited (1). From the physicist point of view these films provide an initeresting range of systems from totally amorphous to crystalline.

The present work deals with one specific electrolessly deposited thin metal system, Ni-P films grown in alkaline environment. Ni-P films grown in acidic solution have been the subject of a large ammount of research work for under the proper conditions, they can exhibit total amorphicity $(2,3,4)$. On the other hand basic grown Ni-P has not been treated until very recently. One of the newly discovered properties is that using the same basic solution both photo-selective negative and positive deposition is possible(5). It is, al so known that the amount of co-deposited phosphorous varies the amount of crystallinity of the films. The aim of the present work is to clarify the nature of the partial erystallinity observed.

1 Radial distribution functions, RDF, will be calculated for a series of films grown in metallizing baths of different pH 


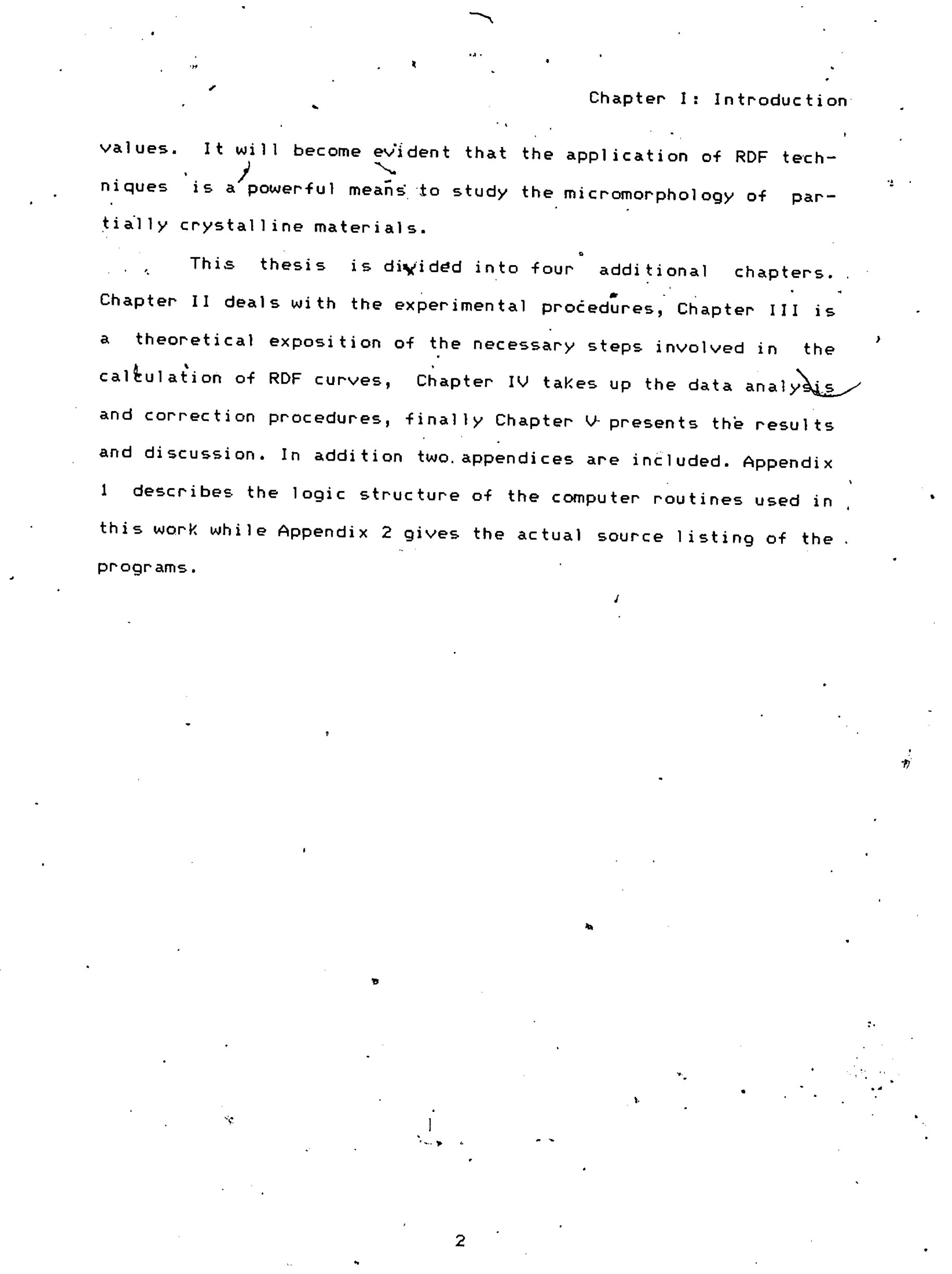




\section{CHAPTER II}

\section{Experimental}

1 Films

i) Deposition

The thin films used for this study were grown on microscope glass slides coated with a.thin layer of Formvar. In order to apply the formuar layer the following procedure was used. The glass slide was placed inside a large burette and formvar solution,.. consisting of $4 \mathrm{~g}$ of polyvinylformal in 11 of ethylene dichloride, was run through the burette. The thickness of the Formuar layer is directiy proportional to the flow rate of the solution i.e. to obtain a thin formvar layer the solution imust be drained at a very. Slow rate, typically a formvar solution of $250 \mathrm{ml}$ was, drained in. 10 seconds.

The films were grown following standard electroless deposition techniques $(6,7)$ (see Tabie 11-1). The Formuar substrate was activated by immersing the slide successively in solutions of $\mathrm{SnCl}_{2}$ and $\mathrm{PdCl}_{2}$. These solutions are refered to as sensitizer and Activator respectively. Their overall effect is to form nucleation centers. on which the metal films start to grow. The metallizing bath was kept at a constant temperature of $43^{\circ} \mathrm{C}$ and its $\mathrm{pH}$ was recorded with a FISHER DIGITAL PH METER 107 while the films were deposited. The slide was left in the metalizing bath until the films had grown to give a smooth metatlic shine. This was an indication that the metal film was nearly continypus (see figure $v-1)$. The time required for deposition varied af a function of the $\mathrm{pH}$ of the bath. The actual composition of all solutions used is given in Tabies.II-2 to II-4. 
ii) Sample Preparation

As soon as the deposition process was finished, the slide was rinsed in distilled water, then the metallized Formvar layer was separated from the glass slide by partially floating it in distilled water. At this point an electron microscope sample holder grid was inserted between the glass and the Formvar. The water was then removed taking special care that the grid remained between the Formvar and the glass at the desired position. After the slide was nearly dry the metal film was cut around the grid, which could then be lifted by a pair of fine tweezers. The films were not dried totally because the Formuar layer would stick again to the glass and the grid would not lift from the glass slide without breaking the metallized formvar layer sitting on the grid.

\begin{tabular}{|l|r|}
\hline SOLUTION & TIME \\
\hline Sensitizer & $2.5 \mathrm{~min}$ \\
Rinse & $30 \mathrm{sec}$ \\
Activator & $3 \mathrm{~min}$ \\
Rinse & 30 sec \\
Metallizing & $\mathrm{pH}$ dependent \\
\hline
\end{tabular}

Table II-1 Film deposition process 
、

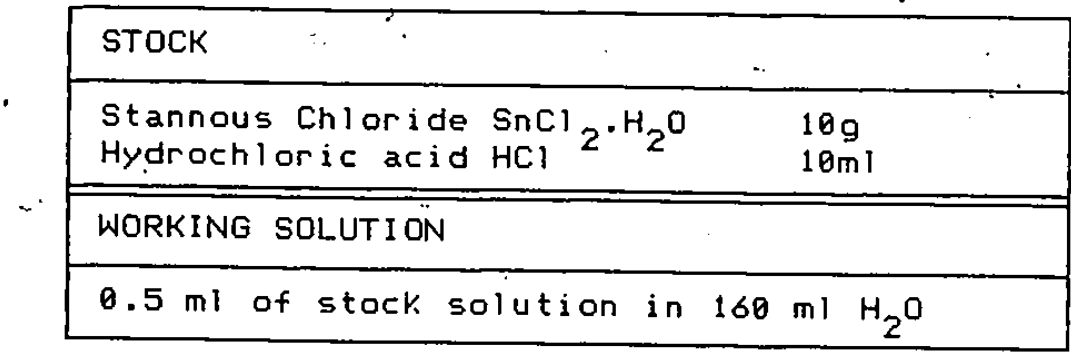

Table II-2 Composition of Sensitizer Solution

\begin{tabular}{|l|l|}
\hline STOCK \\
\hline Palladium Chloride $\mathrm{PdCl}^{2}$ & $10 \mathrm{~g}$ \\
Hydrochloric acid $\mathrm{HCl}^{2}$ & \\
\hline WORKING SOLUTION & \\
\hline $1 \mathrm{ml}$ of stock solution in $200 \mathrm{ml}$ of $\mathrm{H}_{2} \mathrm{O}$ \\
\hline
\end{tabular}

Table II-3 Composition of Activator Solution

\begin{tabular}{|llr|}
\hline STOCK & & \\
\hline Nickel Sulfate & $\mathrm{NiSO}_{4} \cdot 6 \mathrm{H}_{2} \mathrm{O}$ & $30 \mathrm{~g} / 1$ \\
Sodium Hypophosphite & $\mathrm{NaH}_{2} \mathrm{PO}_{2} \cdot \mathrm{H}_{2} \mathrm{O}$ & $10.6 \mathrm{~g} / 1$ \\
Sodium Citrate & $\mathrm{Na}_{3} \mathrm{C}_{6} \mathrm{H}_{5} \mathrm{O}_{7} \cdot 2 \mathrm{H}_{2} \mathrm{O}$ & $200 \mathrm{~g} / 1$ \\
Ammonium Chloride & $\mathrm{NH}_{4} \mathrm{Cl}$ & $53.6 \mathrm{~g} / 1$ \\
\hline \hline WORKING,SOLUTION & & \\
\hline Add concentrated NaOH to adjust $\mathrm{PH}$ to desired \\
\hline
\end{tabular}

Table II-4. Composition of metallizing Solution 


\section{Electron Microscopy}

Since a number of different samples were studied and "the
results were to be compared a standard examination technique was
developed. The main goal was to view these samples in the "as
deposited" state, thus all samples were examined the. same day
they were grown. It is also known that heat treatment will trans-
form the as deposited Ni-P films to a series of different phases
until a stable two phase state of face centered cubic Ni and body
centered tètragonal $\mathrm{Ni}_{3}{ }^{P}$ is reached ( 8 ).

Hence if during the examination of the samples the electron beam is condensed to a small size it can heat the sample causing it to deteriorate by changing state. This heating technique can actualiy sometimes be useful and has been successfully used by other authors to study the different phases of Ni-P films (9)

, however in this study parkmeters were chosen (see Table II5) so that the electron beam width and intensity caused no herating effects leaving the samples in the as deposited state. The electron microscope used for the examination of the samples was a JEOL model JEM-100CX. The sources of experimental data were Bright Field electron micrographs and Selected Area Diffraction patterns which were recorded photographically. on KODAK Electron Image Film 4463. The effective focal length used for the SAD was cakculated using a standard thin film of pure aluminum.

3 Recording of Diffraction Patterns

The photographic films with the diffraction pattern,s were scanndd by a standard JARRELL ASH densitometer at a speed of 25 $\mathrm{mm} / \mathrm{min}$. The densitometer was equipped with a non cooled RCA: IP28 
photomultiplier which gave a small current.signal, up to $3.0 \mathrm{E}-5$ amps, that was fed to a KEITHLEY 410 micro-microammeter. This ammeter is provided with an output for driving a strip chart recorder, and it generates a 5 volt signal at full scale meter deflection which is particularly suitable for use as the input of a DEC ADU11-A analog to digital converter (ADC). The ADC samples an analog voltage signal in the range of $-5 V$ to $5 V$ and converts it to a series of octal numbers from 0 to 7777 . The ADC was controlled by a program implemented in a PDP $11 / 03$ computer (see appendix 1), whose action was to determine the sampling rate, eliminate random noise and to store the data in ASCII files for later use. The elimination of the random background noise was achieved by performing two different types of averaging. First, to facilitate calculations it was desired to digitize the diffraction pattern to 1824 points, each of these points being the average of 8 consecutive sampled points. Second, many runs of each diffraction pattern were taken and the overall average determined. A diagram representing the recording process is given in Table $11-6$.

\begin{tabular}{|lc|}
\hline \multicolumn{1}{|c|}{ Accelerating voltage } & $100 \mathrm{KV}$ \\
\hline \hline Electron inicrographs \\
\hline Objective aperture & $120 \mu_{\mathrm{m}}$ \\
Magnification & $20000 \mathrm{X}$ \\
Photographic exposure & $5.6 \mathrm{sec}$ \\
\hline \hline Selected Area Diffraction & \\
\hline Field aperture & $250 \mu_{\mathrm{m}}$ \\
Focal length & $236 \mathrm{~mm}$ \\
Photographic exposure & see chapter IV \\
\hline
\end{tabular}

Table Il-5 Electron Microscope setting for all films examined 


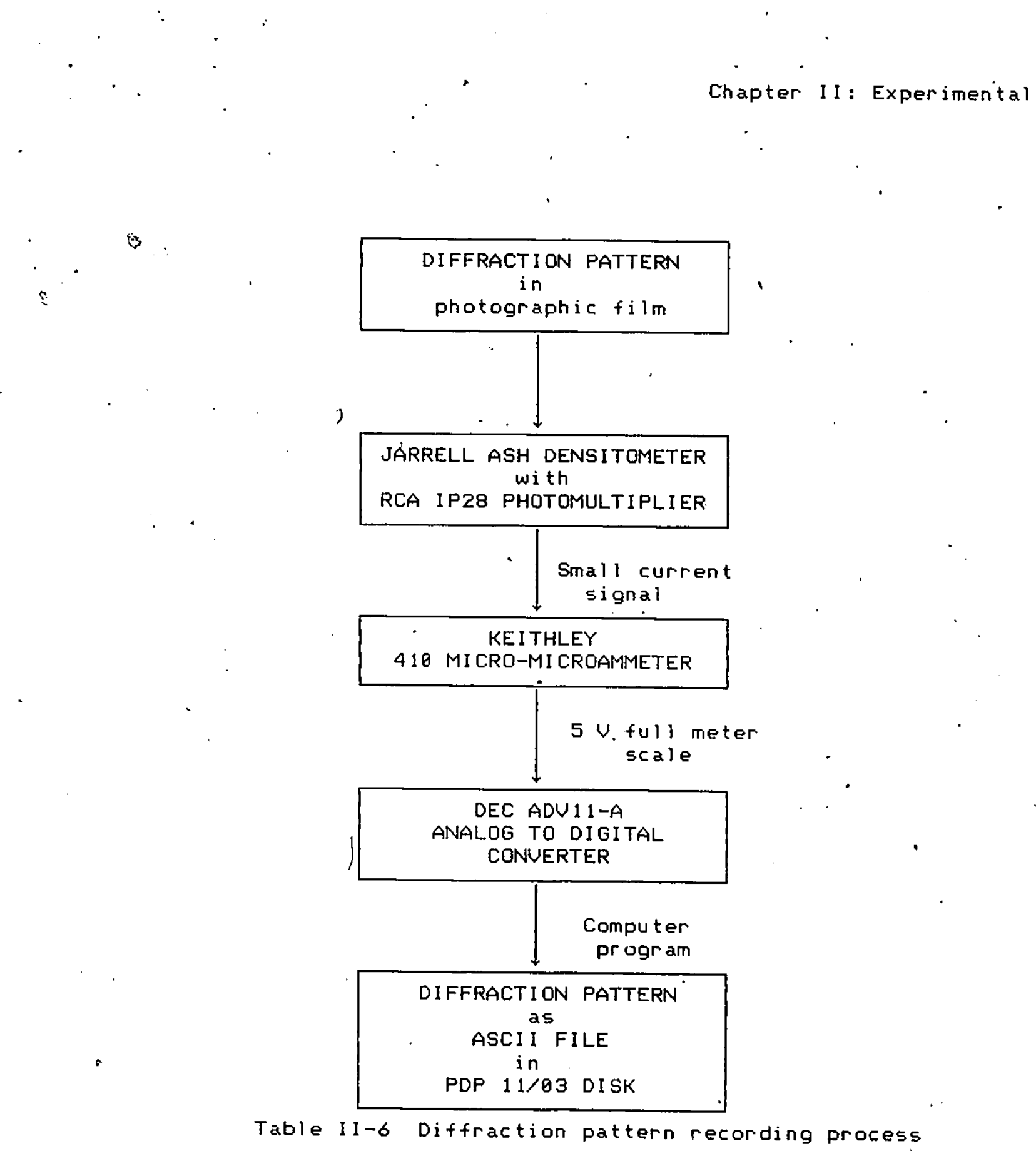

$8^{n}$ 


\section{CHAPTER II I}

Theoretical

Considerations

I) Introduction

The derivation of distribution functions from interference patterns of X-rays or electrons for materials containing a single species was first achieved by Zernike and Prins (10) in 1927. The first application of this technique was carried out in 1930 by Debye and Menke (11) in studying the structure of. liquid mercury. Since ther a good number of authors $(12-18)$ have treated the subject, expanding the theory to cover materials with more thăn one species.

The aim of this section is to present this theory in a general fashion while'trying to give sufficient background to obtain a thorough understanding of the concepts involved in electron diffraction experiments: Let us consider now some of the factors that ought to be taken into consideration when studying the scattering of an electron beam.

The interference pattern obtained by electron diffraction is determined by the manner in which the atoms are distributed in the scattering lattice of the observed sample. Of the various interactions that arise with the passage of an electron' beam through the sample, coulombic attraction and repulsion are by far the most significant and thus are the only ones that need be considered. The range and duration of these interactions is short even with respect to atomic magnitudes and by using accelerating potentials in excess of $30 \mathrm{KV}$ the range can be reduced to a level that permits the use of useful approximations. The electron distribution of the individual scattering atoms in the 
lattice is assumed to be spherical. The initial beam is described as a parallel electron wave in a spherical atomic force field. With these approximations the Hamiltonian for the system is. determined. The corresponding schroedinger equation describes the way in which the electron wave changes as it passes through the field. On the emerging side of the field the potential energy decreases, to zero and the electron wave function will assume an asymptotic form. The scattered beam, as observed at come point remote from the scattering center; is the resultant, of all waves emanating from the different atomic centers. Thus the wave function of the peam is obtained by adding the wave functions due to the scattering of the individual atoms. Each of these component waves has traveled a different distance to reach the point of observation and consequently interference effects are abserved. On the scale of the observer the scattered beam of electrons can be treated as if it came from a single point, i.e. the wave. function has spherical form and its intensity is inversely proportional to the distance from the scattering center.

During the collision process there exists the possibility that either of two different types of events may occur. In one the incoming electron deflects off the target without energy exchange, and in the other there is an energy exchange. These two processes are referred as elastic and inelastic scattering respectively. The elastically scattered electrons retain their original wavelength while inelastically scattered electrons after losing some of their energy obtain a longer wavelength. The difference of wavelengths can be large enough. to cause interfe- 
chapter III: Theoretical Considerations Fence effects between the elastic and inelastic parts of the scattered beam, thus to reduce unwanted interference effects inelastic scattering is always minimized.

II) Atomic Elastic Scattering

i) Classical Treatment

Let us consider first the classical treatment of scattering by a coulombic force field. It should be noted that while many aspects of the classical treatment are inappropiate for atomic scale phenomena, it does nevertheless give estimates of the magnitude of some. of the parameters of the problem.

The standard classical tireatment which deals with the case of a moving body scattered by an inverse square force. field exerted upon it by a stationary object of infinite mass is solved in Goldstein's book (19).

If the moving body has sufficient kinetic energy to avoid capture its path will be hyperbolic. If the force is coulombic and assuming that the moving object is an electron and that the stationary object bas a charge of qe then we have the relation:

$$
p \tan \theta=\frac{q \mathrm{e}^{2}}{m v_{0}^{2}} \quad \therefore \quad \text { (1) }
$$

where $m$ is the mass of the electron, $v_{0}$ its initial velocity and $P$ is the impact parameter. 'The angle of deflection, $\theta$ increases with'the charge of the scattering atom and decreases with increasing. Kinetic energy. As a measure of the effective range of the coulombic interaction we can determine the impact parameter corresponding to the smallest measurable deflection urder typical experimental conditions. We assume that the it is impractical to 


$$
\text { chapter ill: Theoretical Considerations }
$$

measure the intensity of scattered electron beams with scatteing angle of less than $1^{\circ}$. If we take that as our minimum measurable defiection assuming that the incident electrons have a kinetic energy of $188 \mathrm{kV}$ and that the charge of the scattering atoms is 1 , then the maximum impact parameter for which the deflections are significant is less than 8.01 angstroms. Thus the probabjhity that an electron, in its passage through an atomic field, will suffer a measurable deflection is small. Even if the orientation of the crystal lattice with respect to the path of the electron

1 is such that the electron may pass through the force field of more than one atom, it still is unlikely that more tion one measurable deflection will take place. This line of thought constitutes at least a qualitative justification for the use of approximations to describe the scattering centres.

ii) The Schroedinger Equation

The target atom is treated as stationary thus the only Kinetic energy operator in the Hamiltonian for the system is that of the beam elegtton. The potential interaction.term is that for the beam election and an atom with a time averaged electron distribution. Since we assumed that the electron distribution had spherical symmetry, the potential energy will be a function of a single variable $r$, the distance from the beam electron to the atomic nucleus.

The general form of the Schroedinger equation in polar coordinates is 


$$
\begin{aligned}
& \text { f. Chapter III: Theoretical iconsiderations } \\
& \frac{-h^{2}}{8 \pi^{2} m} \bar{V}^{2}[R(r) Y(\varphi)]+V(r) R(r) Y(\phi)=R(r) Y(\varphi) E \quad ; \quad \text { (2) } \\
& \text { where } \\
& \bar{v}_{r, \phi}^{2}=\frac{1}{r^{2}} \frac{\delta}{\delta r}\left[\frac{r^{2} \delta}{\delta r}\right]+\frac{1}{r^{2} \sin \phi} \frac{\delta}{\delta \phi}\left[\frac{\sin \phi \delta \phi}{\delta \phi}\right] \\
& \text { and } \phi=2 \theta \text { is the angle of deflection. } \\
& \text { - The separation of variables is accomplished in the. } \\
& \frac{-h}{8 \pi^{2} m}\left[\frac{1}{r^{2}} \frac{\delta}{\delta r}\left[\frac{r^{2} \delta[R(r) Y(\phi)]}{\delta r}\right]\right. \\
& \left.+\frac{1}{r^{2} \sin \phi} \frac{\delta}{\delta \phi}\left[\frac{\sin \phi d[R(r) Y(\phi)]}{\delta \phi}\right]\right]+[E-U(r)] R(r) Y(\phi)=0 . \\
& \text { Rearrange to give } \\
& \begin{aligned}
\frac{Y(\phi)}{r^{2}} & \frac{d}{d r}\left[\frac{r^{2} d R(r)}{d r}\right]+\frac{R(r)}{r^{2} \sin \phi} \frac{d}{d \phi}\left[\frac{\sin \phi d Y(\phi)}{d \phi}\right]_{-} \\
& +[K-U(r)] R(r) Y(\phi)=\theta
\end{aligned} \\
& k^{2}=\frac{8 \pi^{2} m E}{h^{2}} \quad U(r)=\frac{8 \pi^{2} m U(r)}{h^{2}}
\end{aligned}
$$

Multiplying equation (5) by $r^{2}$ and dividing by the wave function $R(r) Y(0)$ yields:

$$
\begin{aligned}
& \frac{1}{R(r)} \frac{d}{d r}\left[\frac{r^{2} d R(r)}{d r}\right]+\left[k^{2}-\dot{U}(r)\right] r^{2}=\cdot \\
& \quad \frac{-1}{-Y(\phi) \sin \phi} \frac{d}{d \phi}\left[\frac{\sin \phi d Y(\phi)}{d \phi}\right](6)
\end{aligned}
$$

Since the variables are independent, equation (6) can only be satisfied if both sides are equal to a constant. Let this constant be $c$, then the differential equation for $Y\langle 0\rangle$ is 
$\frac{1}{-Y(\phi) \sin \phi} \frac{d}{d \phi}\left[\frac{\sin \phi d Y(\phi)}{d \phi}\right]=-\operatorname{cr}(\phi)$

by making the transformation $X=\cos \$$ we get.

$\frac{d}{d X}\left[\left(1-X^{2}\right) \frac{d Y}{d X}\right]+c Y=0$

This is the general form of the, Legendre Differential Equation. Solutions to this equation exists if $c=1(1+1)$, where 1 is a positive integer. The solutions are given by

$Y(\phi)=P_{1}(\cos \phi)$

- which are the Legendre polynomials. The functional form of the Legendre polynomials is well known (26).

So far we have found that we are dealing with a system that has quantized eigenstates. The quantum number 1 , which characterizes these states, is associated with an angular momentum value of $L=\left[(1(1+1)]^{1 / 2} \hbar\right.$. These are the states available to the individual electrons. The incoming beam will contain electrons distributed among the available states, thus the wave function of the beam will be of the form

$\Psi(r, \phi)=\sum_{1=0}^{\infty} A_{1} R_{1}(r) P_{1}(\cos \phi)$

where the coefficients $A_{1}$ will be determined by suitable boundary conditions.

From equation.(6) the radial wave equation can be determined as

$\frac{1}{R_{1}(r)} \frac{d}{d r}\left[\frac{r^{2} d R_{1}(r)}{d r}\right]+\left[k^{2}-U(r)+r^{2}=1(1+1)\right.$

which rearranges to 
$\frac{1}{r^{2}} \frac{d}{d r}\left[\frac{r^{2} d R_{1}(r)}{d r}\right]+\left[k^{2}-U(r)-\frac{1(1+i)}{r^{2}}\right] R_{1}(r)=0$

iii) Asympotic Solution

At large $r, r \rightarrow \infty$, both $U(r)$ and $r^{-2}$ approach,zero. Thus the solutions of equation (12) will approach the solutions of

$\frac{1}{r^{2}} \frac{d}{d r}\left[\frac{r^{2} d R_{1}(r)}{d r}\right]=-k^{2} R_{1}(r)$

The general solution of equation (13) is of the form

$R_{1}(r)=B_{1} r^{-1} \sin (k r)+\dot{C}_{1} r^{-1} \cos (k r)$

where the coefficients $B_{1}$ and $C_{1}$ maty be real or imaginary. At small $r$ the functions $R_{1}(r)$ must also approach the solutions of the equation obtained by setting term $U(r)$ equal to zero in equation (12)

$\frac{1}{r^{2}} \frac{d}{d r}\left[\frac{r^{2} d R_{1}(r)}{d r^{0}}\right]+\left[k^{2}-\frac{1(1+1)}{r^{2}}\right] R_{1}(r)=0(15)$

This is a form of the Bessel's equation and its solutions are well known (21). These are of the form

$\lambda \quad R_{1}(r)=\left[\frac{\pi}{2 k r}\right]^{/ 2} J_{1+K_{2}}(k r)=J_{1}(k r)$

We are interested in the asympotic form of the solutions given in equation (16) which are finite for all values of $r$. This will give us a description of the incident beam since it has suffered no potential interaction. The asympotic form of the solutions is 


$$
\begin{aligned}
R_{1}(r)= & \frac{1}{k r} \sin \left(k r-\frac{1 \pi}{2}\right) \\
& B y \text { inserting equation (16a) into equation (16) and }
\end{aligned}
$$
Demembering that the incident beam is represented by a plane wave function we obtain

$\sum_{1=0}^{\infty} A_{1} R_{1}(r) P_{1}(\cos \phi)=e^{i k z}=e^{i k r \cos \theta}$

To obtain the coefficients $A_{1}$ we multiply both sides of equation (17) by $P_{1}(\cos \phi)$ sind and integrate from $\theta$ to $\pi$

$\int_{0}^{\pi} P_{1}\langle\cos \phi) \sin \phi e^{i k r \cos \phi} d \phi=\int_{\theta}^{\pi} A_{1} R_{1}(r) P_{1}^{2}(\cos \phi) \sin \phi d \phi$

Letting $t=\cos \$$ we botain

$\cdot \int_{-1}^{1} P_{1}(t) e^{i k r t} d t=A_{1} R_{1}(r) \int_{-1}^{1} P_{1}^{2}(t) d t$

$$
=\frac{2}{21+1} A_{1} R_{1}(r)
$$

Integrating the left hand side by parts yields

$$
\int_{-1}^{1} P_{1}(t) e^{i k r t} d t=\frac{1}{i k r}\left[e^{i k r t} P_{1}(t)\right]_{-1}^{+1}-\frac{1}{i k r} \int_{-1}^{1} e^{i k r t} P_{1}^{\prime}(t) d t
$$

The second term is of the order of $r^{-2}$ and in our asympotic assumption can be neglected thus

$$
\begin{aligned}
& \frac{2}{21+1} A_{1} R_{1}(r)=\frac{1}{i k r}\left[e^{i k r t} P_{1}(t)\right]-1 \\
& 1 \text { Since } \cdots P_{1}(1)=1 \text { and } P_{1}(-1)=(-1)^{\prime} \text { the right hand side of } \\
& \text { equation (21) is }
\end{aligned}
$$


RHS $=\frac{1}{i k r}\left[e^{i k r t} P_{1}(t)\right]_{-1}^{+1}=\frac{1}{i k r} e^{i k r}-(-1) i e^{-i k r}$

Recall that $(-1)^{\prime}=e^{i \pi i}$, thus.

$R H S=\frac{1}{i k r}\left[e^{i k r}-e^{i \pi l} e^{-i k r}\right]$.

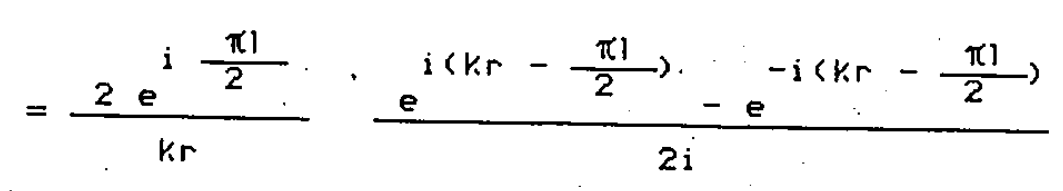

but e $\frac{\pi}{2}=i^{1}$ thus

RHS $=\frac{2 i l}{k r} \sin \left(k r-\frac{\pi}{2}\right)$

Hence equation (21) becomes

$\frac{2}{2 l+1} A_{1} R_{1}(r)=\frac{2}{k r} i^{1} \sin \left(k r-\frac{\pi l}{2}\right)$

substituting (16a) in (25) we get

$\frac{2}{21+1} A_{1} \frac{2}{k r} \sin \left(k-\frac{\pi 1}{2}\right)=\frac{2}{k r} i^{1} \sin \left\langle k r-\frac{\pi 1}{2}\right)$

Therefore

$$
A_{1}=(21+1) i^{1}
$$

and consequently the wave, function for the incident beam is $e^{i k z}=\sum_{l=0}^{\infty}(21+1) i^{l} \frac{1}{k r} \sin \left(k r-\frac{\pi l^{b}}{2}\right) P_{1}(\cos \phi)$

iv) The Scattered. Beam

As previousiy stated the wave function of the scattered beam $c$ an be considered to have spherical symmetry in which the scattered amplitude $f(\phi)$ will be determined by the nature of the scattering center. A substantial part of the beam that passes 
through the potential field will be undeflected, thus there will be a significant plane wave component. From these consideration we can anticipate that the. wave function of the 'scattered beam will be of the form:

$$
\psi(r, \phi)=\frac{1}{r} f(\phi) e^{i k r}+e^{i k z}
$$

We approach the problem of finding. the asympotic form of the scattered wave function in the same manner as we did for the incident beam. The angliar dependence for both incident and scattered beams are the same, thus the angular functions will again be the Legendre polynomials. The radial functions must be solutions of both equations (13) and (15), furthermore the radial functions must approacti the form given in equation ( $16 a$ ) as $U(r$ ) becomes vanishingly small. However unlike the incident beam, the scattered beam -has a past history arising from its passage through the atomic field, thus it can be determined (22) that the radial part of the scattered beam wave function has the form.

$R_{1}(r)=\frac{1}{k r} \sin \left(k r-\frac{\pi l}{2}+\eta_{1}\right)$

where $\eta_{1}$ is called the partial wave phase shift and depends on $k$ and $U\langle r\rangle$. We can now write the wave function as

$\because \psi(r, \phi)=\sum_{1=\theta}^{\infty} A_{1} P_{j}(\cos \phi) \frac{1}{k r} \sin \left(k r-\frac{\pi 1}{2}+\eta_{1}\right)$

Substituting equation (28) in. (38)

$$
\begin{aligned}
\sum_{i=0}^{\infty} A_{1} P_{1}(\cos \phi) & \frac{1}{k r} \sin \left(k r-\frac{\pi 1}{2}+\eta_{\gamma}\right\rangle \\
& =\frac{1}{r} f(\phi) e^{i k r}+e^{i k r \cos \phi}
\end{aligned}
$$




$$
\begin{aligned}
& \text { substituting the plane wave expansion of equation (27) yields } \\
& \left.-\sum_{l=0}^{\infty} A_{1} P_{1}\right\}(\cos \phi) \frac{-1}{k r} \sin \left(k r-\frac{\pi l}{2}+\eta_{1}\right) \\
& =\frac{1}{r} f(\phi) e^{i k r}+\sum_{i=0}^{\infty}(21+1) i \sin \left(k r \quad-\frac{\pi l}{2}\right) P_{1}(\cos \theta) \\
& \sum_{i=0}^{\infty} \frac{1}{k r} P_{1}(\cos \phi)\left[A_{1} \sin \left(k r-\frac{\pi l}{2}+\eta_{1}\right)-(21+1) i \sin \left(k r-\frac{\pi i}{2}\right)\right] \\
& =\frac{1}{r} f(\varphi) e^{i k r}
\end{aligned}
$$

Equation (33) represent's the spherical part of the scattered wave function. We have to chose the $A_{1}$ coefficients so that the LHS of the equation will only have terms containing exp(ikr). Consider the term in brackets in equation (33)

$T=A_{1} \sin \left(k r-\frac{\pi l}{2}+\eta_{1}\right\rangle-(21+1) i^{\prime} \sin \left\langle k r-\frac{\pi l}{2}\right\rangle$

$=A_{1} \frac{e^{i\left(k r-\frac{1 \pi}{2}\right)} e^{i \eta_{1}}-e^{-i\left(k r-\frac{1 \pi}{2}\right)} e^{i \eta_{1}}}{2 i}$.

$-(2)+1) i)\left[\frac{e^{i\left(k r-\frac{1 \pi}{2}\right)}-e^{-i\left(k r-\frac{1 \pi}{2} j\right.}}{2 i}\right]$

collecting terms

$T=\frac{1}{2 i}\left[e^{i\left(k r-\frac{1 \pi}{2}\right)}\left[A_{1} e^{i \eta_{1}}-(21+1) i l\right]\right.$

$\left.-e^{-i\left(k r-\frac{1 \pi}{2}\right)}\left[A_{1} e^{-i \eta_{1}}-(21+1) i^{l}\right]\right]$

consequently by the previously stated conditions 


$$
A_{1} e^{-i \eta 1}-(21+1) i^{1}=B
$$

hence

$\left.A_{1}=(2)+1\right\rangle i^{1} e^{i \eta_{1}}$

Substituting equations (35) and (36) in (33)

$\frac{1}{r}+(\phi) e^{i k r}=$

$\sum_{i=0}^{\infty} \frac{1}{k r} P_{1}(\cos \theta) \frac{1}{2 i} e^{i\left(k r-\frac{1 \pi}{2}\right)}(21+1) i\left(e^{2 i \eta_{1}}-1\right\rangle$

thus

$f(\phi)=\sum_{i=0}^{\infty} \frac{1}{2 i k} P_{1}(\cos \phi) e^{-\frac{1 \pi}{2}} i^{1}(21+1)\left(e^{2 i \eta_{1}}-1\right)$

and since $i^{l}=e^{\frac{1 \pi}{2}}$

$f(\theta)=\frac{1}{2 i k} \sum_{1=0}^{\infty}(21+1)\left(e^{2 i n_{1}}-1\right) P_{1}(\cos \theta)$

this expression gives us the amplitude of the scattered

electron wave.

v) The Born Approximation

- The determination of the scattering amplitudes $f(0)$ requires the evaluation of all the partial wave shifts $\eta_{1}$. Consider then the term in equation (39) which contains the wave shifts

$$
e^{i \eta_{1}}-1=2 i \eta_{1}+2 i^{2} \eta_{1}^{2}+\frac{1}{3} 4 i^{3} \eta_{1}^{3}+\ldots \ldots
$$

Provided that the wave shifts are small this series will 


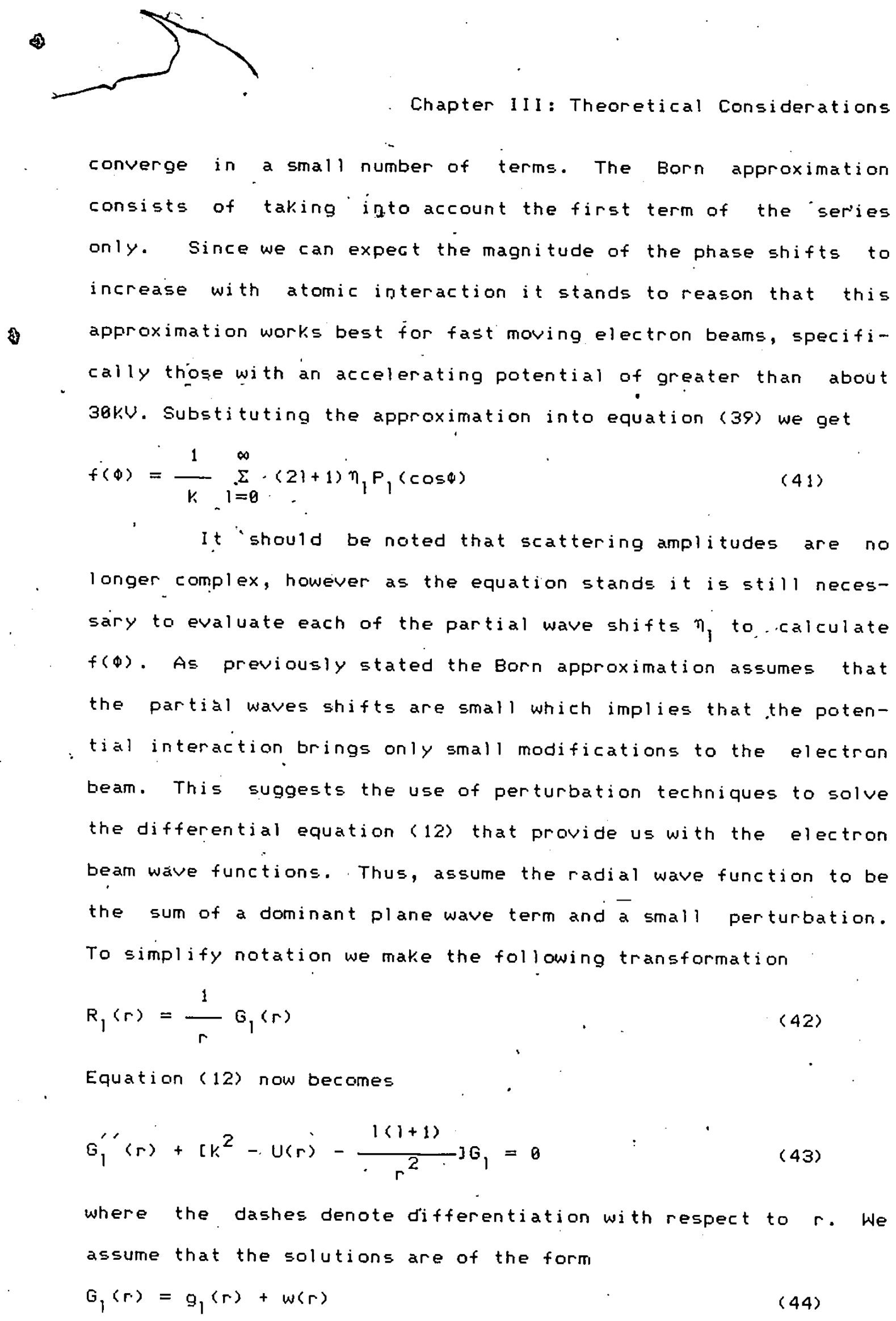
approximation works best for fast moving electron beams, specifically those with an accelerating potential of greater than about $30 k U$. Substituting the approximation into equation (39) we get

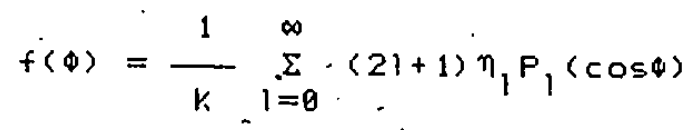

It 'should be noted that scattering amplitudes are no longer complex, however as the equation stands it is still necessary to evaluate each of the partial wave shifts $\eta_{1}$ to,.calculate $f(\phi)$. As previously stated the Born approximation assumes that the partial waves shifts are small which implies that the potential interaction brings only small modifications to the electron beam. This suggests the use of perturbation techniques to solve the differential equation (12) that provide us with the electron beam wave functions. Thus, assume the radial wave function to be the sum of a dominant plane wave term and a small perturbation. To simplify notation we make the following transformation

$R_{1}(r)=\frac{1}{r} G_{1}(r)$

Equation (12) now becomes

$G_{1}^{\prime \prime}(r)+\left[k^{2}-U(r)-\frac{1(1+1)}{r^{2}}-\right] G_{1}=0$

where the dashes denote differentiation with respect to $r$. We assume that the solutions are of the form

$G_{1}(r)=g_{1}(r)+w(r)$ 
where $g_{1}(r)$ are the solution of equation

$g_{1}^{\prime \prime}(r)+\left[k^{2}-\frac{1(1+1)}{r^{2}}\right] g_{1}=0$

and they are of the form

$g_{1}(r)=\left[\frac{\pi k r}{2}\right]^{1 / 2} J_{1+\psi_{2}}(k r)$

$w(r)$ is the small perturbation term.

Substituting in equation (43) we obtain

$g_{1}^{\prime \prime}(r)+\left[k^{2}-\frac{1(1+1)}{r^{2}}\right] g_{1}$
$+w^{\prime \prime}+\left[k^{2}-\frac{1(1+1)}{r^{2}}\right] w=U(r) g_{1}+U(r) w$

The term in the first line of the equation is zero and

neglecting the small term $U(r) w$ we get

$w^{\prime \prime}+\left[k^{2}-\frac{1(1+1\rangle}{r^{2}}\right] w=u\langle r\rangle g_{1}$

Let $w(r)=g_{1}(r) h(r)$. Thus

$h^{\prime \prime} g_{1}+2 g_{1}^{\prime} h^{\prime}+h\left[g_{1}^{\prime \prime}+\left[k^{2}-\frac{1(1+1)}{r^{2}}\right] g_{1}\right] h=U(r) g_{1}$ (48)

which reduces to

$h^{\prime \prime} g_{1}+2 g_{1}^{\prime} h '=U(r) g_{1}$.

multiplying (49) by $g_{1}(r)$ and integrating we get

$\left[h^{\prime} g_{1}^{2}\right]=u(r) g_{1}^{2}(r)$

$h^{\prime} g_{1}^{2}=\int_{0}^{r} U(r) g_{1}^{2}(r) d r$.

For large $r$ we have already seen that $g_{1} \propto \sin \left(k r-\frac{\pi l}{2}\right.$, , 
Chapter III: Theoretical Considerations

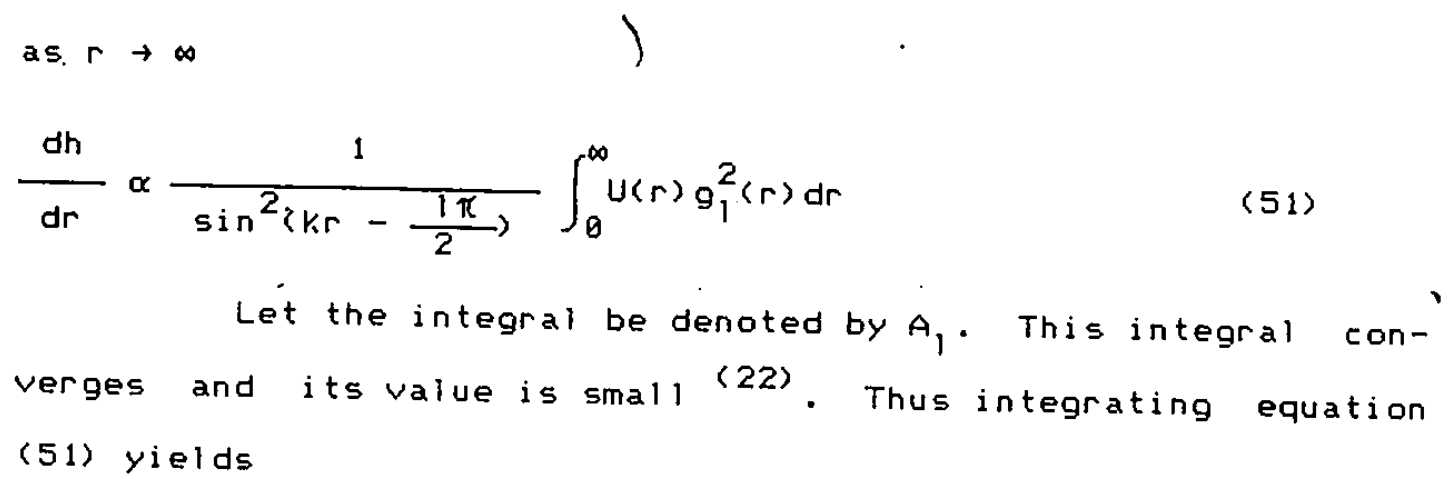

Let the integral be denoted by $A_{1}$. This integral converges and its value is small (22). Thus integrating equation (51) yields

$h \alpha-\frac{A_{1}}{k}\left[\cot \left(k r-\frac{\pi 1}{2}\right)+C\right]$

where $C$ is a constant. Hence $G_{1}=g_{1}+g_{1} h$ becomes

$G_{1} \alpha \sin \left(k r-\frac{\pi i}{2}\right)-\frac{A_{1}}{K}\left[\cos \left(k r-\frac{\pi 1}{2}\right)+\operatorname{csin}\left(k r-\frac{\pi)}{2}\right)\right]$

Since $\frac{A_{1}}{k}$ is small

$\cos \frac{-A_{1}}{k} \approx 1$ and $\sin \frac{A_{1}}{k} \approx \frac{A_{1}}{k}$

neglecting the smaller order terms we have that

$G_{1} \alpha \sin \left(k r-\frac{\pi 1}{2}+\eta_{1}\right)$

where $\eta_{1}=-\frac{A_{1}}{k}$

Expanding equations (55) we get

$\eta_{1}=-\frac{1}{k} \int_{0}^{\infty} U(r) g_{1}^{2}(r) d r$

Substituting equations (5a) and (45)

$\eta_{1}=\frac{-1}{k} \int_{0}^{\infty} \frac{8 \pi^{2} m}{h^{2}} v(r) \frac{\pi k r}{2} J_{1+\psi_{2}}^{2}(k r) d r$ 


$$
\begin{aligned}
= & \frac{4 \pi^{3}}{h^{2}} m \int_{0}^{\infty} v(r) J_{1+k_{2}}^{2}(k r) r d r \\
& =\frac{4 \pi^{3}}{h^{2}} m \int_{0}^{\infty} v(r) \frac{2 k r}{\pi} J_{1}^{2} r d r
\end{aligned}
$$

therefore

$\eta_{1}=\frac{8 \pi^{2} k m}{h^{2}} \int_{0}^{\infty} v(r) J_{1}^{2} r^{2} d r$

Consider now the well known expansion (23).

$$
\frac{\sin (K r)}{K r}=\sum_{i=0}^{\infty}(21+1) P_{j}(\cos \phi) J_{1}^{2}
$$

where $k=\frac{4 \pi \sin \theta}{\lambda}$

Substituting equation (57) in (56)

$\eta_{1}=\frac{8 \pi^{2} k m}{h^{2}}\left[\sum_{1=0}^{\infty}+(21+1) P_{1}(\cos \phi)\right]^{-1} \int_{0}^{\infty} v(r) \frac{\sin K r}{k r} r^{2} d r$ and finally substituting into equation (41) we get

$f(\theta)=\frac{8 \pi^{2} m}{h^{2}} \int_{0}^{\infty} U(r) \frac{\sin K r}{K r} r^{2} d r$

Now we have the scattering amplitudes in terms of only the potential for the interaction of the electron beam and the atom. The calculations of the potential and consequently of the $f(\phi)$, which are referred to as atomic scattering factors, have been calculated by a number. of authors and their values have been tabulated. In this study we have used the scattering factors given by Doyle and Turner (24). 
II) Scattering by an Ensemble of Atoms.

The beam scattered by one of the atoms in an ensemble of $N$ atoms is represented by the wave function

$\psi_{i}\left\langle r_{i}, \theta\right\rangle=e^{i k z_{i}}+\frac{1}{r} f_{i}(\theta) e^{i k r_{i}}$

where $\theta=x_{2} d$ is the angle of deflection and both $r_{i}$ and $z_{i}$ have their origin at the nucleus of the ith atom. To determine the scattering of the lattice we shall express all the wave functions in terms of variables with a common origin. Consider the following diagram

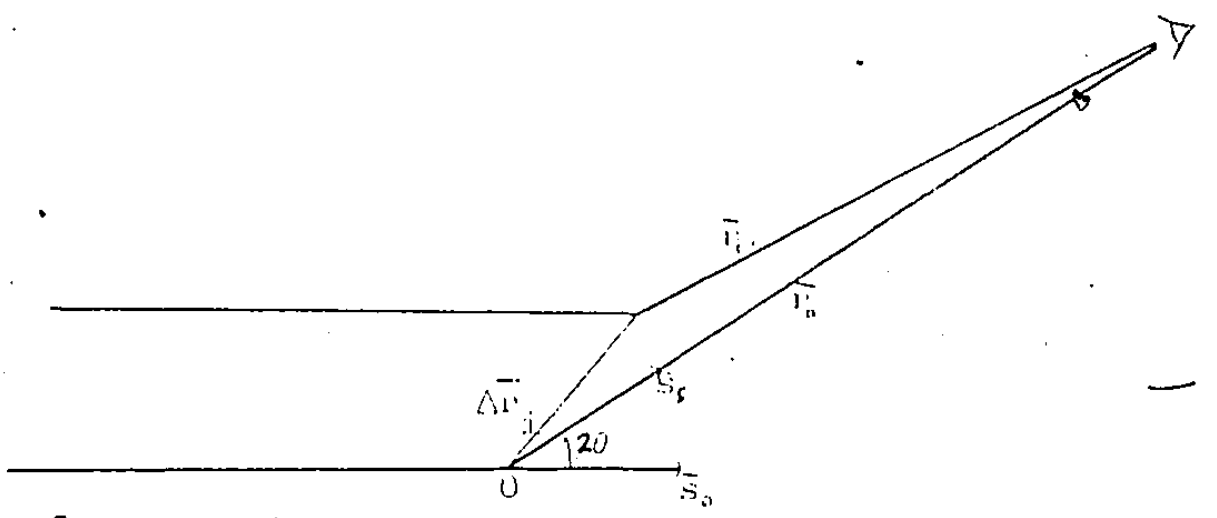

where o represents some arbitrary but common origin.

Let $\bar{s}_{0}$ be the unit vector in the incoming beam direction

$\bar{s}_{s}$ be the unit vector in the direction of the scattering

$\vec{s}=\bar{s}_{0}-\bar{s}_{s}$, thus $|\bar{s}|=s=2 \sin \theta$

fand we denote $\Delta z_{i}=z_{0}-z_{i}$

We change origins by multiplying equation (60) with $\exp \left(i k \Delta z_{i}\right)$, thus

$\psi_{i}\left\langle r_{i}, \theta\right\rangle=e^{i K z}+\frac{1}{r} f_{i}(\theta) e^{i K \Delta z} i e^{i K\left(\left|\bar{r}_{0}-\Delta \bar{r}_{i}\right|\right)}$ 
Chapter III: Theoretical Considerations

$$
\begin{aligned}
& =e^{i k z_{0}}+\frac{i}{r} f_{i}(\theta) e^{i k \bar{s}_{0} \Delta \bar{r}_{i}} e^{i k\left(\bar{r}_{0}-\Delta \bar{r}_{i} \bar{s}\right)} \\
& =e^{i k z_{0}}+\frac{1}{r} f_{i}(\theta) e^{i k \Delta \bar{r}_{i}\left(\bar{s}_{0}-\bar{s}_{i}\right)} e^{i k r_{0}} .
\end{aligned}
$$

The wave function representing the scattering from the whole ensembie of atoms is.the sum of the wave functions of the contributing atoms

$\psi(r, \theta)=\sum_{i=\theta}^{N} \psi_{i}\left(r_{i}, \theta\right) \cdot$

Consequently the intensity of the scattered beam is

$I(r, \theta)=\sum_{i, j}^{N} f_{i}^{*}(\theta) f_{j}(\theta) e^{i k \bar{S} \cdot \bar{r}_{i j}}$

Where the vector $\vec{r}_{i j}=\overrightarrow{\Delta r}_{j}-\overrightarrow{\Delta r}_{i^{-}}$Its magnitude is the distance separating the $i$ th and the $j$ th atoms. In this expression there will be $N$ terms for which $i=j$ and $r_{i}=r_{j}$ for each of these terms the exponential would be unity, this allows us to rewrite the expression as

$I=\sum_{i=1}^{N}\left|f_{i}\right|^{2}+\sum_{\substack{i, j \\ i \neq j}}^{N} f_{i} f_{j} e^{i k \bar{s} \cdot \bar{r}_{i j}}$

But as we have seen in the previous section under the Born approximation the atomic scattering factors, $f(\theta)$, are real, thus -

$I=\sum_{i=1}^{N} f_{i}^{2}+\sum_{i \neq j}^{N} f_{i} f_{j} e^{i k \bar{S} \cdot \bar{r}} i j$

This is quite a general result for any ensemble of atoms, 
periadic or not. If the ensemble of atoms were part of a lattice for a crystalline material $r_{i j}$ would take a specific set of values and equation (65) would yield a diffraction function with sharp and well defined peaks. On the other hand if we are dealing with a more amorphous material $r_{i}$ may be oriented in any direction relative to s with equal probability. In this case the. exponential term containing $r_{i j}$ is averaged over all directions

$\left\langle e^{i k \bar{S} \cdot \bar{r}_{i j}}\right\rangle=\frac{1}{4 \pi r_{i j}^{2}} \int_{0}^{\pi} e^{i k S r \cos \alpha} 2 \pi r_{i j} \sin \alpha d \alpha=\frac{\sin \left(k S r_{i j}\right)}{k S r_{i j}}$

Letting $s=\frac{2 \sin \theta}{\lambda}$ we get

$I=\sum_{j=1}^{N} f_{j}^{2}+\sum_{i=1}^{N} \underset{i \neq j}{N} \sum_{j=1}^{N} f_{i} f_{j} \frac{\sin 2 \pi s r_{i j}}{2 \pi s r_{i j}}$

In most cases the number of species in the sample is small, but the total number of atoms hit by the beam is always very large and this allows us to replace the summation by integration over radial distribution functions $4 \pi r^{2} p_{i j}(r)$, representing the number of $j$ type atoms surrounding an $i$ type atom at, distance $r$. Letting $x_{1}, x_{2}, x_{3}, \ldots x_{n}$ be the atomic fraction of atoms having scattering factors $f_{1}, f_{2}, \ldots f_{n}$, where $n$ is the number of species then

$$
I(s)=N \underset{i=1}{n} x_{i} f_{i}^{2}
$$

$$
+N \sum_{i=1}^{n} \sum_{j=1}^{n} x_{i} f_{i} f_{j} \int_{\theta}^{\infty} 4 \pi r^{2} \rho_{i j}(r) \frac{\sin 2 \pi s r}{2 \pi s r} d r
$$

We break the integral in the following manner 


$$
\begin{aligned}
I(s) & =N \underset{i=1}{\sum_{i}} x_{i} f_{i}^{2} \\
& +N \sum_{i=1}^{n} \sum_{j=1}^{n} x_{i} f_{i} f_{j} \int_{0}^{\infty} 4 \pi r^{2}\left[\rho_{i j}(r)-\bar{\rho}_{i j}\right] \frac{\sin 2 \pi s r}{2 \pi s r} d r \\
& +N \sum_{i=1}^{n} \sum_{j=1}^{n} x_{i} f_{i} f_{j} \int_{\theta}^{\infty} 4 \pi r^{2} \bar{\rho}_{i j} \frac{\sin 2 \pi s r}{2 \pi s r} d r
\end{aligned}
$$

where $\vec{\rho}_{i j}$ is the avearge density. The last term has only a very small contribution for small angles. (25), in most cases this contribution is unobservable since it is lost ih the undeflected beam. However measurable contribution in the small angle regime may arise if the sample contains regions of excess or deficient density (26), but under normal circumstances the third term cart be neglected and hence

$$
\begin{aligned}
I\langle s\rangle=N \sum_{i=1}^{n} x_{i} f_{i}^{2} & =\sum_{i, j}^{n} x_{i} f_{i} f_{j} \int_{\theta}^{\infty} 4 \pi r^{2}\left[\rho_{i j}(r)-\bar{\rho}_{i j} j \frac{\sin 2 \pi s r}{2 \pi s r} d r\right.
\end{aligned}
$$

Equation (70) gives us the intensity profile of the scattered beam when the sample contains any number of species. In this study we are only interested in samples with one species only thus we can reduce the equation to give

$$
\begin{aligned}
I(s) & =N f^{2}(s)+N f^{2}(s) \int_{0}^{\infty} 4 \pi r^{2}\left[\rho(r)-\rho_{0}\right] \frac{\sin 2 \pi s r}{2 \pi s r} d r \\
\cdot & =N f^{2}(s)\left[1+\frac{2}{s} \int_{0}^{\infty} r\left[\rho(r)-\rho_{0}\right] \sin 2 \pi s r d r\right]
\end{aligned}
$$

Rearrange to give 
$s\left[\frac{I(s)}{N f^{2}(s)}-1\right]=2 \int_{0}^{\infty} r\left[\rho(r)-\rho_{0}\right] \sin 2 \pi s r d r$

The reduced interference functions $i(s)$ is defined as

$i(s)=s\left[\frac{I(s)}{N f^{2}(s)}-1\right]$

such that

$i(s)=2 \int_{0}^{\infty} r\left[\rho(r)-\rho_{0}\right] \sin 2 \pi s r d r$

which has the form of a Sine Fourier Transform with the inversion formula of

$r\left[\rho(r)-\rho_{0}\right]=2 \int_{0}^{\infty} i(s) \sin 2 \pi s r d s$

Therefore, the reduced radial distribution function defined as

$G(r)=4 \pi r\left[\rho(r)-\rho_{0}\right]$

,

. (76)

is given by

$G(r)=8 \pi \int_{0}^{\infty} i(s) \sin 2 \pi s r d s$

and finally the radial distribution function is

$\operatorname{RDF}(r)=4 \pi r^{2} \rho(r)=4 \pi r^{2} \rho_{0}+8 \pi r \int_{\theta}^{\infty} i(s) \sin 2 \pi \operatorname{sid} d s$

(78) 


\section{CHAPTER IV}

Data $\operatorname{Ar} a 130 i=$

The diffraction data acquired contained random high frequency noise, probably caused by the detection apparatus. In the region of large $s$ the ratio of signal to noise is quite smal) (12), hence it is of primary importance to be able to remove this random noise without degrading the underlying information.

The standard technique used to eliminate random errors is simple averaging of a large number of runs. The main disadvantage of only using averaging is the time involved in the data collection, specially, as in this study, each run takes a few minutes to complete. The use of compined smoothing and averaging conisiderably reduces the instrument time required. A characteristic of both procedures is that the noise is reduced approximately as the square root of the number of points used. Thus if it is desired to improve the signal to noise ratio by a factor of 10, simple averaging would require a total of 180 runs. On the other hand, a similar improvement can be achieve by making only 16 runs and a 9-point least square smooth

16 runs $\quad \approx 4 x^{\circ}$ improvement

9-point smooth $\approx 3 \times$ improvement

The least square smoothing technique used in this study is that described by Savitzky et.al. (27), and the actual programs used are 1 isted in Appendix 2. In addition to random errors the interference curves obtained are subject to a number of systematic errors, each of which must be corrected before calculating the distribution functions. The systematic errors can be 


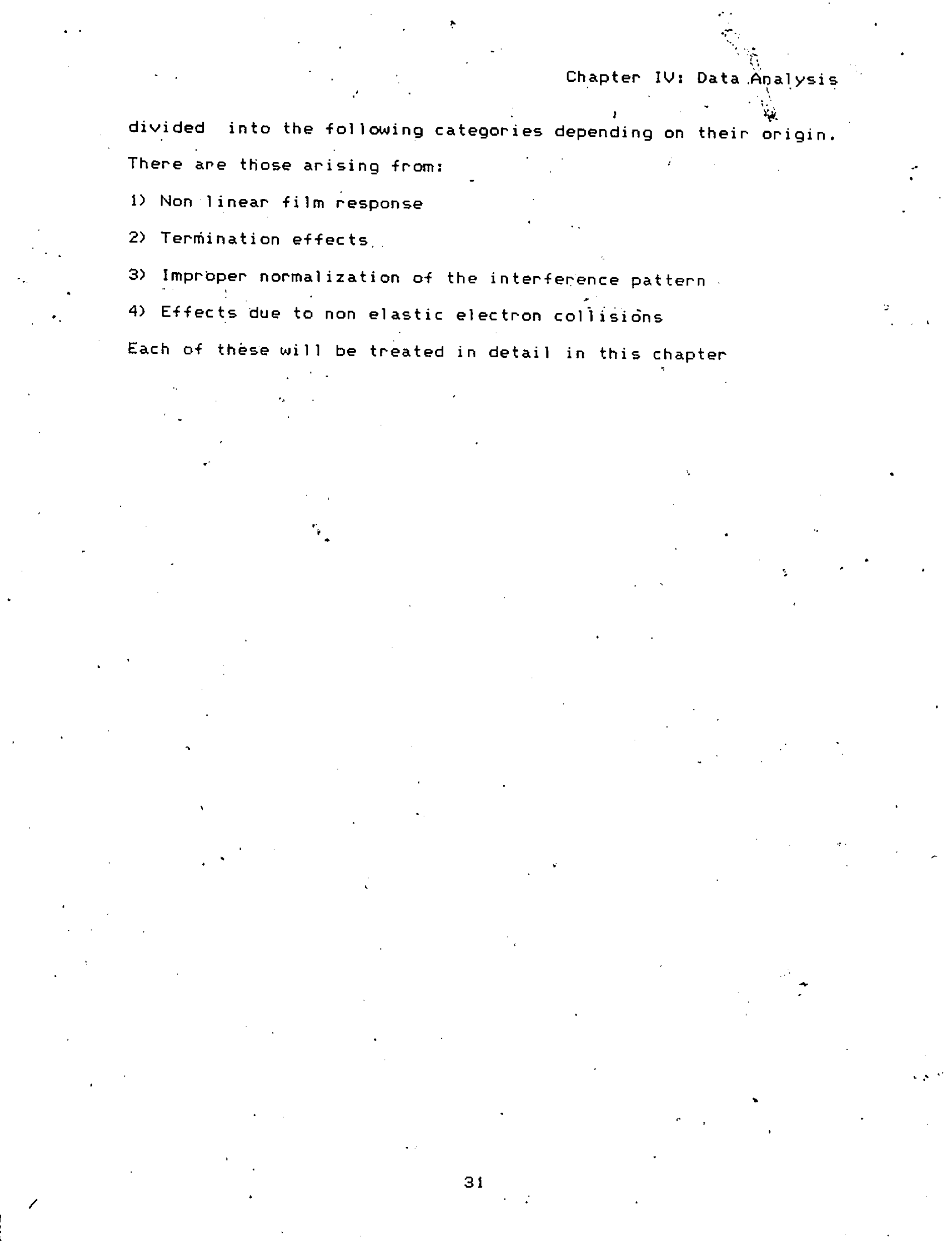


i) Non Linear Film Response:

Before starting this discussion a few quantities pertain-a ing.to photographic film response ought to be defined (28). - Diffuse. Density, this is the density of silver particies per unit volume in the developed photographic errulsion. It is given

by the following version of Beer's Law

$D(s)=\log _{10} \frac{T_{\max }}{T(s)}$

where $T_{\max }$ corresponds to $108 \%$ transmission, i.e. the transmission of a part of film that has not been exposed to either' light or the electron beam. $T(s)$ is the tiransmission function corresponding to the diffraction pattern, in our case thiswould be the output of our densitometer.

-Exposure, this is defined by the reciprocity law, fómulated by Bunsen and Roscoe ${ }^{(28)}$. which states that the product of a photochemical reaction is dependent on the total energy involved, thus $E=1 t$

where $E$ is the exposure

1 is the intensity.

$t$ is the time of exposire

This is generally true for photographic materials except for exposures. of very low or of very high levels, of intensity. This loss of intensity is known as the reciprocity effect. The largest deviations from the normal occur at. exposures of fow intensities In this work the intensities employed were sufficiently large so that we can expect equation (80) to hold.

The plot of the diffuse density versus the exposure'is called the characteristic curve of the film and it varies consi- 
derably from one type of film to another, however characteristic curves have features that are common to all (see figure IV-1). These are 1) The Toe, where the density rises very slowly with increasing intensity. 2) The Linear region, where the densities are linearly proportional to the intensities. 3) The Saturation region, where the slope of the curve decreases with increasing intensity, this corresponds to the situation where the incident electrons fail to encounter silver ions that have not been previously excited.

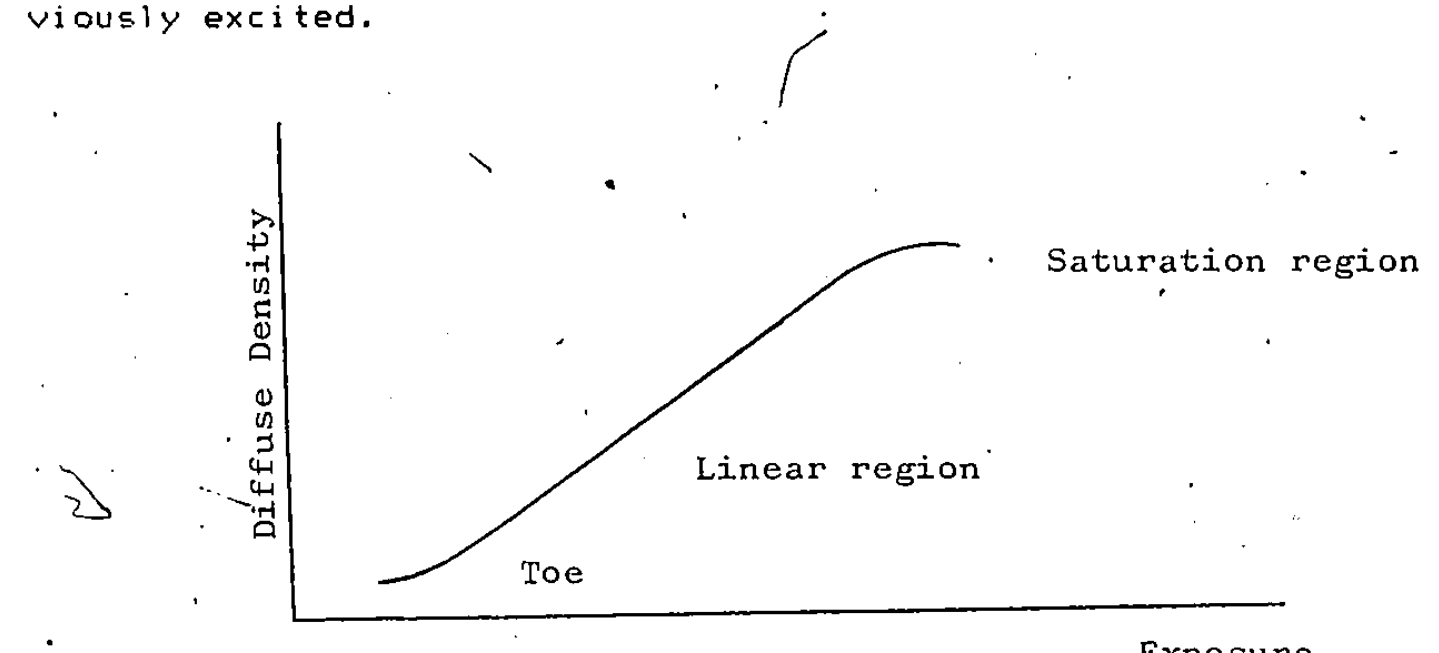
Figure IV-1 Typical characteristic curve for photographic film

The major, problem that arises from the usage of photographic film for the recording of diffraction patterns is its inability to respond linearly to all the intensities that may be present in a given pattern. Typically the difference between the lowest and highest peak intensity may vary. up to five orders of magnitude and this is iarger than the linear range of most films. Hence it is desirable to find the time of exposure that would yieid a picture in which all peaks of the diffraction 
pattern would be recorded in the linear region or as close to it as possible. To accomplish this the following procedure was adapted. Using a single sample a series of pictures with different exposure times was taken. Special care was taken such that no setting in the electron microscope was changed assuring equal beam intensity for all pictures (see figures IV-2, IV-3). From the corresponding densitrometer curbes a diffuse density versus exposure curve was constructed for the different distinct peaks in the diffraction pattern (see figures IV-4). In the linear region of these plots the slope is given by

$m=\frac{\Delta D}{\Delta t}$

from equation ( 80 ) we have $t=E / I$ since $I$ is constant within each curve

$\Delta \mathrm{t}=\frac{\Delta \mathrm{E}}{\mathrm{I}}$,

hence

$\mathrm{m}=\frac{\Delta \mathrm{D}}{\Delta \mathrm{E}} \mathrm{I}$

where $\triangle D / \Delta E$ is the slope of the characteristic curve and consequently we see that any change in the slope in the curves in figure IV-4 must be due to a change in the slope in the characteristic curve, i.e. a deviation from the linear region.

A close examination of figure IV-4 reveals that the only exposure time for which the intensity of all peaks fall in athe. inear region is $0.12 \mathrm{sec}$, this exposure time was then repeatedy used in all pictures taken. 


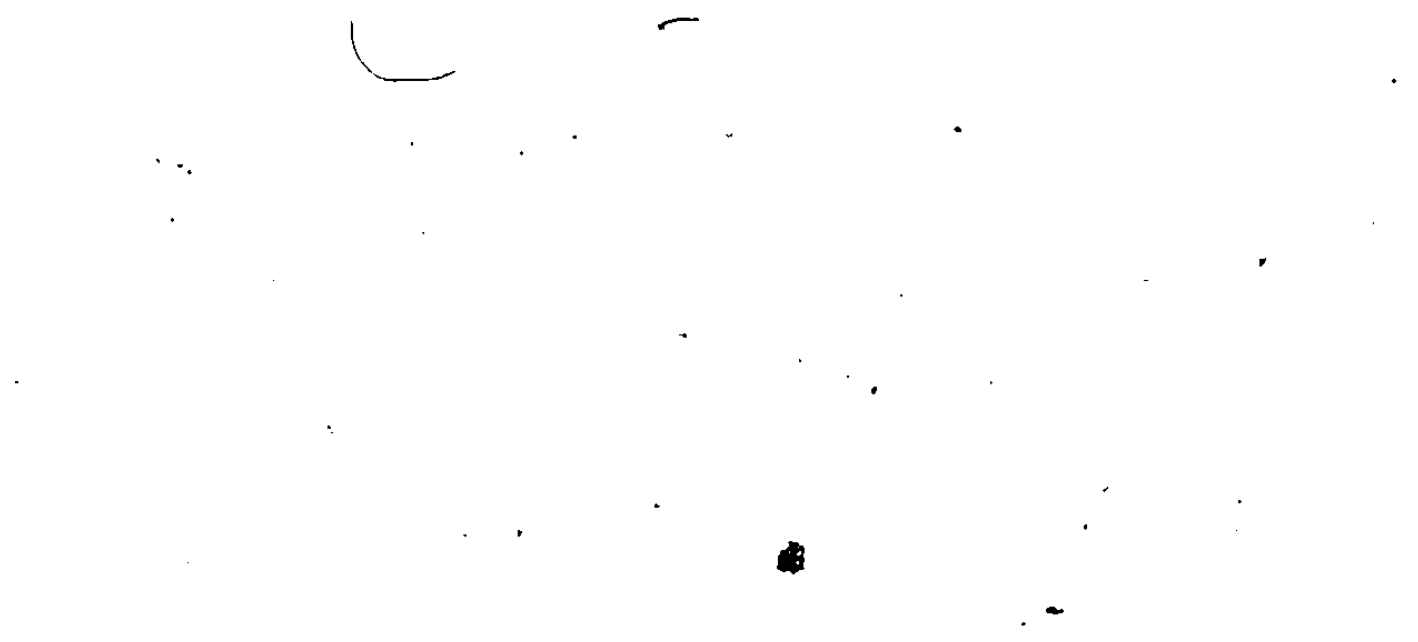

Figures IV-2, IV-3 Series of diffraction pattern curves of the same sample taken with varying exposure time Figure. IV-4. Plot of diffuse density Vs. exposure time for the different well defined peaks present in figures. $I V-2$ and $I V-3$ 
1

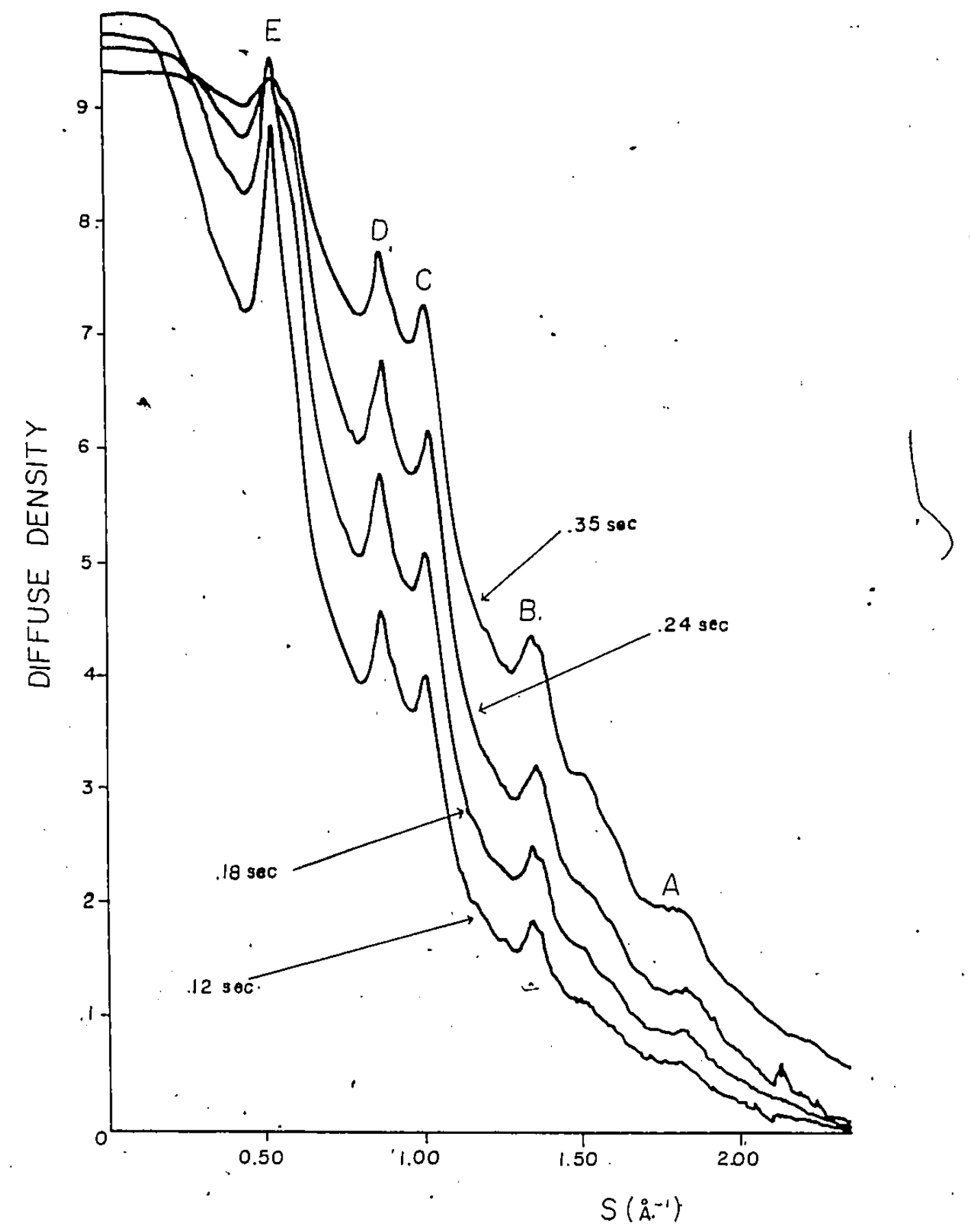

Figure IV-2 


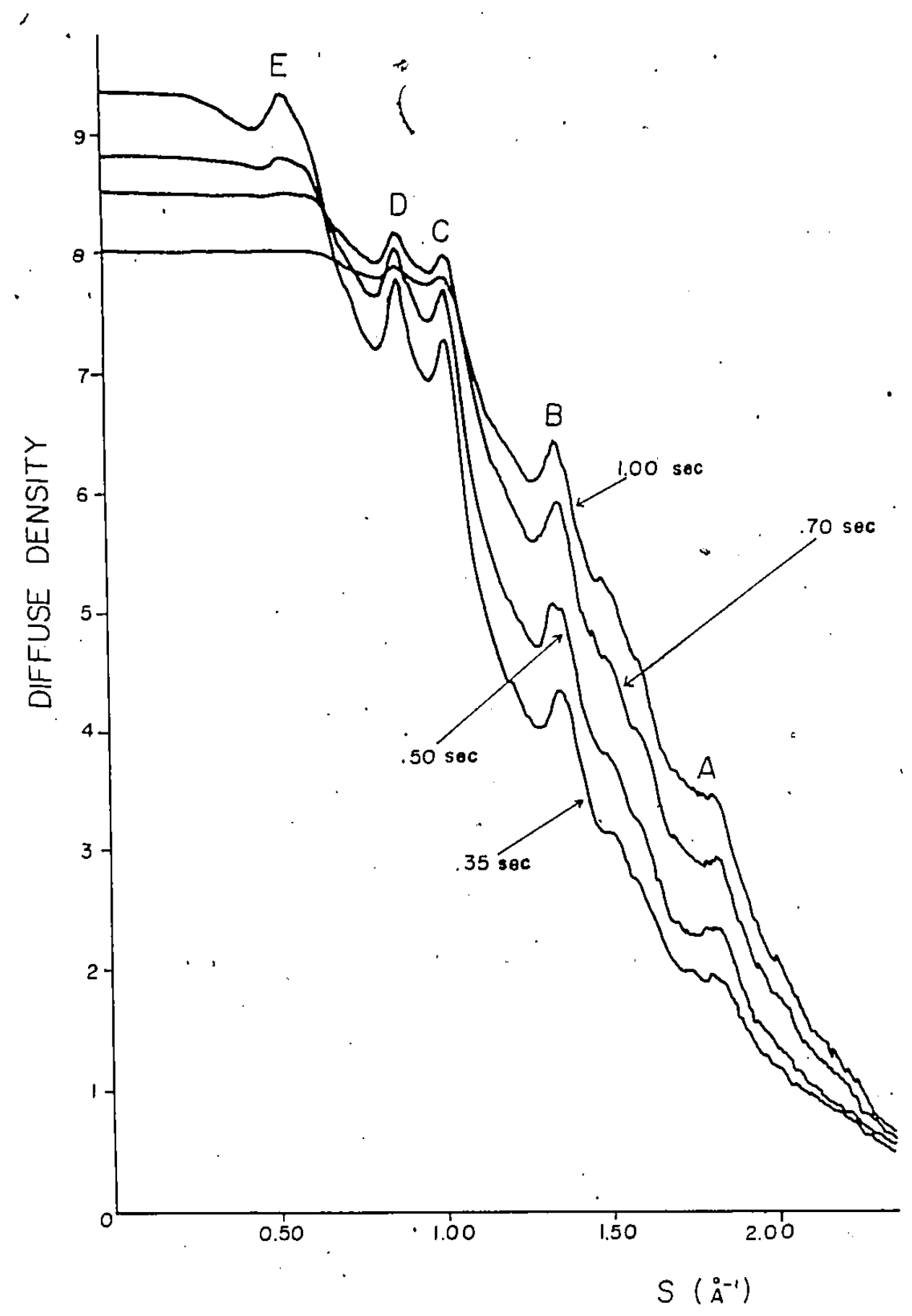

7

Figure IV -3 


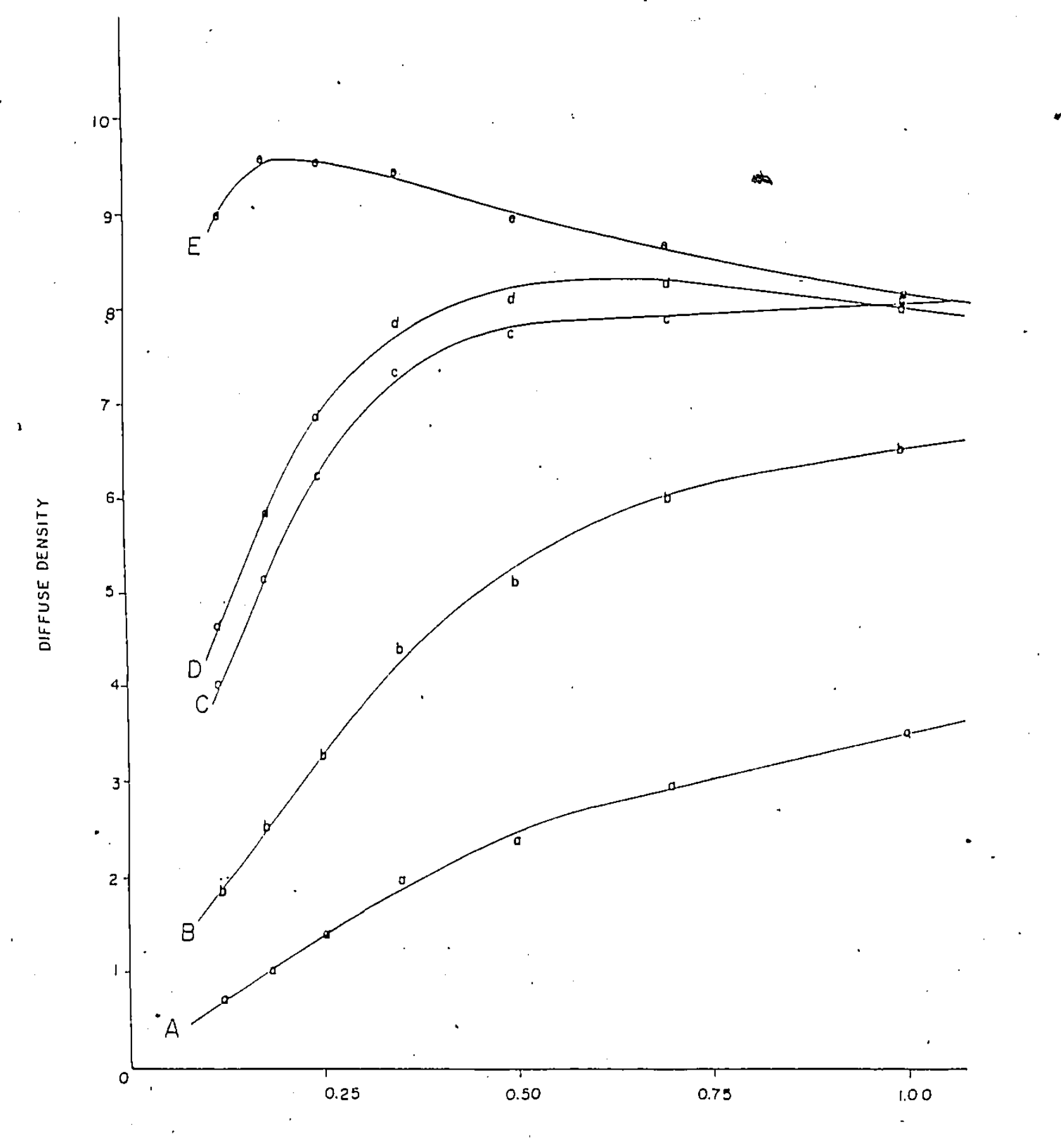

TIME OF EXPOSURE ( $3 \theta 0$ )

Figure IV-4 
i i) Termination Effects

Consider equation.(77) which states

$G(r)=8 \pi \int_{0}^{\infty} i(s) \sin 2 \pi \operatorname{sids}$

To accurately determine the reduced radial distribution function, $(G(r)$, an integration up to infinity is to be calculated. This leads to the obvious problem: the experimental data is finite and only allows the integration to be carried out up to 'max' the maximum value of the scattering parameter. The question that arises is, what effects does the termination of 5 have on $G(r) ?$

We can think of the truncation of the upper limits in the integral as having multiplied $i(s)$ by a "terminating" function $g(s)$. The terminating function will have the property that it will equal zero for all values of $s$ above $s_{\text {max }}$. Thus we have in practice

$G_{t}(r)=8 \pi \int_{0}^{\infty} Y(s) \sin 2 \pi \operatorname{srds}$

where $Y(s)=i(s) g(s)$

Let's adopt the following notation

$G_{t}(r) \Leftrightarrow Y(s)$

where $\Leftrightarrow$ denotes a Fourier Transformation.

We then have the following Fourier transform pairs:

$G_{t}(r) \Leftrightarrow Y(s)=i(s) g(s)$

$g(s) \quad \Leftrightarrow h(r)$

$i(s) \quad \Leftrightarrow G(r)$

Recall now the form of the convolution integral which is defined as (29)

$x$ 
Chapter IV: Data Analysis

$w(t)=\int_{-\infty}^{\infty} x(\tau) y(t-\tau) d \tau=x(t) * y(t)$

(85)

where $*$ denotes convolution.

The convolution theorem $(29,36)$ states that if we have :

Fourier transform pairs

$y(t)^{\circ} \Leftrightarrow Y(f)$ and $x(t) \Leftrightarrow X(f)$

then

$x(t) * y(t) \Leftrightarrow x(f) Y(f)$

For our particular case

$Y(s)=i(s) g(s)$

$G_{t}^{\mathbb{N}}(r)=G(r) * \mathbb{N}^{\mathbb{N}}(r)$

thus

$G_{t}(r)=\int_{0}^{\infty} h\left(r-r^{\prime}\right) G(r) d r^{\prime} \varphi$

In the simplest case in which we have just the experimental i(s), the termination function is a square wave pulse defined by

$$
\begin{aligned}
g(s) & =1|s| \leq s_{\max } \\
& =0|s|>s_{\max }
\end{aligned}
$$

its Fourier transform, commonly refered to as the "modifying" function, is given by

$h(r)=2 s_{\max } \frac{\sin 2 \pi s_{\max }{ }^{r}}{2 \pi s_{\max } r}=2 s_{\max } \operatorname{sinc}\left(2 \pi s_{\max } r\right)$

Figure IU-5 shows the Fourier transform pair $g(s)(=>h(r)$. Thus

$G_{t}(r)=16 \pi s_{\max } \int_{0}^{\infty} \frac{\sin 2 \pi s_{\max }\left(r^{\prime}-r^{\prime}\right)}{2 \pi s_{\max }\left(r-r^{\prime}\right)} G\left(r^{\prime}\right) d r$ 


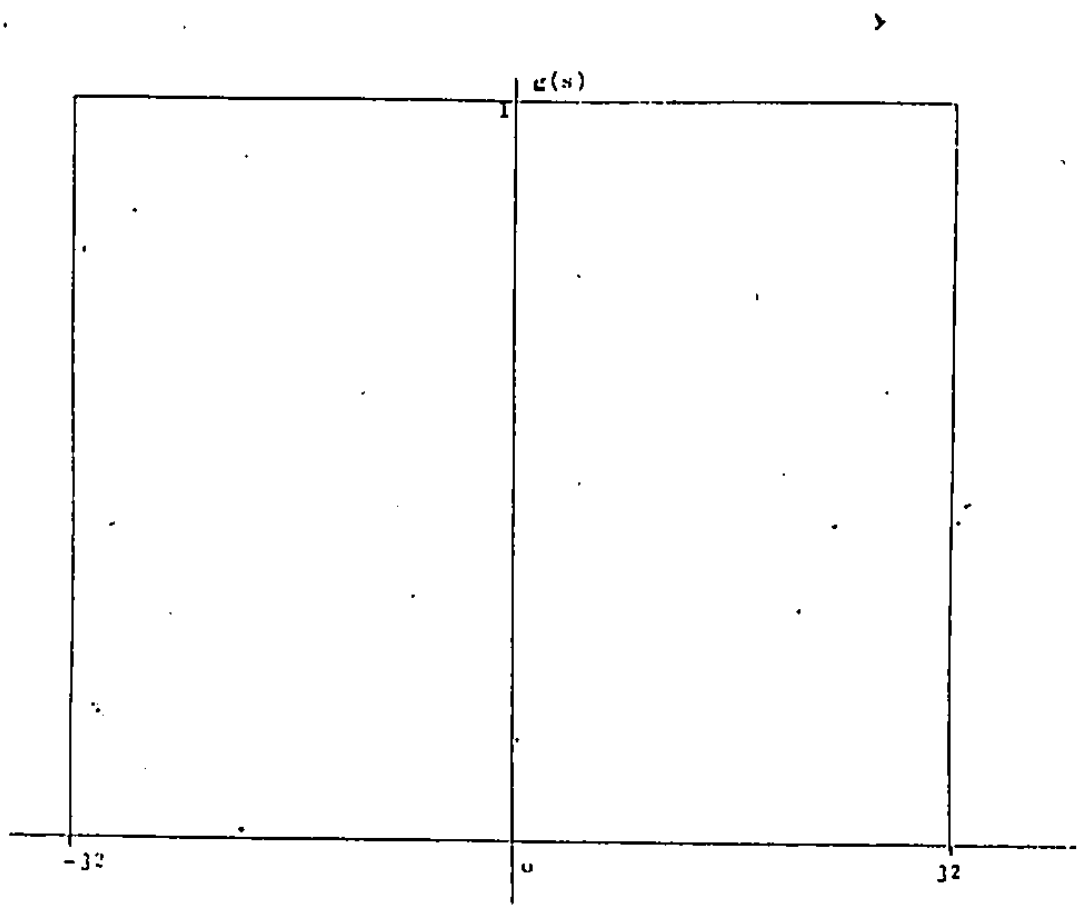

ง

Figure IV-5

Scuare Wave Pulse truncating function : and corresponding Fourier transform

\section{I}

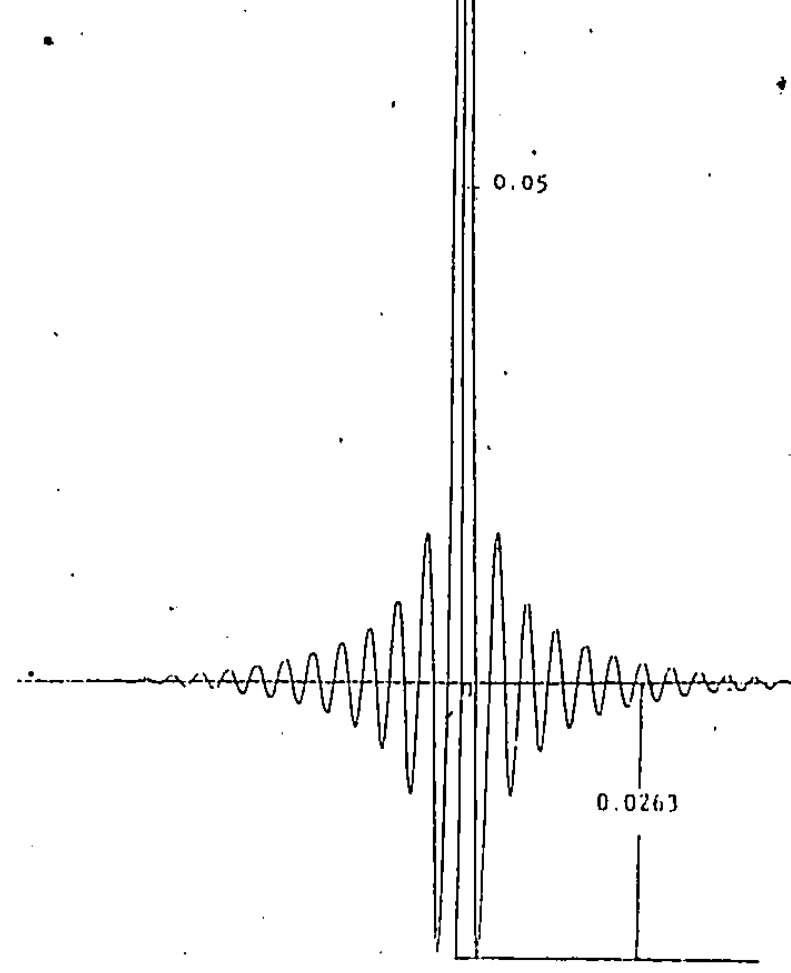


In equation ( 88$) G\left(r^{\prime}\right)$ is the ideal reduced radial distribution function which would be obtained if there was no termination, and $G_{t}(r)$ is the "somewhat" modified function we obtain using the experimental data. The effect of the modifying function is twofold; first it brodidens all peaks and second, and most important, it generates spurious peaks, refered to as ripples, which may be mistaken for real information. In order to minimize such ripples the most convenient method is to use a terminating function whose Fourier transform contains oscillations of smaller amplitude than those of the sine function. Two functions that comply with such criteria are the triangular and hanning function (figures IV-6, IV-7). The triangular function is particularly useful for cases in which negative oscillations are undesirable, as in Fourier spectroscapy. Another point to be considered is the fact that each terminating function broadens the peaks of $G(r)$ by different amounts. Bell (31). gives the following ist comparing the full width at half maximum of the main peak of the modifying function corresponding to some of the most frequently used termiriating functions

Terminating function $\%$ increase in FWHM

\begin{tabular}{l|c}
\hline square wave pulse & 0 \\
hanning $\left[0.5+0.5 \cos \left(\pi s / 2 s_{\max }\right)\right]$ & 31 \\
triangular $\left[1-|s| / s_{\max }\right]$ & 48 \\
square $\operatorname{tri}$ anguhar $\left[1-\left(s / s_{\max }\right)^{2}\right]^{2}$ &
\end{tabular}

The hanning function was the terminating function used in this study for it not only suppresses all ripples but it introduces the least amount of broadening : 


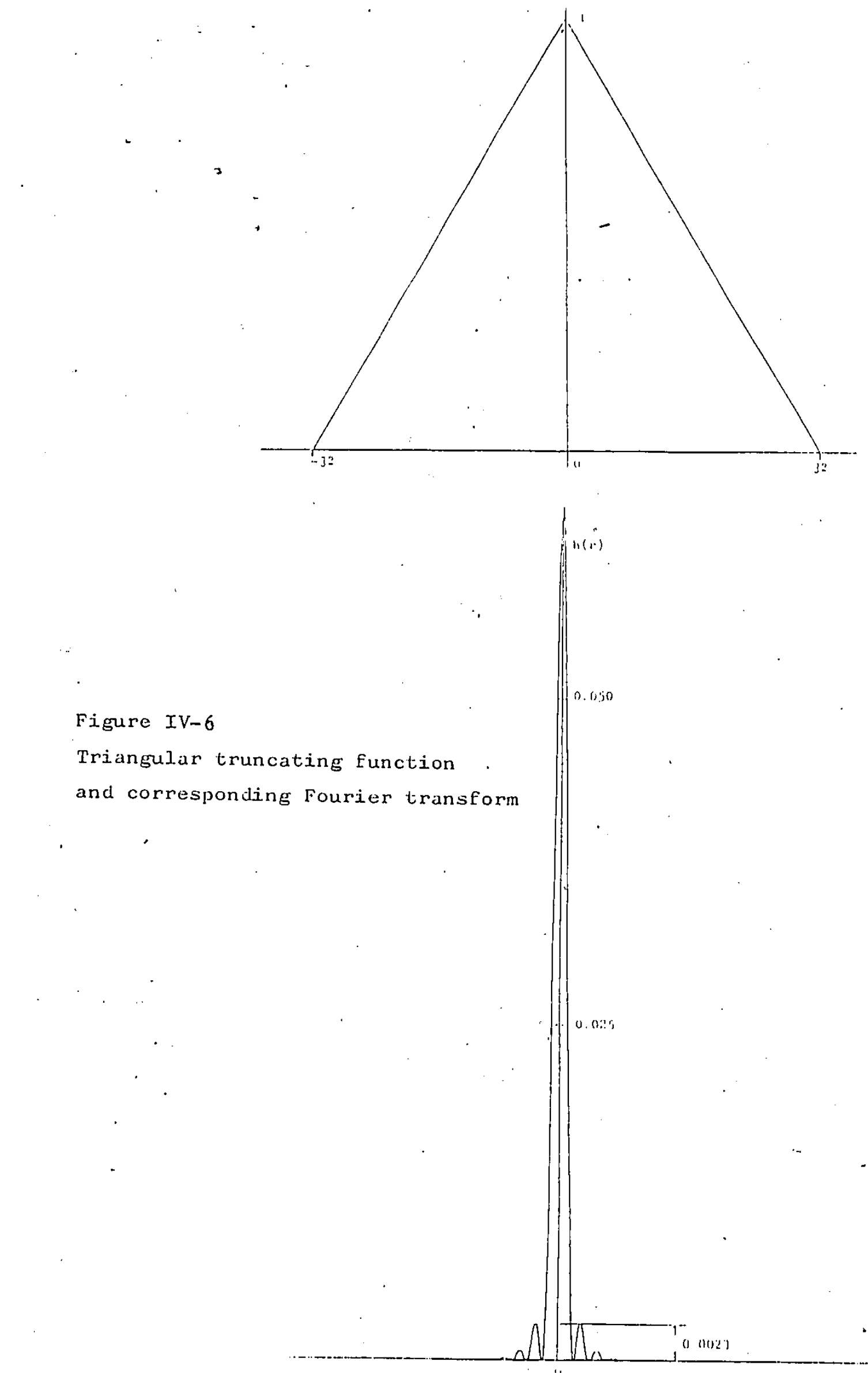




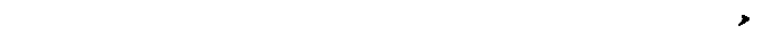

,
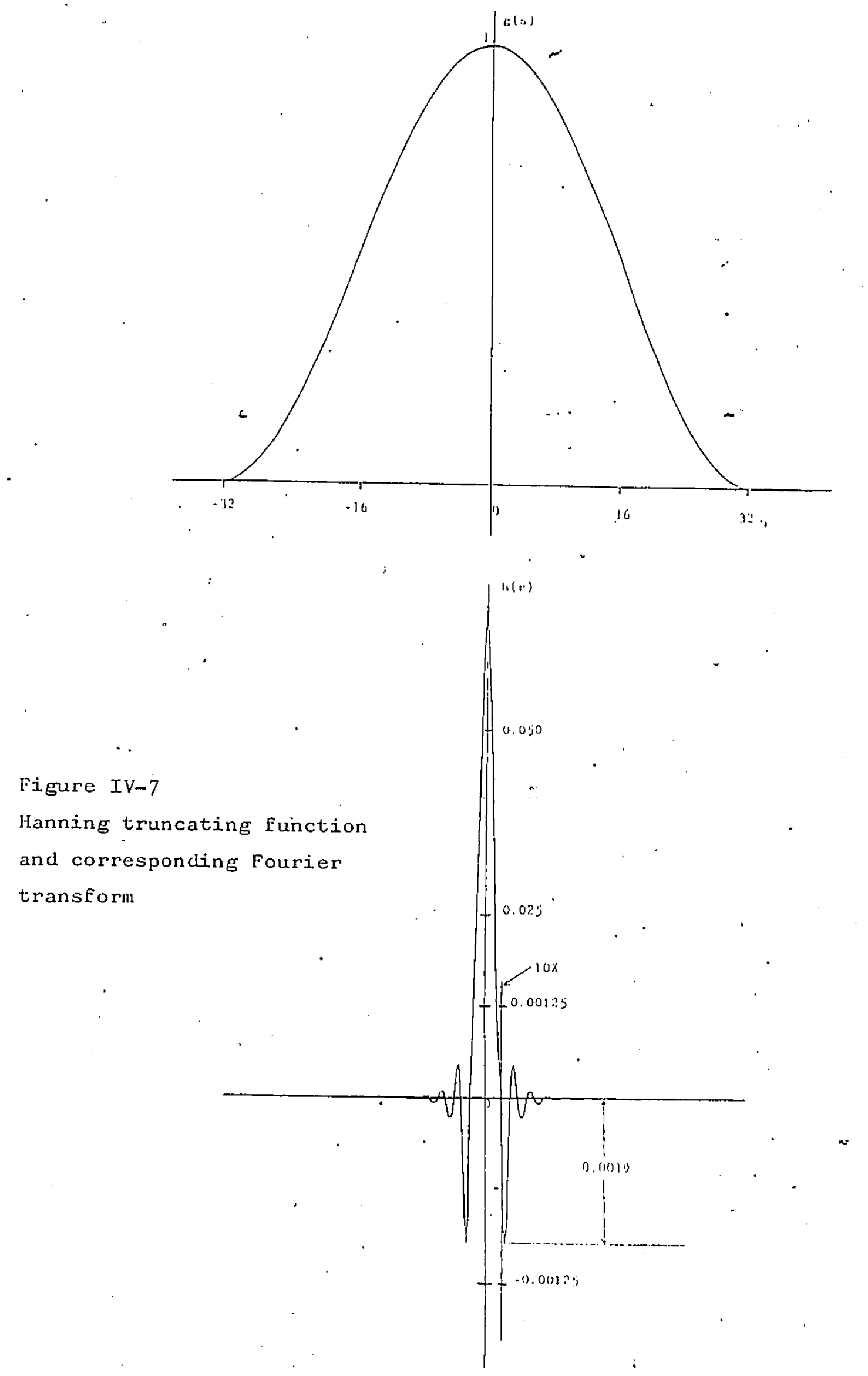

aning truncating function transform 
i i i) Normalization

The experimental interference curve I(s) is obtained in arbitrary units, the problem. is to determine i(s) in absoluten. units.

Recall equation $(>1)$ which stated
$I(s)=N f^{2}(s)\left[1+\frac{2}{s} \int_{0}^{\infty} r\left[\rho(r)-\rho_{0}\right] \sin 2 \pi s r d r\right]$

The integral in this equation extends over a short interval since we can expect $\left[\rho(r)-\rho_{0}\right]$ to approach zero at distances of a few atomic diameters. By dividing the r-axis into small intervals \& we can replace the integral by a sum

$$
\begin{gathered}
\frac{I(s)}{N}=f^{2}+f^{2} \sum_{i} Y_{i} \frac{\sin 2 \pi s r_{i}}{2 \pi s r_{i}} \\
\text { where } Y_{i}=\int_{r_{i}-\delta / 2}^{r_{i}+\delta / 2} 4 \pi r^{2}\left[\rho(r)-\rho_{0}\right] d r
\end{gathered}
$$

The variation of $\frac{I(s)}{N}$ above $f^{2}$ is.

$\frac{1(s)}{N}-f^{2}(s)=f^{2}(s) \sum_{i} Y_{i} \frac{\sin 2 \pi s r_{i}}{2 \pi s r_{i}}$

From this equation we can see that $I(s) / N$ oscillates about $f^{2}$ with decreasing amplitude of oscillations, "due to. the

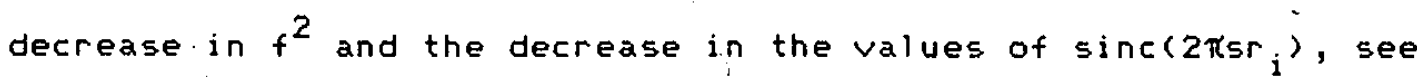
figure IU-8.

The units of the $f^{2}$ curve are known. In order to obtain $I(s) / N$ in absolute units it is necessary only to multiply the experimental interference function by a suitable factor so that 


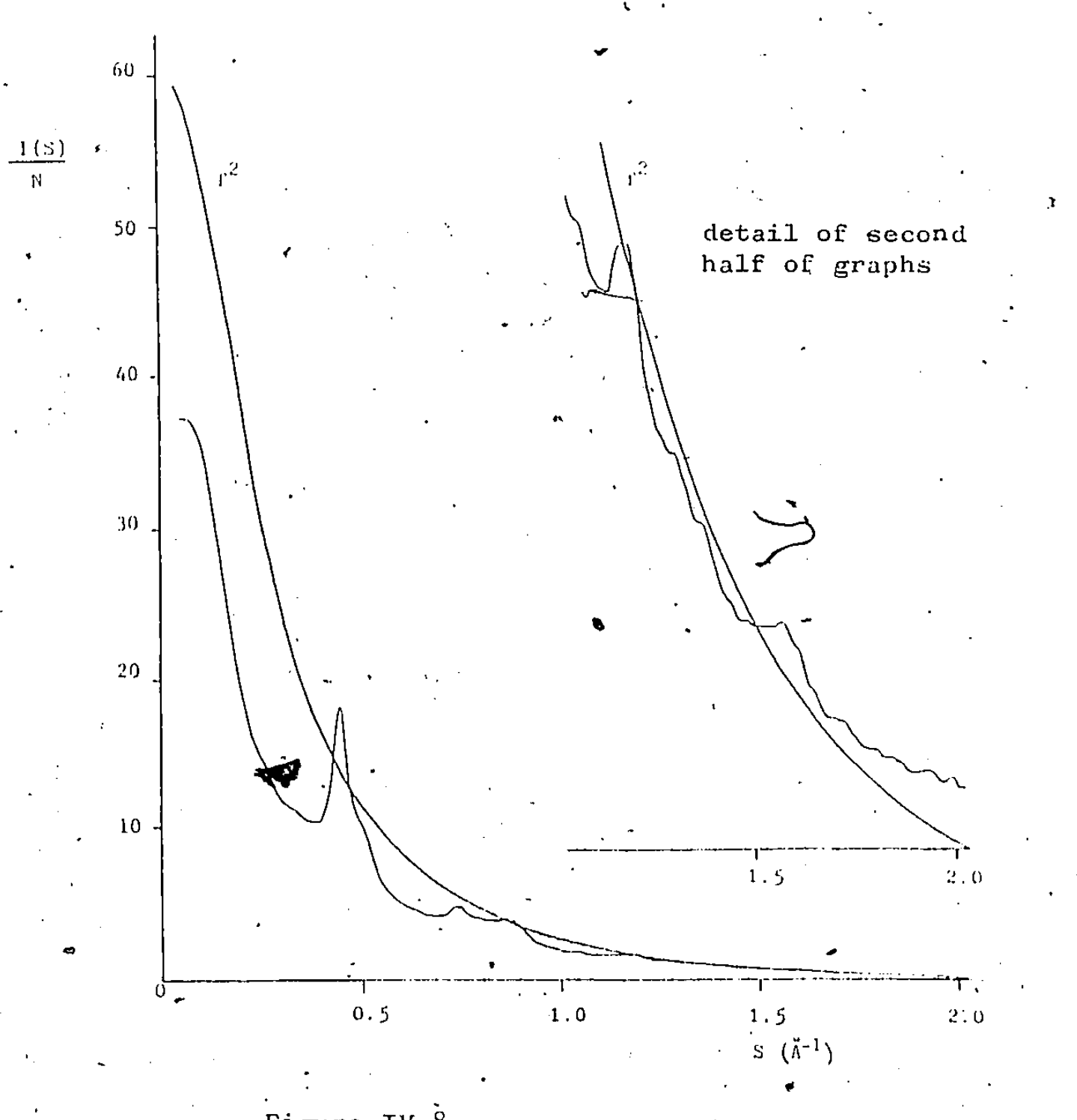

Figure IV- $\dot{8}$

$\therefore \quad I(s) / N$ and $f^{2}(s)$ curves for typical sample.

Note the oscillations of $I(s) / N$ about $\mathrm{f}^{2}(\mathrm{~s})$ 


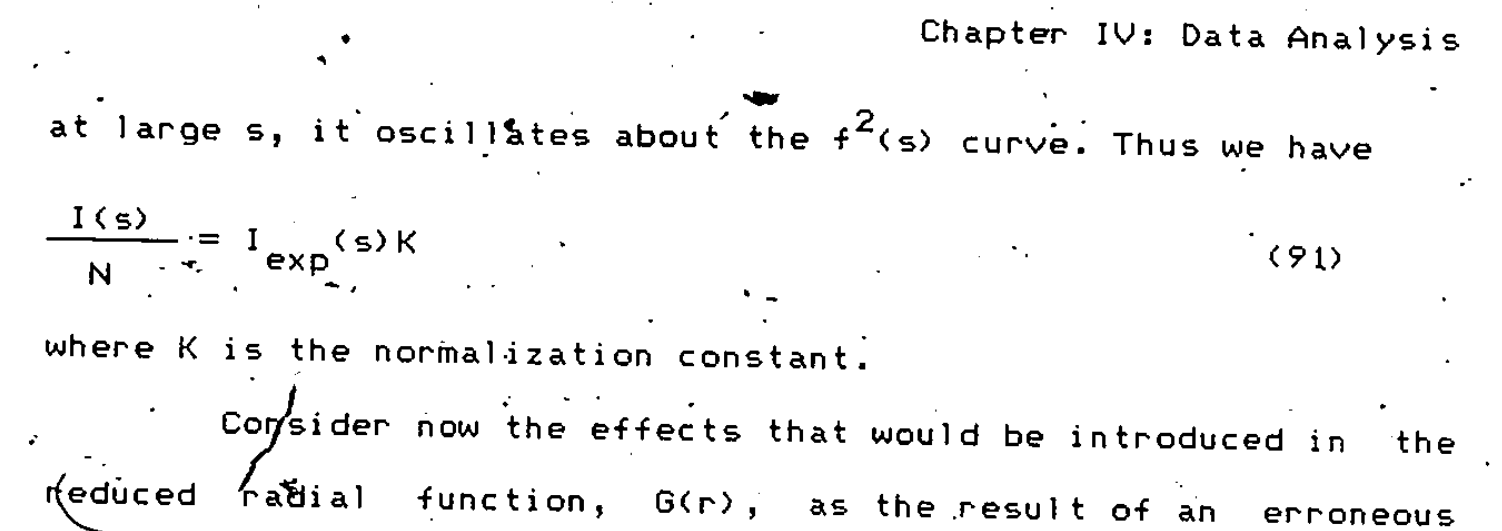
reduced rafial function, $G(r)$, as the result of an erroneous normalization constant. Recall that

$i(s)=s\left[\frac{I \exp K}{f^{2}(s)}-1\right]$

and

$G(r)=8 \pi \int_{0}^{\infty} i(s) \sin 2 \pi s r d s$

the errof-introduced in i(s) is

$$
\begin{aligned}
\Delta \mathrm{i}(s) & =\frac{\delta \mathrm{i}}{\delta \mathrm{K}} \Delta \mathrm{K} \\
& =\frac{s \mathrm{I}(s)}{\mathrm{f}^{2}} \frac{\Delta \mathrm{K}}{\mathrm{K}}=\frac{\Delta \mathrm{K}}{\mathrm{K}} \mathrm{i}(s)+\frac{\Delta \mathrm{K}}{\mathrm{K}} \cdot \mathrm{s}
\end{aligned}
$$

the error in $G(r)$ is

$$
\begin{aligned}
\Delta G & =\frac{\delta G}{\delta K} \cdot \Delta K \\
- & \Delta K 8 \pi \int_{0}^{\infty} \frac{\delta i(s)}{\delta K} \sin 2 \pi s r d s \\
& =\frac{\Delta K}{K} 8 \pi\left[\int_{\theta}^{\infty} i(s) \sin 2 \pi s r d s+\sin (2 \pi s r) s d s\right] \\
\Delta G & =\frac{\Delta K}{K}\left[G(r)+8 \pi\left[\frac{\sin 2 \pi s^{r}}{4 \pi^{2} r^{2}}-\frac{s^{2} \cos 2 \pi s^{r}}{2 \pi r}\right]\right.
\end{aligned}
$$

where $s_{m}$ is the maximum value of $s$.

The resulting $G(r)$ is composed of two parts, the first is 
a true function modified by a change of scale and the second is the transform of a straight line of slope $\Delta K / K$. Kaplow et.al (32) have iliustrated these effects and they show that the introduction of a variation as small as one percent from the correct normalization constant produces sharp oscillations in the reduced radial distribution function at values of $r$ close to zero.

This fact can be a useful criterion for the determination of the correct value of the normalization constant. Thus $k$ is chosen as the value that produces, the smallest oscillations in $G(r)$ at values close to zero.

So far we have assumed that the scattering factors, $f^{2}(s)$, were completely accurate. In reality. this is not necessarily the case. Due to approximations used in their calculations we can expect the $f^{2}(S)$ curves to contain some small systematic error. The probable form of this error is

$\Delta\left[\frac{I^{\prime}}{N f^{2}}\right]=\frac{I}{N f^{2}} \in(s)$

where $\epsilon(s)$ is a slowly varying function of $s$. The resulting error in $i(s)$ is

$\Delta i(s)=t i(s)+t s$

Combining this with the error caused by choosing an erroneous normalization constant we obtain

$\Delta i(s)=\left(\epsilon+\frac{\Delta K}{K}\right) \frac{s I(s)}{f^{2}}$.

$\Delta \mathrm{i}(\mathrm{s}):=\left(\varepsilon+\frac{\Delta \mathrm{K}}{\mathrm{K}}\right) \mathrm{i}(\mathrm{s})+\left(\varepsilon+\frac{\Delta \mathrm{K}}{\mathrm{K}}\right) \mathrm{s}$

The effect of this error on the reduced radial distribu- 
tion function is similar to those described above. The error in $G(r)$ produced by the first term in equation (96) is the convolution of the transform of $(\epsilon+\Delta K / K)$ with the true $G(r)$. Since $(\epsilon+\Delta K / K)$ is a slowly varying function the effect of the convolu- tion. is that of a change in scale. The second term $(\epsilon+\Delta K / K) s$ produces sharp oscillations in the region between zero and the first real peak in the reduced radial distribution function. The standard correction procedure used to minimize the effects produced by these errors was developed by Kaplow ${ }^{(32)}$ and will be briefly described here. Consider the reduced radial distribution function, $G(r)$ in the region before the first peak. This peak corresponds to the first nearest neighbour. Now we know that the value of $\rho(r)$ before the first peak is zero. Thus in this region $G(r)=-4 \pi r \rho_{0}$ hence we can think of the errors in this region as modulations about a straight line. Considering again the small region of $r$ between zero and the first peak we may define a function $\Delta G$ which is the difference between the experimentally obtained reduced radial distribution function containing the errors, and a straight line $G(r)=-D r$. Since only the small $r$ region is being considered, the transform of $\Delta G$ will correspond to the second term of equation $(96) "(\epsilon+\Delta K / K) s "$ and then $\Delta i$ can be calculated by multiplying by $I(s) / f^{2}$. The variable parameter for this procedure is the slope $D$, the criterion for choosing it is that the error transform $s(\epsilon+\Delta K / K)$ should not contain sharp oscillations near zero.

iv) Non-elastic Collisions

The effect of non-elastic collisions is to increase the scattering background on the diffraction pattern, hence decreas- 
- ing thite measurable intensity of the observable peaks. The two main factors that have to be controlled to minimize the background are the substrate and sample thickness. Due to the non crystalline nature of the formvar substrate its contribution to the diffraction pattern is that of extremely broad peaks of very low intensity. Thus it is desirable to keep the formuar thickness to a minimum so that its contribution is also small. The thickness of the sample should also be kept small to minimize any multiple scattering that might occur. The errors introduced, by the background were additive in nature similar to those described by Gracizy et.al. (33). More specifically they have the form $i(s)=s\left[\frac{I(s)+t}{f^{2}}-1\right]$ where $f$ is a slowly varying function. This type of error is easily detected and corrected. Its main effect is to make. i(s) oscillate about a slowly varying function $\epsilon$. To correct we just subtract $\epsilon$ so that i $(s)$ properly oscillates about zero. 


\section{- Chapter $v$}

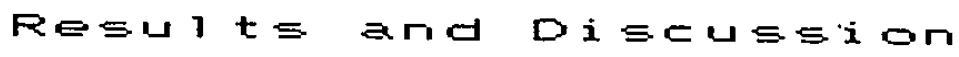

In. figure $V-1$ we present a series of electron micrographs of thin $\mathrm{Ni}-\mathrm{P}$ grown at different $\mathrm{pH}$ values of the metallizing batti (from $\mathrm{pH}$ about 8 through $\mathrm{pH}$ about 12). Care was taker so that each film was grown approximately to. the same thickness. Based on the temperature and $\mathrm{pH}$ of the metallizing bath and the fime of deposition of each film we estimate the thickness of the films to be of the order of 50quastroms. The electron micrographs shaw the usual picture of a discontinuous film consisting of, individual islands. These islands are the result of Sn-Pd nucleation centers present on' the surface after activation before metallizing started $(6)$. We note that as the ph value increases the metal island are larger and more sparsely distributed on the surface. Also in this. connection we observe that each film has nearly uniform island sizes. We attribute this to the following..First, the effect of raising the $\mathrm{pH}$ on the hypophosphite is to increase its. reduction potential ${ }^{(5)}$, thus the enhanced film growth rate. second, it has been observed(5) that some time in the alkaline. bath is necessary before the material present on the substrate after the Sn-Pd sensitization-activation is capable of catalyzing plating. This is expected to result in fewer active nucleation centers available for higher pHs, simply becáuse the time spent in the metallizing bath is shorter.

The tentative models for the Ni-P alloys grown in alkaline environment are those of a solid solution of phosphorus in crystalline fcc nickel structure ${ }^{(6)}$. Hence as far as this point is concerned a high concentration of phosphorus would result in 


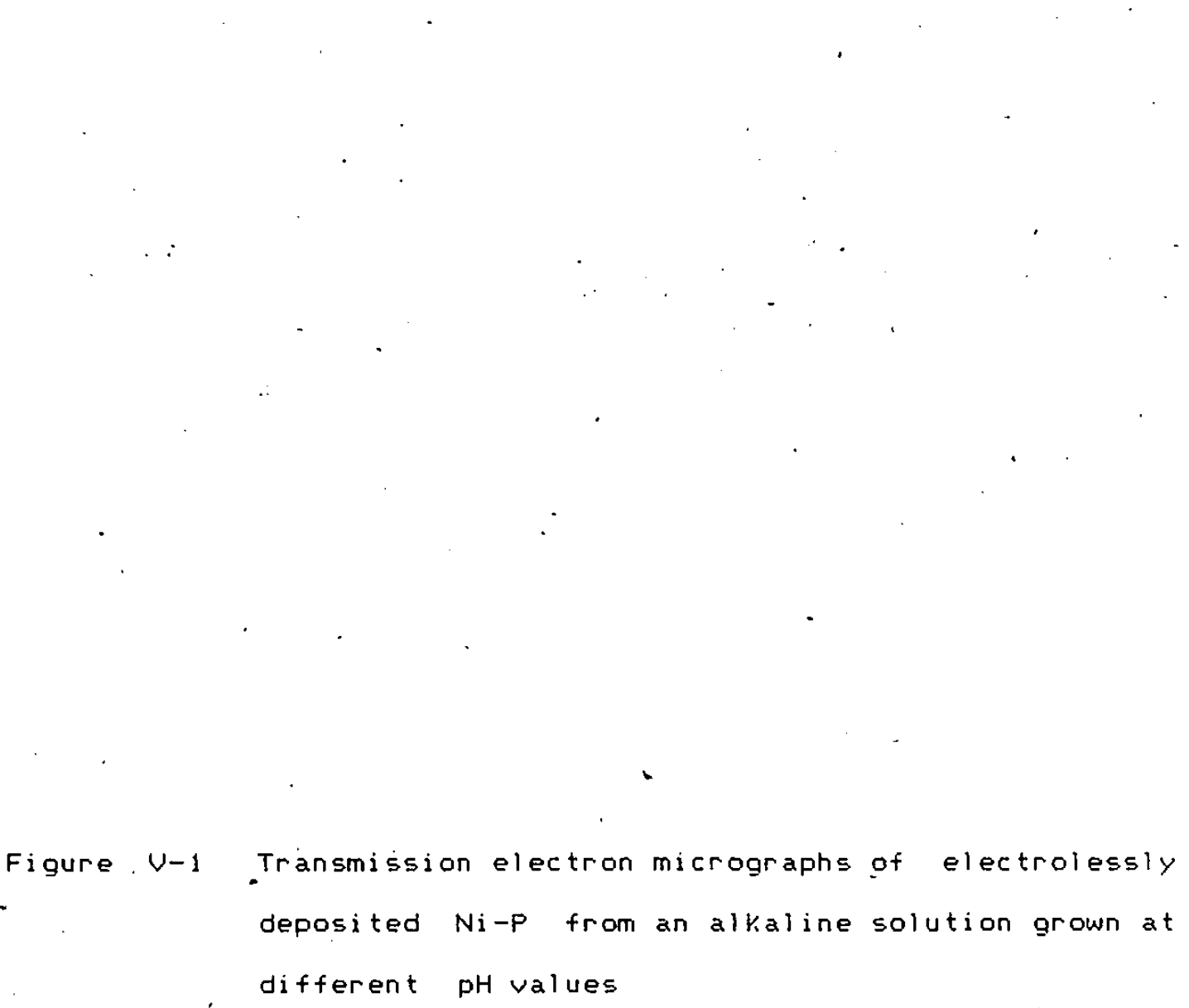



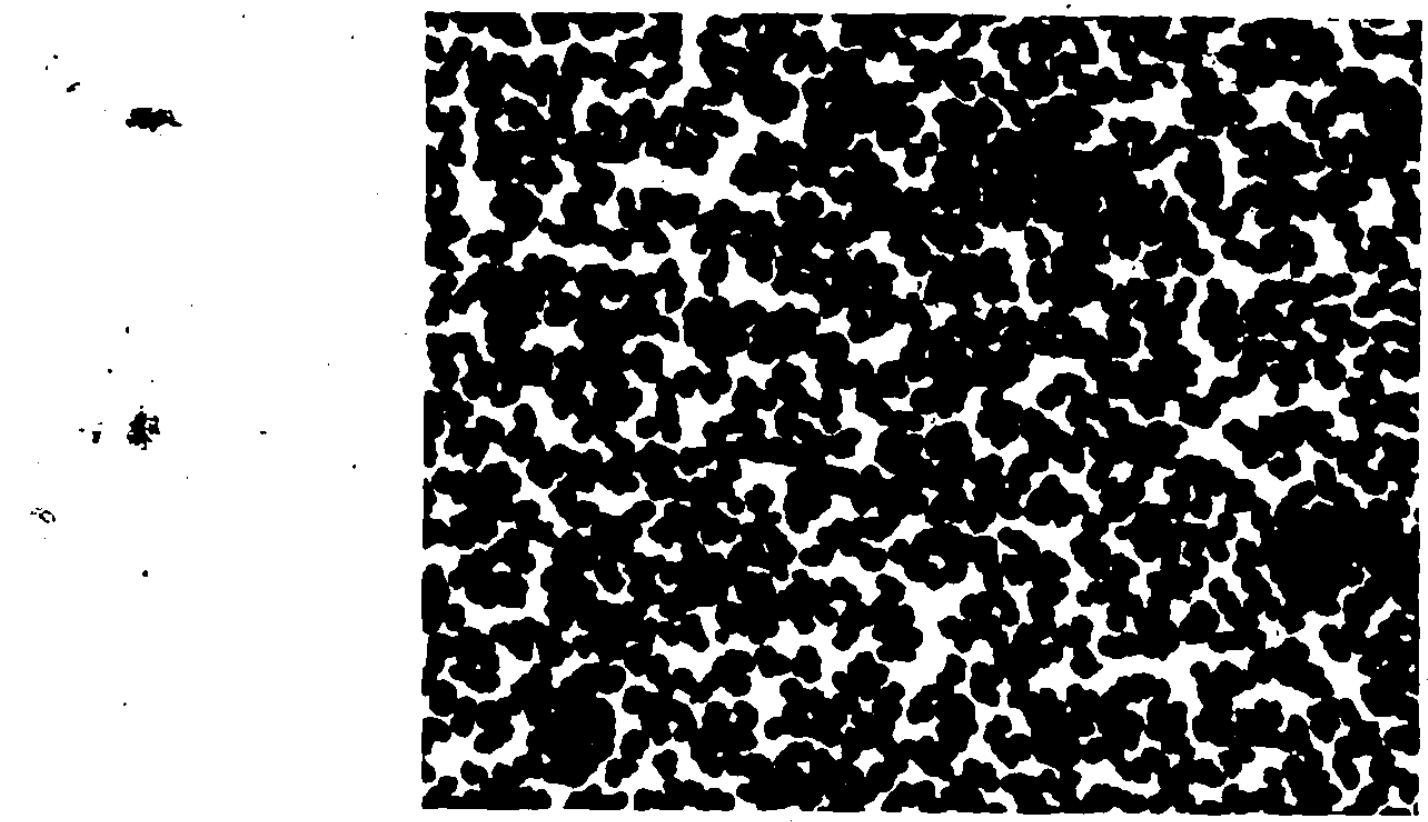

s

Figure V-la pH 12.3

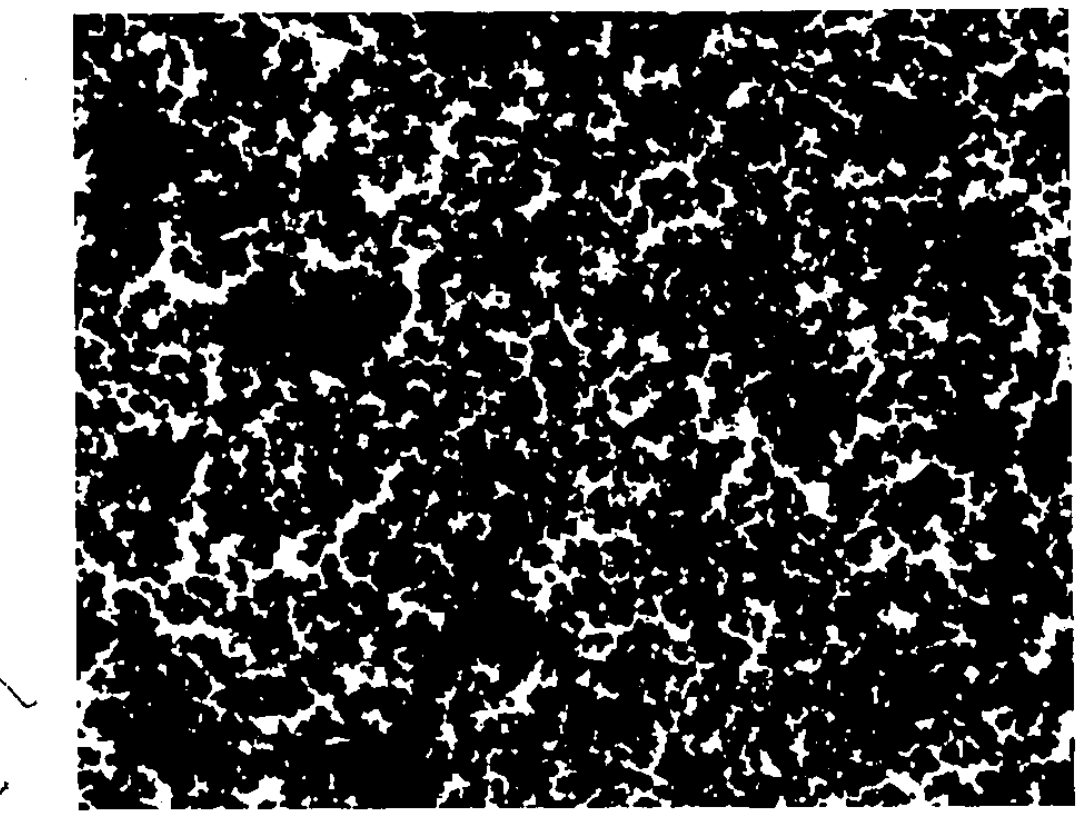

Figure V-Ib pH 10.8 


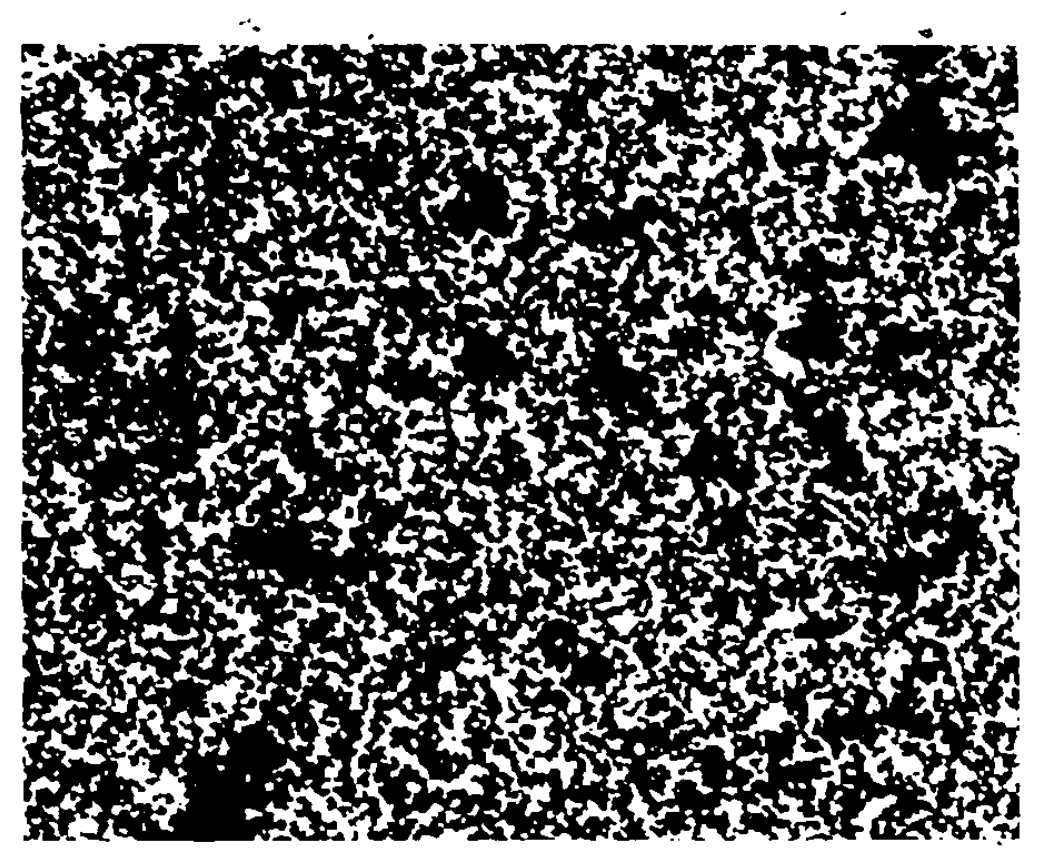

Figure V-1c pH 9.9
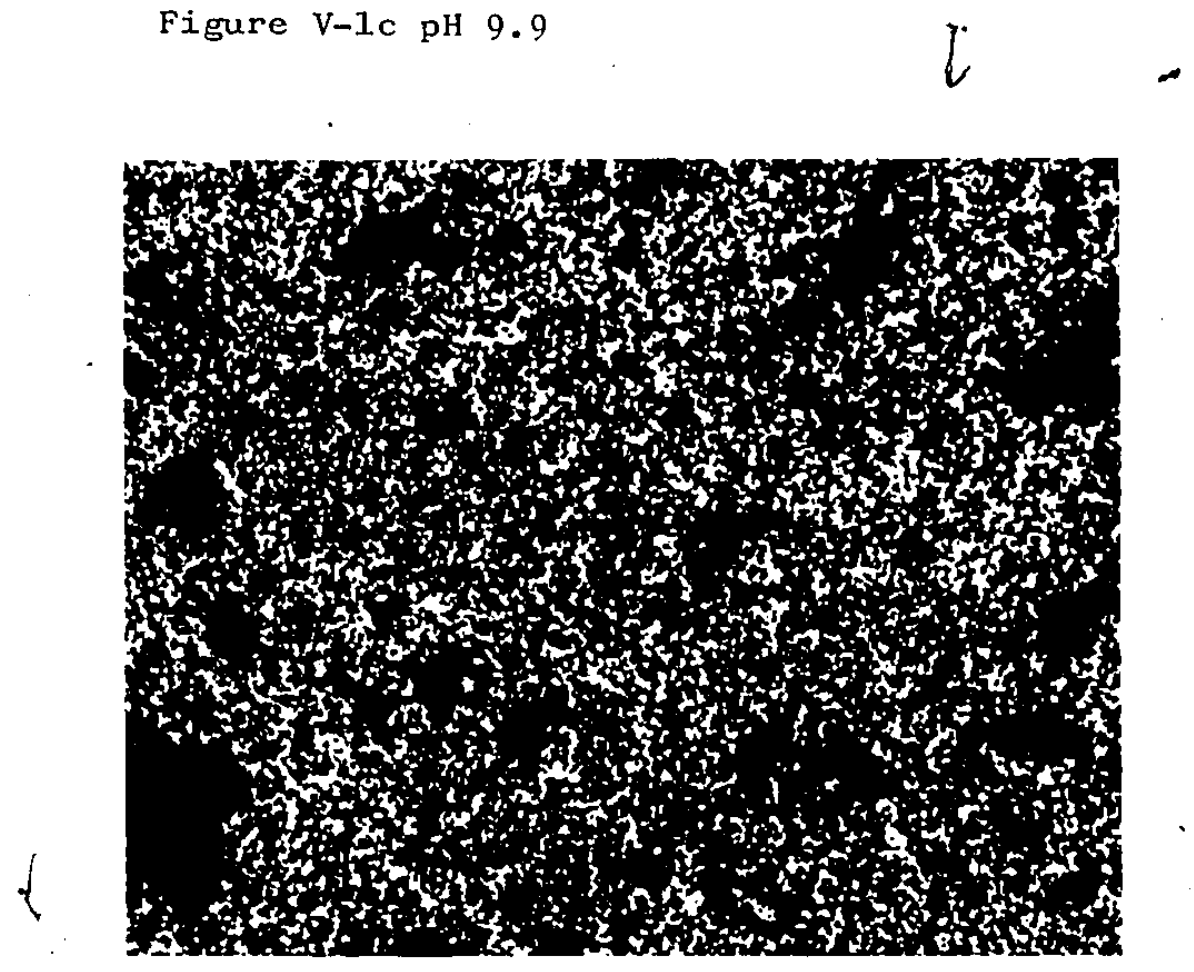

Figure V-I 9.0 

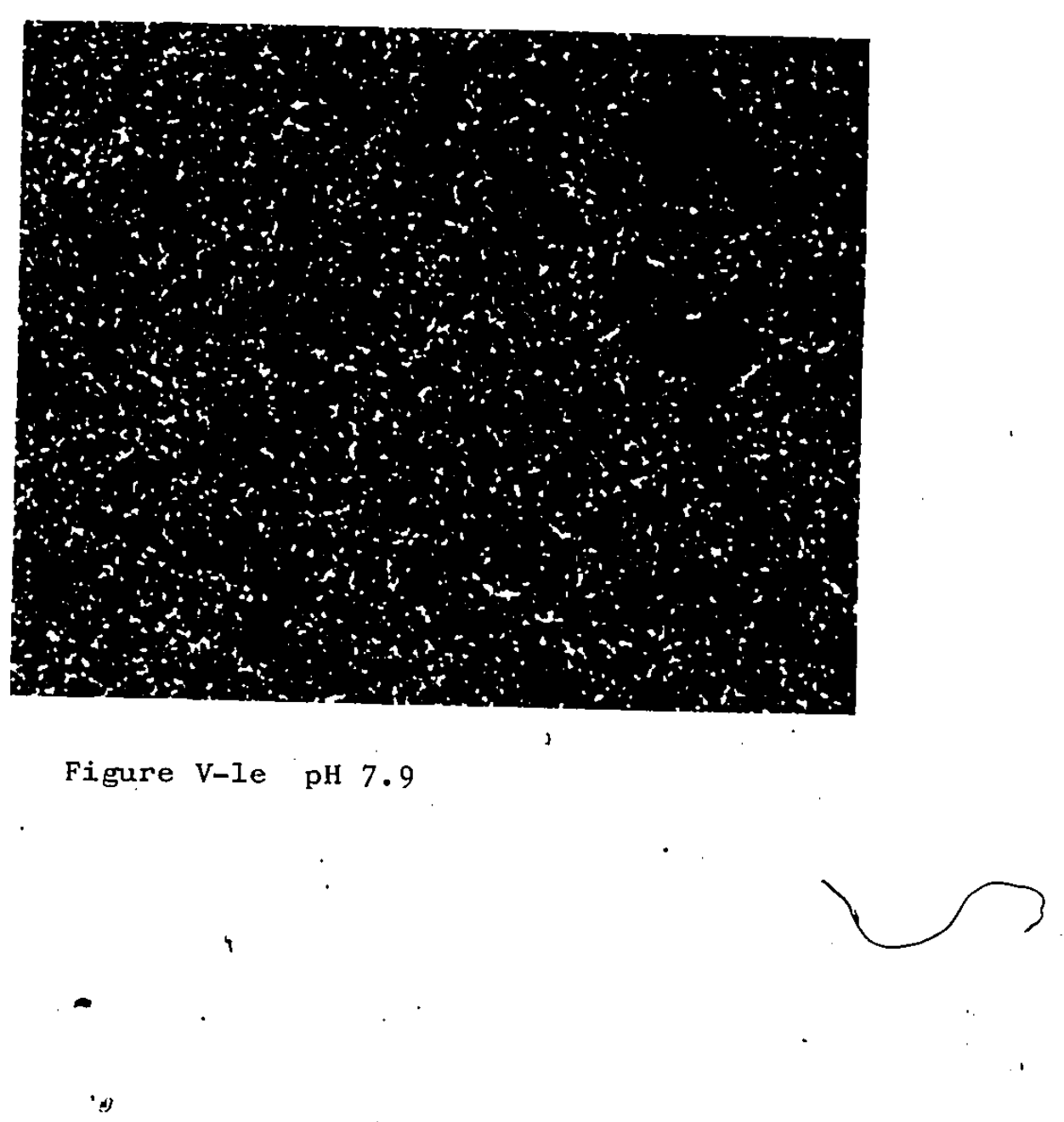
s.

films was estimated using Energy Dispersive $X-r a y$ Analysis as follows. First using as standard a Ni-P film grown in acidic environment with a-known phosphorus content was examined. From this measurement the minimum amount of phosphorus that could be detected using this technique was determined to be about $2 \%$. Consequent examination of the films used for the present study showed that no phosphorus could be detected. Hence we conclude. that the phosphorus content of all films used was less than $2 \%$.

Figure $U-2$ presents the densitometer output curves, before smoothing, of the diffraction patterns obtained from the films corresponding to figure $U-1$

The broadening of the peaks of the diffraction pattern can be initially attributed to one or more of the following:

i) Partial crystallinity

ii) Small crystallite sizes

iii) Internal strains

The effects of large stresses and strains on the lattice are easily recognizable, for they tend to broaden the diffraction peak in the direction of the stress of strain, far more than any of the other peaks. This effect is not observed on the series of diffraction patterns presented in. figure $U-2$, thus whatever stresses and strains are acting on these films are not dependent on - the pH of the metallizing bath. The observable broadening of the peaks is relatively smooth as the $\mathrm{pH}$ increases, this suggest that the broadening is mainly due to changes in the crystallite sizes. It is known (35) that the size contribution to the width of the Bragg diffraction peak $\Delta s$ is related to the crystallite 


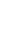


1

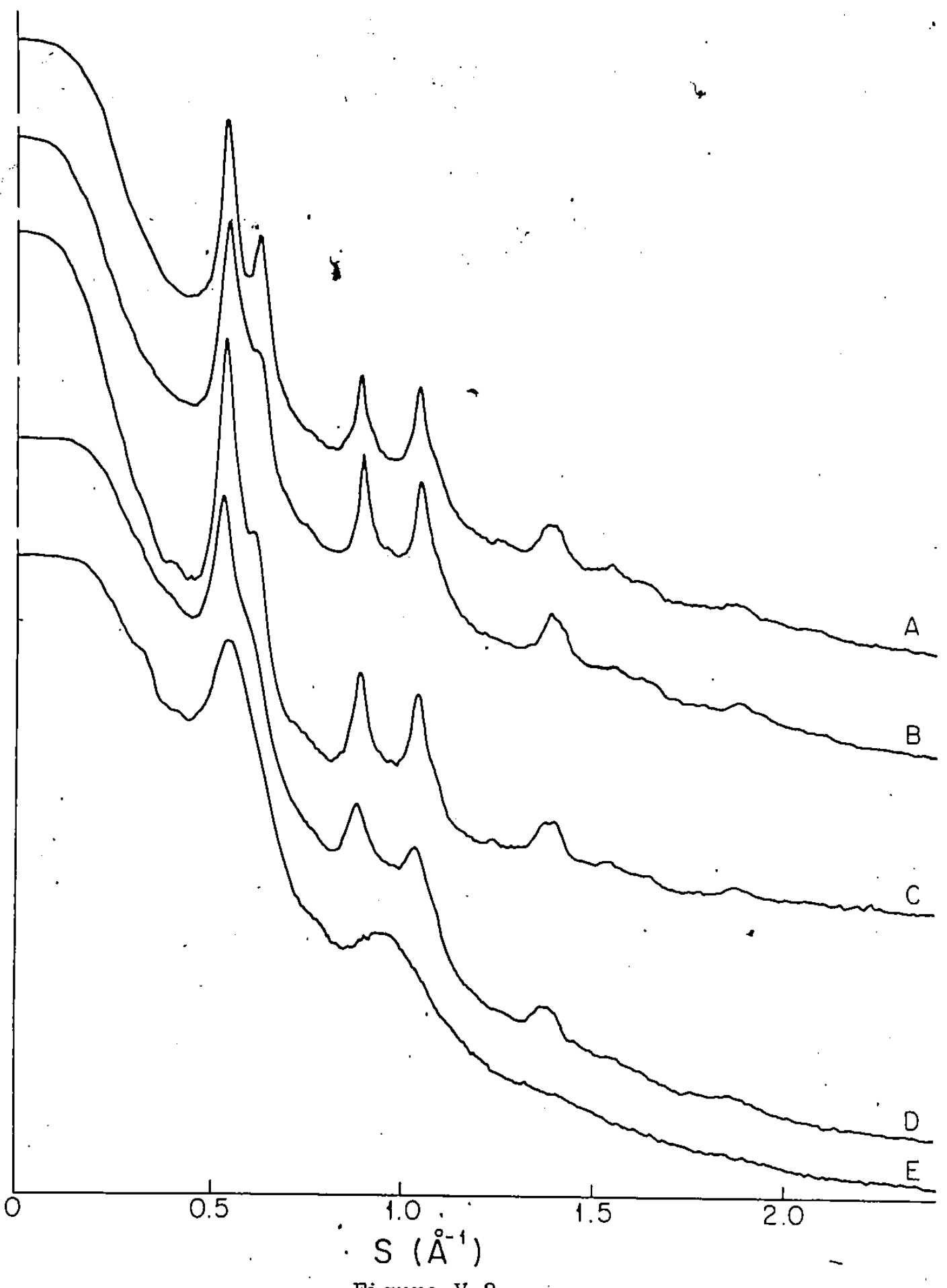

Figure V-2

$\gamma$ 
sizes, D, normal to the diffraction plane by the expression

$\Delta=\mathrm{C} / \mathrm{D}$

(97)

where $C$ is a quantity which depends on the Miller indices of. reflection and the shape of the crystallite. For isotropic crystallites however it is about unity for all reflections. As the sizes of the crystallites decreases all peaks are expected to broaden. This can be observed to be the case in figure $U-2$. The crystallite sizes as determined by equation (97) are given in table $V-1$. The island sizes are determined from figure $V-1$ are given a's approximate ranges between the smallest and largest $i \leq l$ and observed in each sample.

\begin{tabular}{|c|c|c|c|c|}
\hline \multirow{2}{*}{ pH } & $\begin{array}{r}\text { isiand } \\
\text { sizes (A) }\end{array}$ & \multicolumn{3}{|c|}{ Crystallites sizes (Angstroms) } \\
\cline { 2 - 5 } & & 111, & 220. & 311 \\
\hline 12.3 & $600-700$ & 22 & 32 & 32 \\
10.8 & $400-600$ & -17 & 26 & 28 \\
9.9 & $300-400$ & 17 & 17 & 26 \\
9.0 & $200-300$ & 15 & -- & - \\
7.9 & $100-200$ & 11 & & 24 \\
\hline
\end{tabular}

-- peaks not clearly resolved

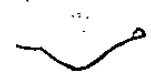

Table U-1 Island and crystallite sizes

Figures $\dot{V}-3$ and $U-4$ give the $i(s)$ curves obtained after the correction procedure. From these the reduced radial distribution functions, $G\langle r\rangle$, were calculated.

It is important to realize that the information that the reduced RDF provides is inherently present in the diffraction pattern; the reduced RDF just gives us this information in.a way that is simpler to examine. The $G(r)$, curves show average one 


$$
\begin{aligned}
& \text { Figures } U-3, U-4 \quad i(s) \text { curves obtained after correction } \\
& \text { Figure } V-5, V-6 \text { Reduced RDF }(G(r)) \text { curves corresponding to } \\
& \text { curves (A) - (D) in figure } V-2
\end{aligned}
$$

0 


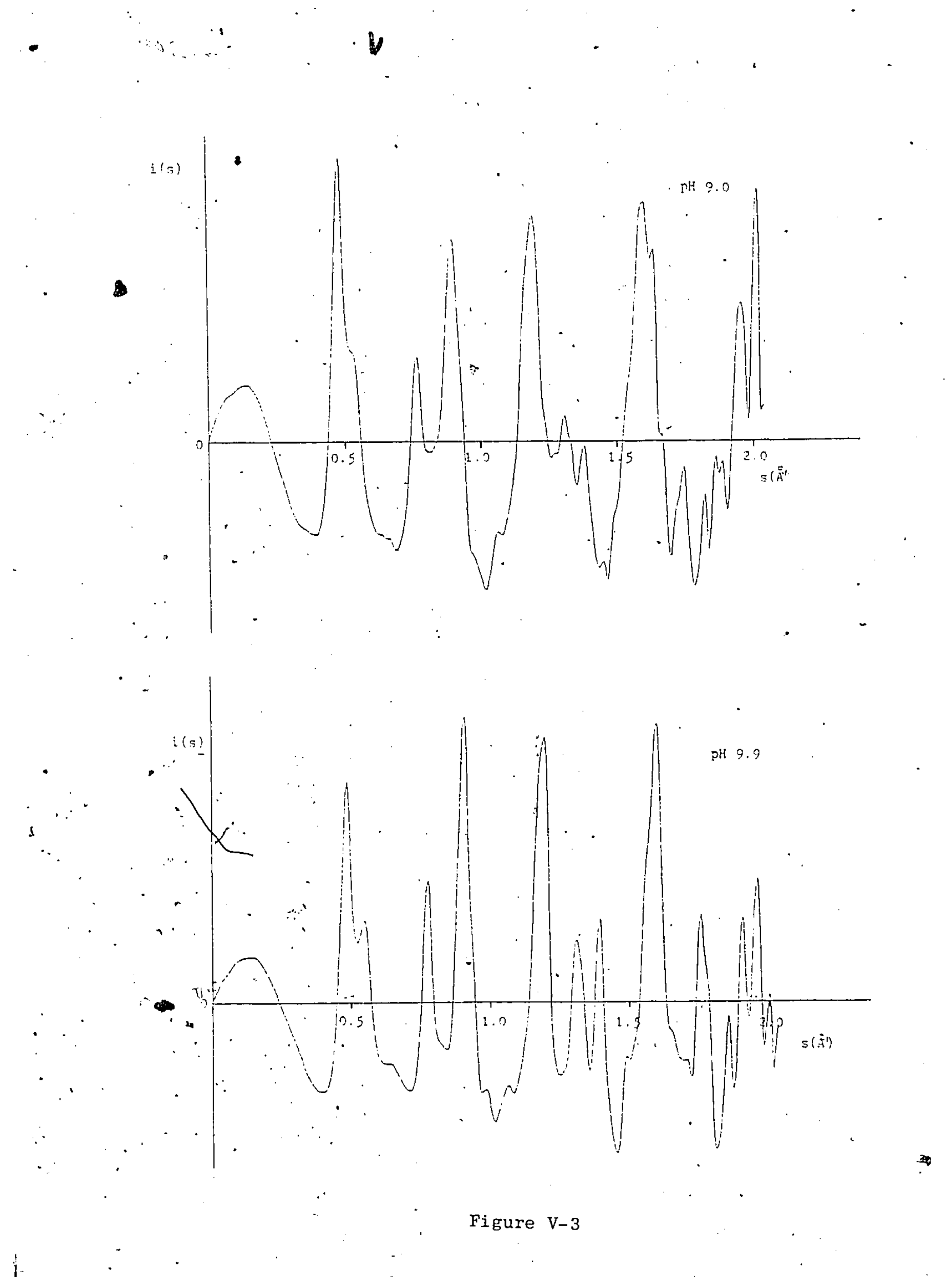




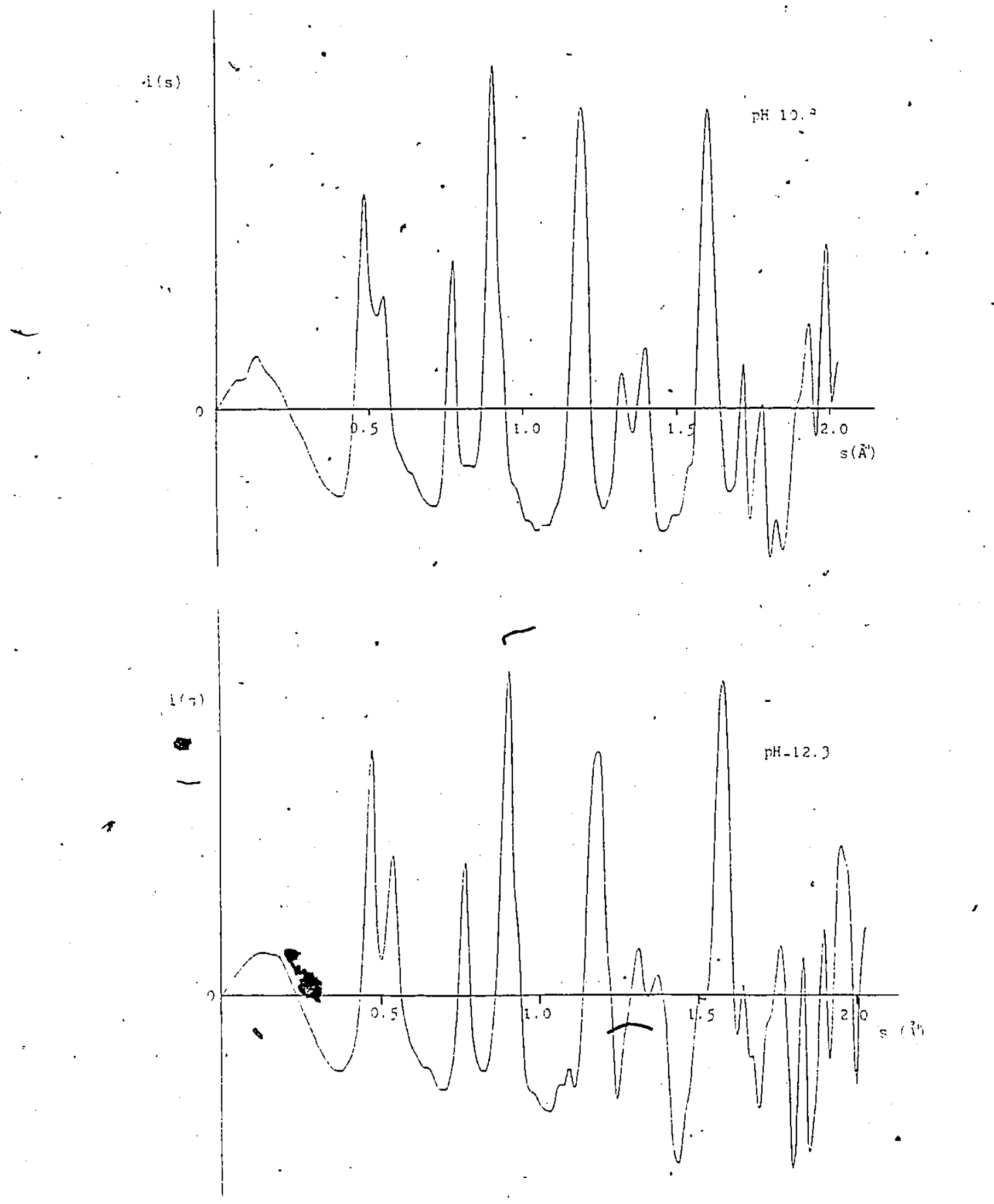

- Figure V-4 


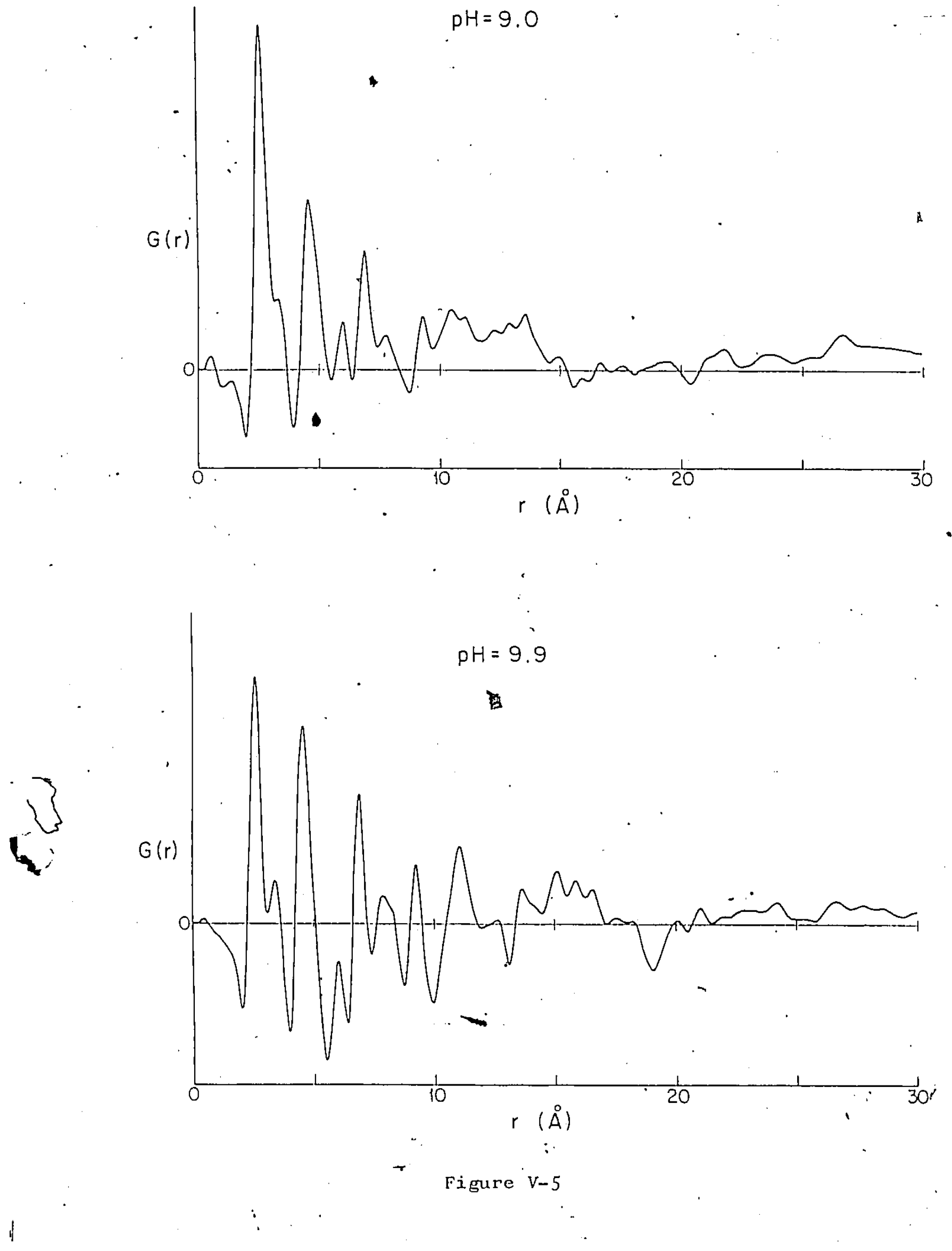




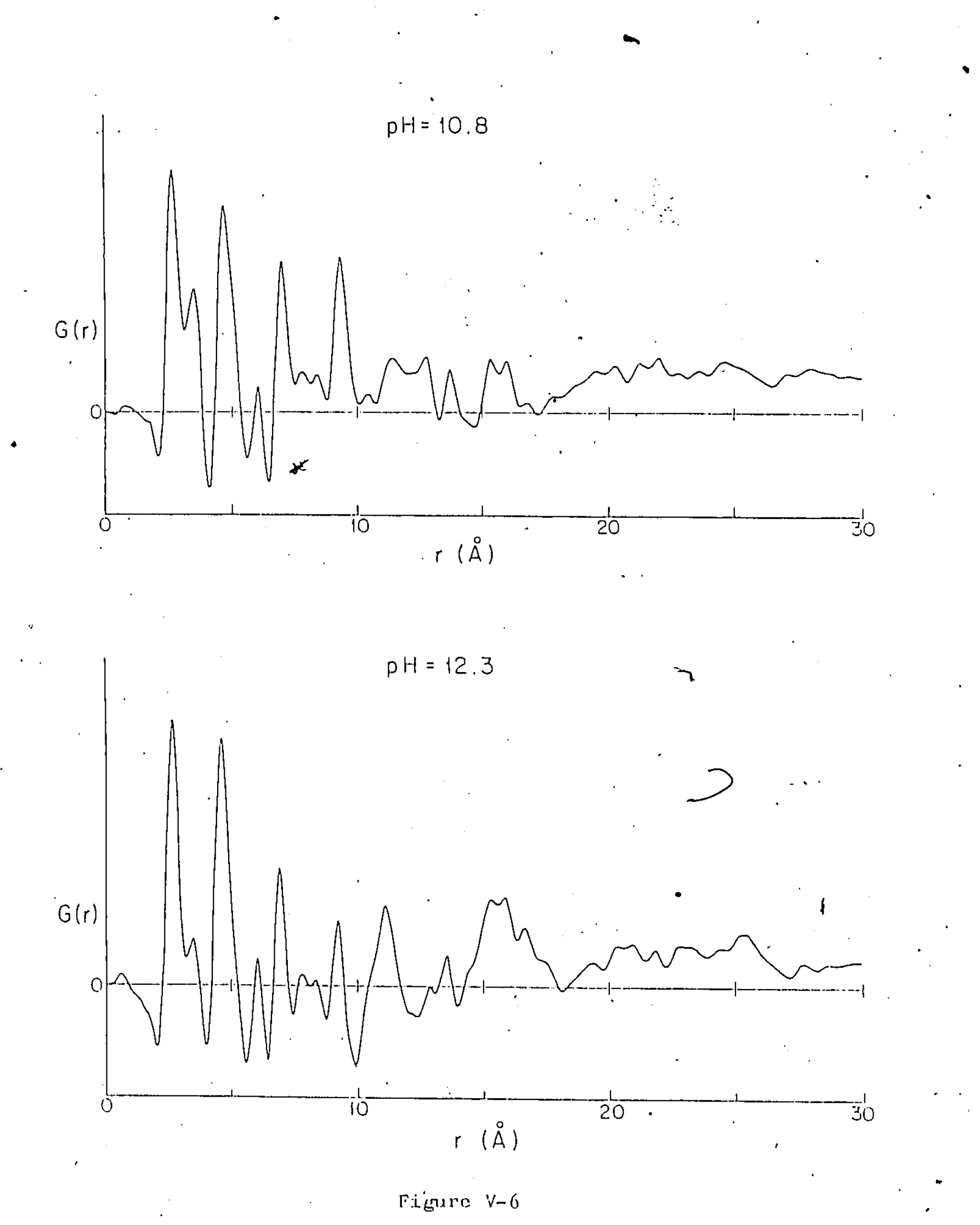


dimensional information about the locally varying three dimensional strugture of the thin films. For a crystalline material the reduced. RDF would contain sharp peaks corresponding to the various distances of each neighbour. For example if the sample being studied had fcc structure, then the reduced RDF would show a sharp neighbour peak follow by peaks at dishances $\sqrt{2}, \sqrt{3}, 2$, etc. relative to the first peak distance. As the crystallinity of the sample decreases we can expect the following changes in the reduced RDF. Generally all the peaks willyecome broader! some, of them might shift position and if the amprphicity is high enough some of the peaks will disappear. Figure $U-5$ and $V-6$ gives the reduced RDF curves obtained from the samples shown in figure $V-1$, the reduced RDF corresponding to the $\mathrm{film}$ grown at $\mathrm{pH} .7 .9$ was not calculated since we felt that its phosphorus content would not be low enough to justify the single species treatment used for the rest of the samples. Table $U-2$ presents the location of the first $\because$ ten peaks in each of the reduced RDF curves.

\begin{tabular}{|c|c|c|c|c|c|c|c|c|c|c|}
\hline \multirow{2}{*}{$\mathrm{pH}$} & \multicolumn{6}{|c|}{ distance $r$ corresponding to 10 first peaks (angstroms) } \\
\cline { 2 - 10 } & 1 & 2 & 3 & 4 & 5 & 6 & 7 & 8 & 9 & 10 \\
\hline 12.3 & 2.6 & 3.5 & 4.6 & 6.0 & 6.9 & 7.7 & 8.2 & 9.1 & 10.4 & 11.0 \\
10.8 & 2.6 & 3.5 & 4.6 & 6.0 & 6.9 & 7.7 & 8.3 & 9.2 & 10.3 & 11.2 \\
9.9 & 2.6 & 3.4 & 4.6 & 6.0 & 6.9 & 7.8 & 8.2 & 9.2 & - & 11.0 \\
9.0 & 2.6 & 3.3 & 4.6 & 6.0 & 6.9 & 7.7 & - & 9.2 & 10.4 & 11.0 \\
\hline
\end{tabular}

Table $V-2$ First ten peak locations in $G(r)$ curves

The reduced RDF curves lead to the following observations. Each curve could be thought of being, composed of three regions, a region of sharp well defined peaks corresponding to 
short range order, a region of small broad peaks corresponding to the long range order and a small transition region separating the two. From table V-2 we observe that within the region of short order the position of the peaks does not vary as the pH changes, on the other hand the relative intensities of some peaks does change and we also observe that as the $\mathrm{pH}$ increases the peaks become better resolved.

From the above observations a consistent model for the " structure of our.films can be offered. The general feature of earlier models $(6,36)$ is retained, namely that. with increasing $\mathrm{pH}$ of the metallizing bath, i.e decreasing phosphorus content we can expect the films to be more crystalline. The present work however clarifies and finalizes the model. The islands, whose origin is traceable to the nucleation centers $(6,37)$, are made up of component crystallites whose dimensions are strongly $\mathrm{pH}$ dependent. The dependence is such that we observe a doubling of the crystallites size as the $\mathrm{pH}$ is increased from 8 to 12 . We further observe that the short range order as deduced from the reduced RDF curves also. increases with $\mathrm{pH}$, as a matter of fact it would seem that the extend of the shof t'range order nearly equals the crystallite sizes. In,this model a few points require further work, but some speculative considerations may be given. "Consider the varyion relative intensities of some of the peaks in the reduced RDF. curves. First of all we should point out that the area under each peak is a measure of the number of atoms that are located at the distance marked by the peak. This area under the peaks is commonly refered to as the coordination number. Previous work (38) has 
shown that the as deposited $\mathrm{Ni}-\mathrm{P}$ films have a lower material density than that of bulk nickel. This fact might explain the changes in the intensities if we assume that the films obtain their lower density by having consistently vacant sites. Another and not unrelated possibility is that some regularly distributed sites are occupied by the phosphorus atoms. In practice we might expect that the real situation is a combination of the two given explanations.

Another point is the difference between the nearest neighbour distance in bulk rickel, 2.5 angstroms, and the value obtained for our films, 2.6 angstroms. Here we might draw a parallel to the comparative study of solid aluminum and aluminum at the melting point carried out by the MIT group(39). In their studies the differences between the reduced RDF curves for solid and 1 iquid aluminum were possible to explain assuming a quasicrystalline model in which the reduced RDF of the solid is broadened and damped by the introduction of a definite crystallite size and 1 iquid diffusive motions. In our films we not only have: small crystallites but an aggregate of these form small islands. Thus, not as in a solid a given atom sés an interrupted periodic potential; the atoms in our films will "feel" the influence of the physical boundaries of the crystallites and islands that interrupt the periodicity. In conclusion our model for the electroless Ni-P films grown in alkaline solution consists of highly ordered component crystallites of very small size which are strongly affected by the relative large surface to volume ratio of the crystallites and islands, giving us the liquid like appea- rance of the reduced RDF. 
Appendix 1

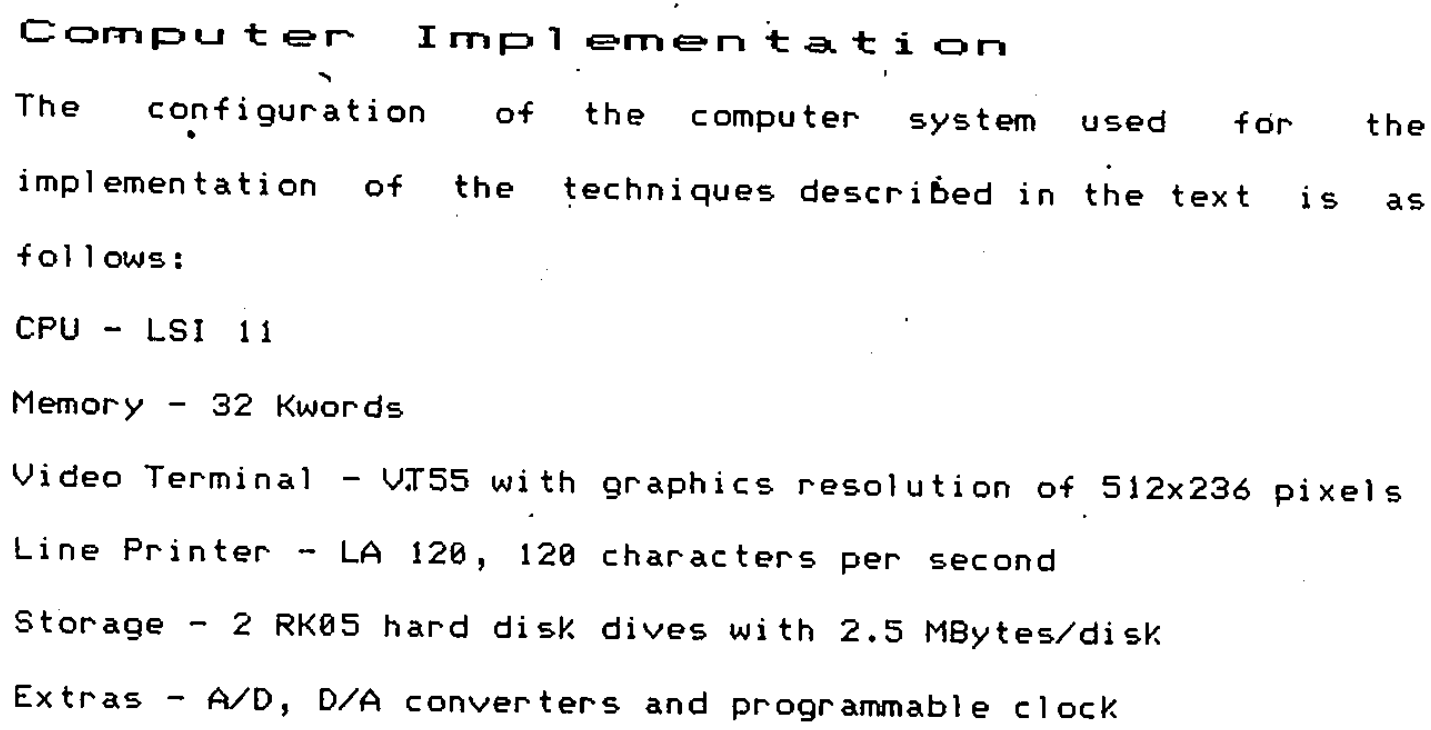




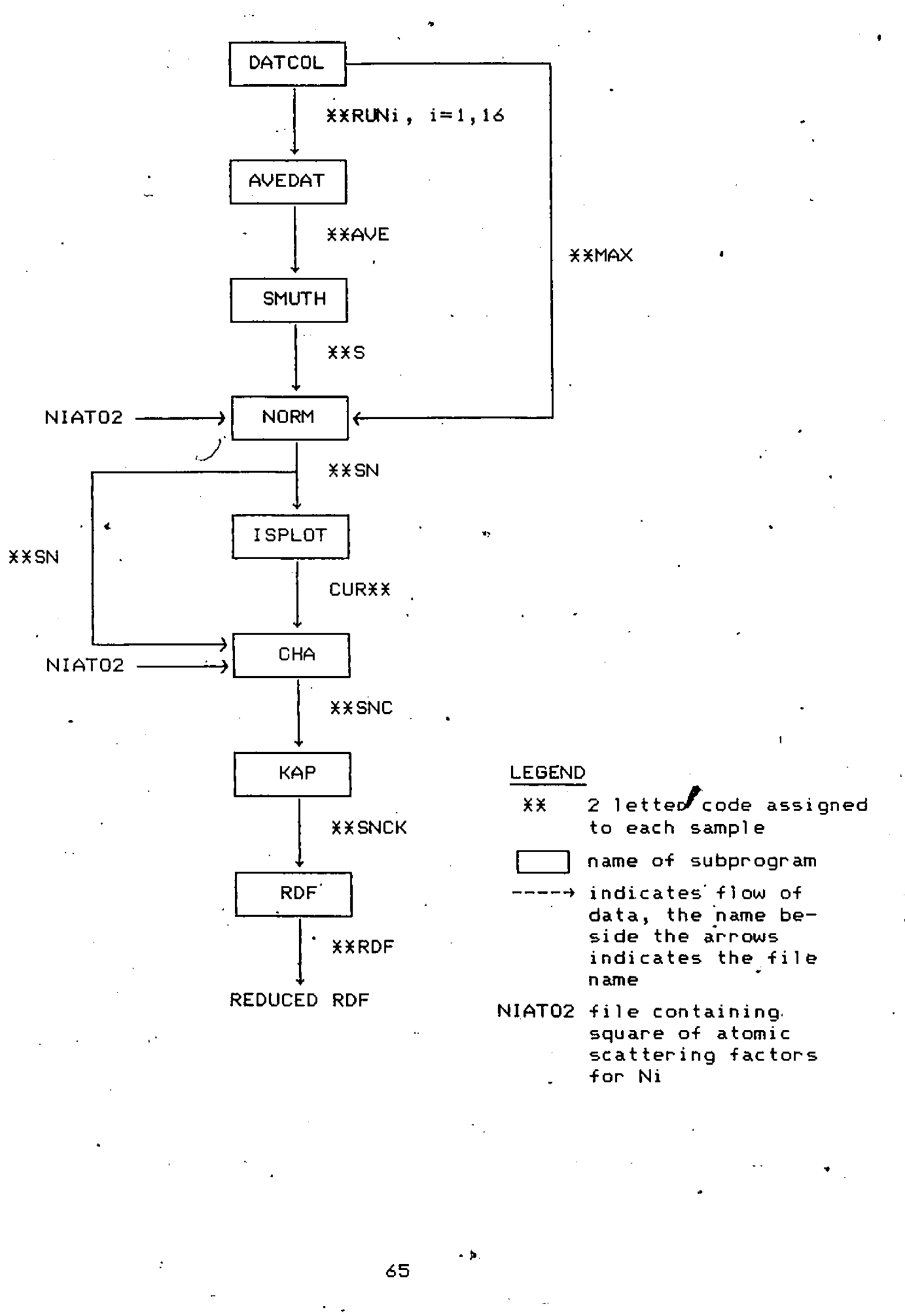


,

$\therefore$
Appendix 2

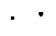

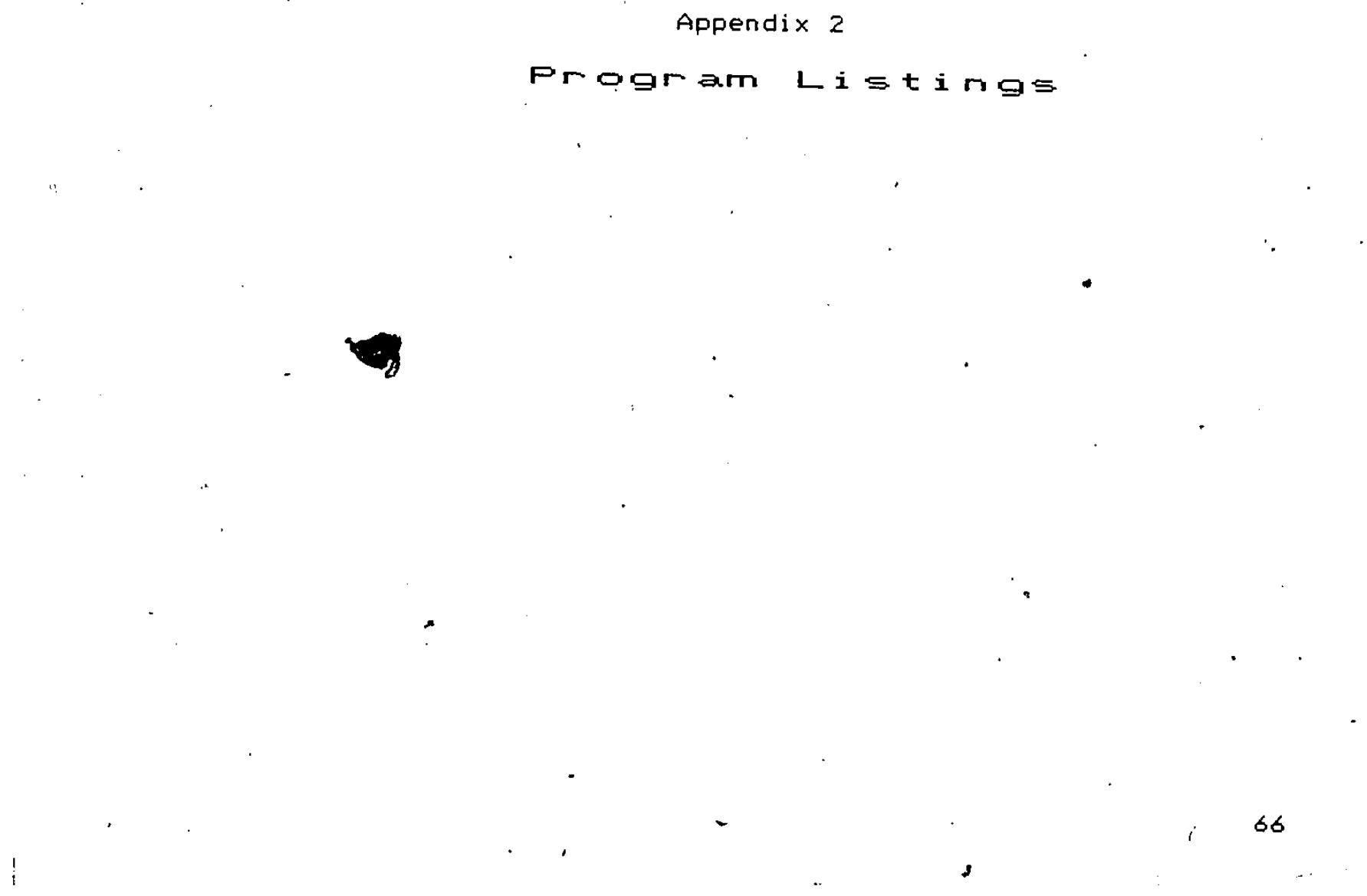




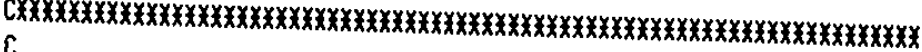 \\ PROGPAY DATCOL}

C

C

C

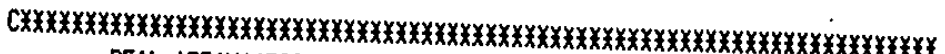

REAL ARPAYI(529), ARRAY2(529), ARRAY3(520)

INTEGER BUF (39), NI(1188), RIGT (528), LEFT(528)

EOUIUALENE(ARRAYI(1), RIGKT(1))

INTEGER OFFSET

LOGICALXI IANS

REALX8 IDNA

290 FORAAT(A6)

58 FOANAT(7I)

333 FORHAT(I7)

C

c

C

INITIALIZE

$N=512$

I $=2 \times \mathrm{N}$

NAXX $=1808$

77

DO $77 \quad I=1$; 38

BUF $(1)=8$

$P I=3.1415926$

$F L A G=\theta$

C

THE USER CAN EITHER CREATE A FILE KITH NEN DATA

OR EXAHINE AN OLD DATA FILE

CALL CLEPLT

TYPE $X$, 'READ OR WRITE?(R or W'

CALL IMCHAR(IANS)

IF (IANS.EQ.' $R^{\prime}$ ) 60 TO 2

IF(IANS.NE. ' $W$ ') 60 TO I

GO TO 3

C

COOE FOR CREATING FILE WITH NEA DATA

FLAG $=1$

CALL CLEAR

(1)

TYPE $X$, 'FILE NAYE?'

$\operatorname{READ}(7,288)$ IONA

CALL ASSICN 28, IDNA)

IF(FLAG.EQ.1) GO TO 98

TYPE $X$,'TAKING IN DATA'

TYPE $x$,

CALL INDATA(NI, MAX, 11)

NRITE $(28,58)$ NAX

IREAD CHARACTER FROY KEYBCARD

GRITE $(28,58)(N J(1), I=1$, NAX)

c GO TO 38

CODE TO EXAMINE OOD DATA FILE

READ $(28,58)$ MUPTS

READ $(28,58)$ (NI (1) , I=1, NUHPTS)

!COLLCT THE DATA FROM DENSITOMETER

$$
\begin{aligned}
& C \\
& c \\
& 90
\end{aligned}
$$



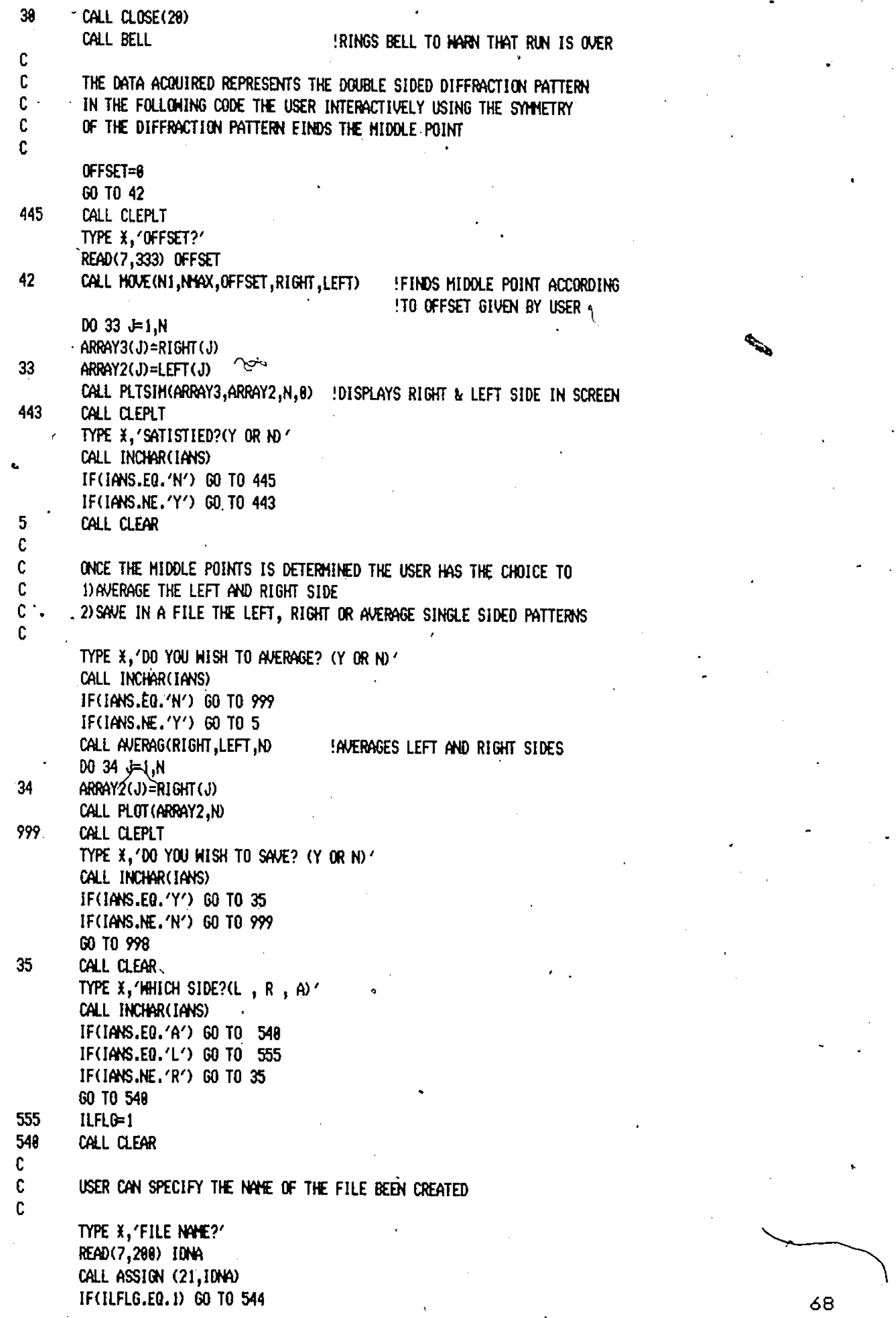


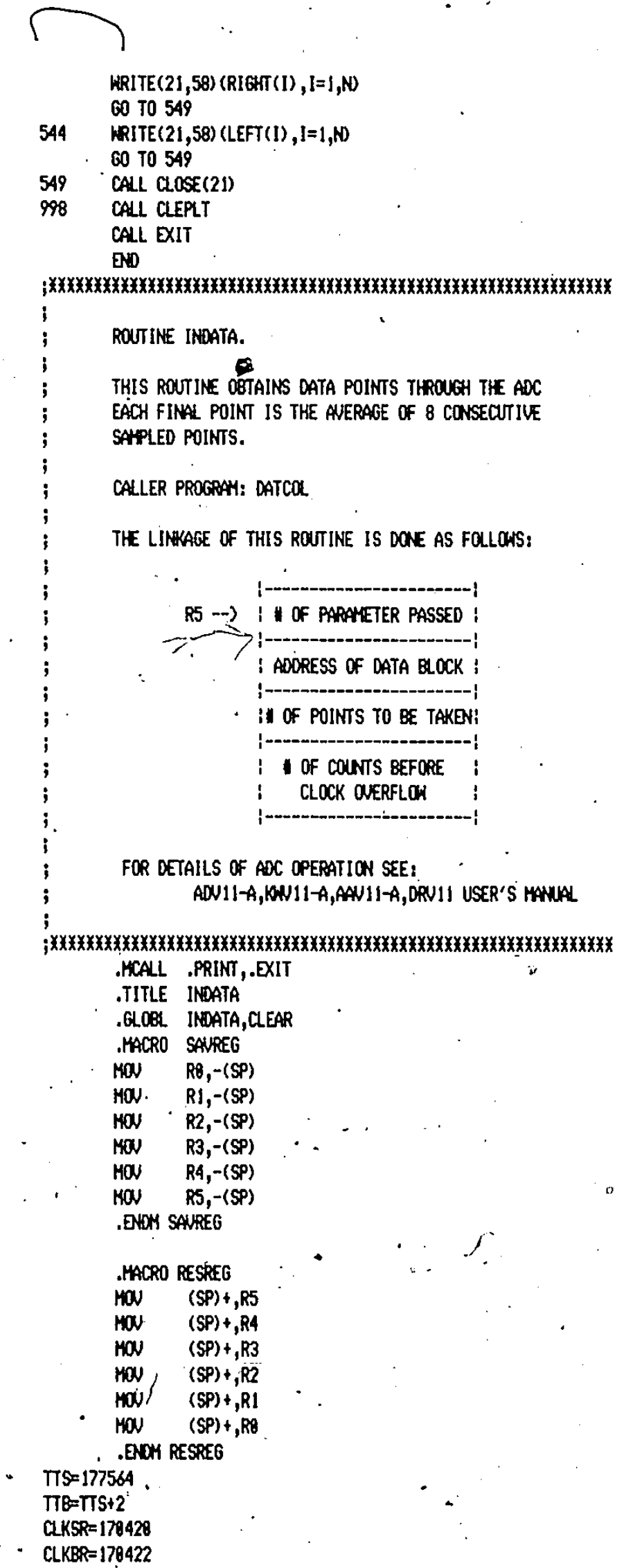


;SAUE REGISTERS

ADSR $=779480$

ADER $=176492$

INDATA: SAPEG

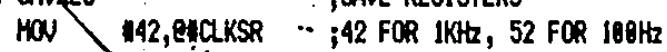

HOW THF,GIAOSR ;SET CLOCK EABAE

MON 2(KS), ADDR ;AODR $<--$ ADDRESS OF DATA BLOCK

HON - EA(RS), RE ; ;RQ (-- OF POINTS TO BE SAYPLED

HOV - RS(RS), R1 ;R1 (- $~$ OF COUNTS DESIRED BEFORE

;OUERFLOH

NEG RI TTAKE 2'S CONPLINENTS

NOW RI,RUCLKBR \& ;INSERT INTO CLOCK'S BUFFÉR

CLR

RI

, $\therefore$ BIC 298, Q BADBR ;

INC RICLKSR ;START SAFPLING

LOOPA: QR

R3

;R3 WILL CONTAIN THE AVERAGE OF 8

. Mai

18., R4

;POINTS

LOOP: TSTB

;IS A.D. READY?

BPL LOOP

;HAIT UNIIL READY

BIC 208 , EICLKSR .

MOU . EMADBR,R2 GGET SA FPLED POINT

BIT 18BBOB,RAADR. ;CHEKS FOR DATA LOST

BEE ERROR

$A D D \quad R 2, R 3$

i

SOB RA,LOOP

;ADOS TO TOTAL

;GOES BACK UNTIL IT GETS 8 POINTS

CLC

ASR R3

ASR $\quad \cdot R 3$

ASR R3

;CLEAR CARRY BIT.

SLB $\quad 4888, R 3$;SLBSTRACT ADC OFFSET

MOV R3,EADDR ;STORE POINT IN DATA BLOCK

ADD . 2, ADOR - ;INCRESENT POINTER IN DATA BLOCK

JSR PC,PRINT . ;SHOW IN SCREEN OF POINTS SAPIE

. ;SO FAR

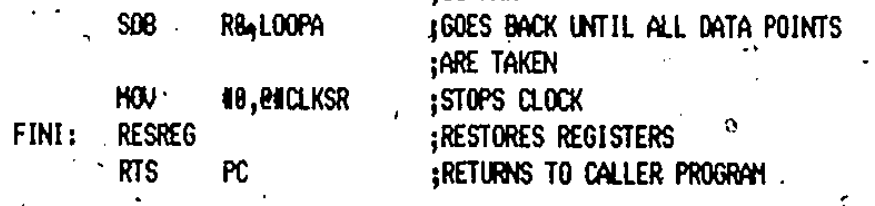

.; THIS SECTION HILL TAKE OCTAL MURBERS AS INPUT

i AD PRINT THEIR DECIKAL EOUIULLENT IN THE SCREN

PRINT: 'SAMREG

HOW Ri, RS .

MON NTABEL, R2

HON . $15, \mathrm{RI}$

LOOP1: CLR RA

DIV . (R2) +,R

$\therefore$ AOD $\quad$ AOS,RA

$\sim \therefore$ JSR PC,TYPE

SOB RI,LOOPI

JSR PC, CR

$\rightarrow$

RESREG

$\begin{array}{lll} & \text { RTS PC } \\ \text { TYPE: } & \text { TSTB } & \begin{array}{l}\text { EITTS } \\ \text { TYPE }\end{array} \\ \text { BPL } & \end{array}$
;SANE REGISTERS .

;R5 CONTAINS MUAEER TO BE PRINTED

;R2 <-- ADONESS OF TAQLE WITH

;PQHERS of 18

GRI (-- I OF DIGITS IN MUHAER

;CLEAR R4 FOR DIVISIOW

;EXTPACT DIGIT

;ADD ASCII BIAS

;PRINT IN SCREEN

;60 BACK UNIIL ALL DIGITS ABE DONE

;FINISH PRINTING

;RESTORE REGISTERS

;RTTURN

;IS SCREEN READY?

;HAIT UNTIL READY 


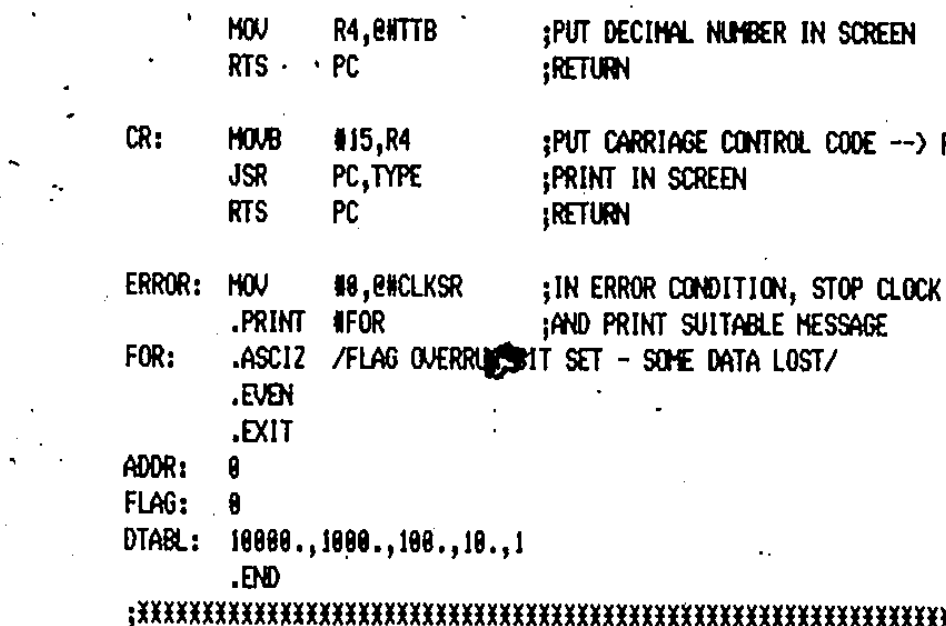

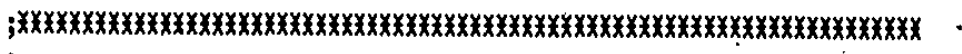

ROUTINE ANERAG

ROUTINE TO AVERAGE THO INPUT DATA FILE CONTAINING INTEGER DATA THE AUERAGED DATA IS RETURED IN THE FIRST ARPAY SPECIFIED IN THE DATA LINKASEE.

DATA LINKAGE IS STANDARD (SEE ROUTINE INDATA) ;

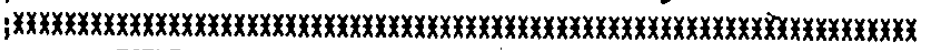
-TITLE AUERAG - globr avepag

ANERAG:

MOV RB, $-(S P)$

MON RI, $(S P)$

MOV R2,-(SP)

HON R3,-(SP)

HON RA, - (SP)

HOV RS, - (SP)

HON 2(R5), RO

MOV $4(R 5), R 1$

HOW $\quad 86(R 5), R 2$

LOOP: $\mathrm{MOW} \quad(R \mathrm{~J})+, \mathrm{R3}$

$A D D \quad$ (RB), R3

CLC

ASR R3

$\mathrm{HON} \quad \mathrm{R3},(\mathrm{R} \theta)+$

SOB R2,LOOP

HOV $\quad(S P)+, R 5$

HOV $\quad(S P)+, R 4$

HOW (SP)',$+ R 3$

MON $\quad(S P)+, R 2$

MON $\quad(S P)+, R 1$

MON $\quad(S P)+, R O$

RTS

PC .ED

¡SAVE REGISTERS<smiles>CCCCCC</smiles><smiles>C1CCCCC1</smiles> 


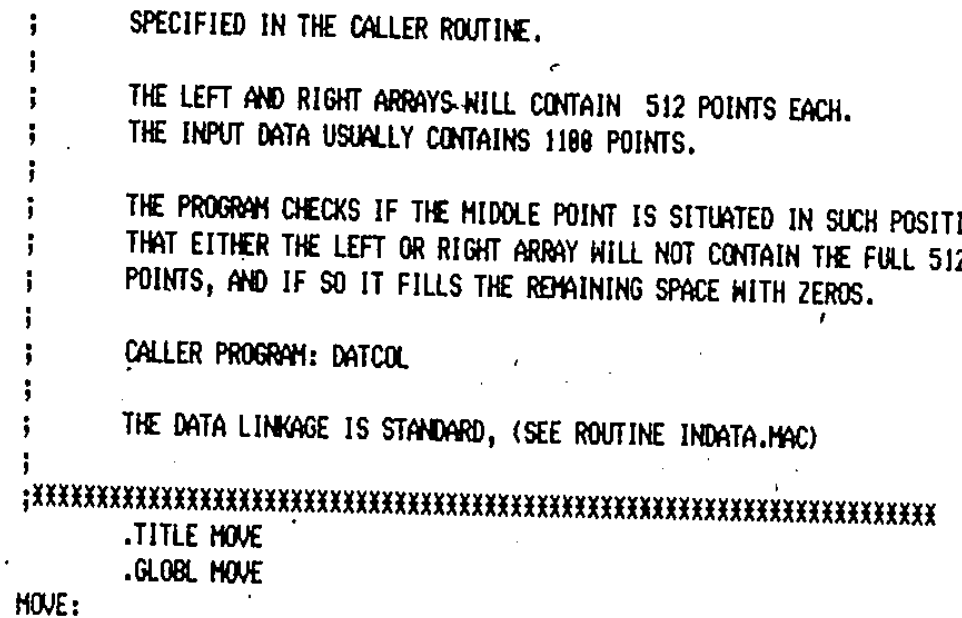

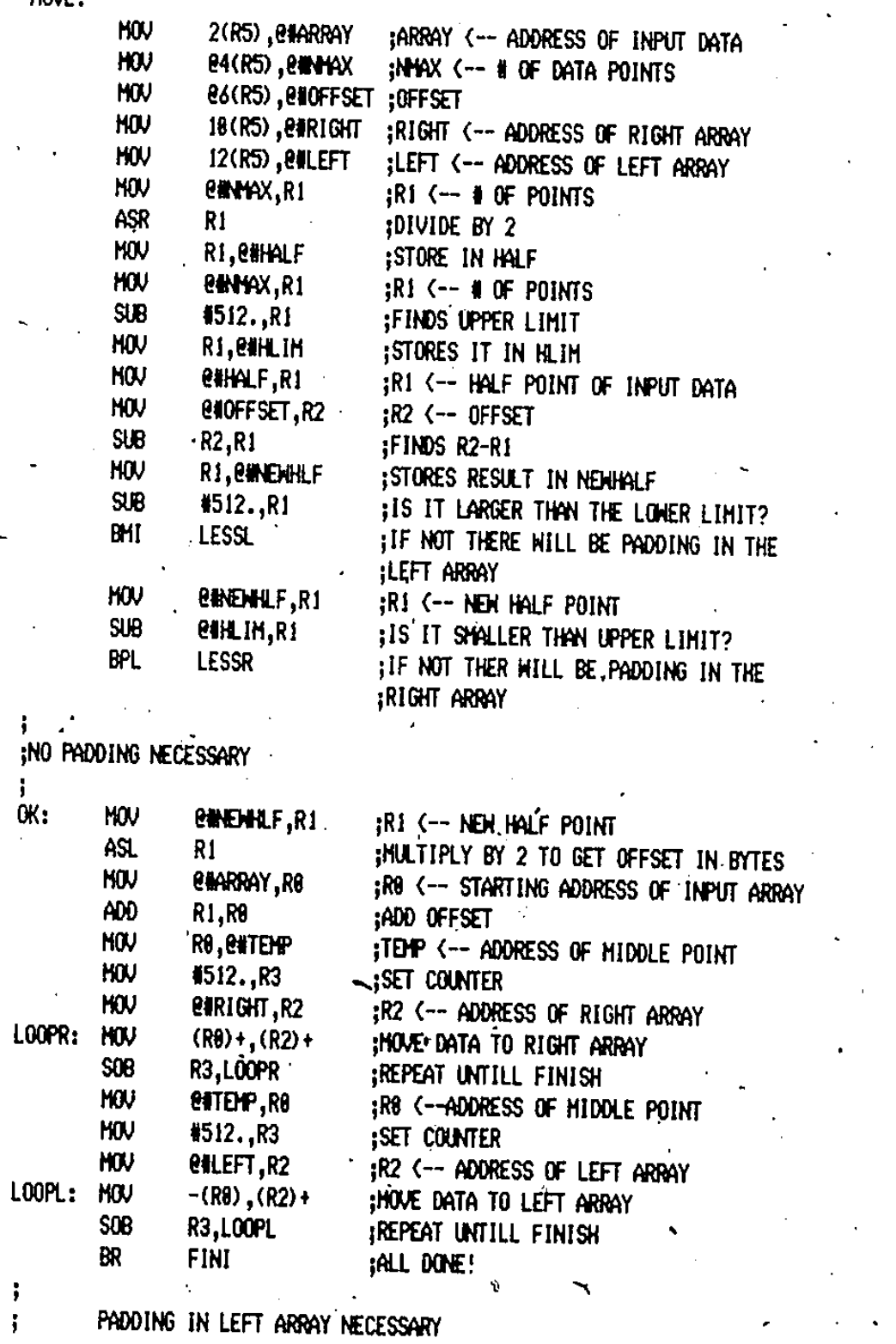


;

LESS: NEG RI

MON RI,QUDIFF ;DIFF <-- POINTS THAT WILL BE ZERO

HOW CNEHLF, RI ;RI (- NEN HALF POINT

HOV CUARRAY, RQ, ;RO (- ADORESS OF INPUT ARRAY

ASL RI FWLTIPLY BY 2 TO GET OFFSET IN BVES

$A D D$ RI,RO ;ADO OFFSET

HOW : RR,QHTEUP ;TEMP (-- ADORESS OF MIDOLE POINT

MON EUNEAHF, R3 ;R3 <- - OF POINTS THAT WILL BE COPIED

HOW EHLEFT, R2 ;R2 S- ADDRESS OF LEFT ARRAY

LOOP1: HOW -(RO),(R2)+ ;MOVE DATA TO LEFT ARRAY

SOB R3,LOOPI ;REPEAT UNTILL DONE

HOW PADIFF, R3 ;R3 <-- REAAINING | OF POINTS

LOOP2: $\mathrm{MON} \quad$ 19, (R2) + ;FILL HITH 2ERO

SOB R3,LOOP2 ;REPEAT UNTILL DONE

MON RITEP,RO ;TEP L- AODRESS OF MIOOLE POINT

HON 、 $\$ 512 ., R 3$;SET COUNTER

KON EIRIGH, R2 ;R2 (- ADDRESS OF RIGHT ARRAY *

LOOPA: $\mathrm{HON} \quad(\mathrm{R} 9)+,(\mathrm{R} 2)+$

SOB R3,LOOP4

;MOVE DATA TO RIGHT ARRAY

;ALL DONE

; padoing in RIGH apoay necegsary

;

LESSR: HOW RI,QUDIFF ;OFF (- - OF POINTS THAT WILL BE 2ERO

MOV QUARPAY,RQ ¿RO <-- ADORESS OF INPUT ARBAY

MON QWEALF, RI ;RI (- NGI HALF POINT

ASL R1

ADD RI,RO

;GET BYTES OFFSET

MON RO,EATERP

MON $512 ., R 3$

SLB

HON

LOOP5: KOW

EUDIFF, R3

;ADD OFFSET

;TEP (-- ADORESS OF MIDOLE POINT

BIRIGT, R2

(RO) +, (R2) +

R3,LOOPS.

;R3 <- 1 OF POINT TO BE COPIED

;R2 (-- ADDRESS OF RIGKT ARRAY

; MOUE DATA TO RIGI ARPAY

HOV

$\rightarrow \quad$ LOOP6: $\mathrm{MON}$

eIDIFF, $R 3$

;REPEAT UNTILL DONE

;R3 <-- OF REAIINING POINTS

$18,(R 2)$

R3,LOCP6

;FILL HITH ZEROS

MOW $1512 ., R 3$

MON ETEP,RO

;UNTILL DONE

MON

LOOP7: $\mathrm{MON}$

QALEFT, R2

;RO <-- AODRESS OF HIDOLE POINT

$-(R 6),(R 2)+$

;R2 (-- ADORESS OF LEFT ARPAY

$S O B \quad R 3,10007$

FINI: RTS

PC

¡HOUE DATA TO LEFT ARPAY

ARPAY: 8

NAX: 8

- OFFSET: $\theta$

HALF: $\theta$

HLIN: 8

NEWLF: 8

RIGHT: $\theta$

LEFT: $\theta$

DIFF: $\theta$

TEMP:

;REPEAT UNTILL DOSE

;RETLRN 


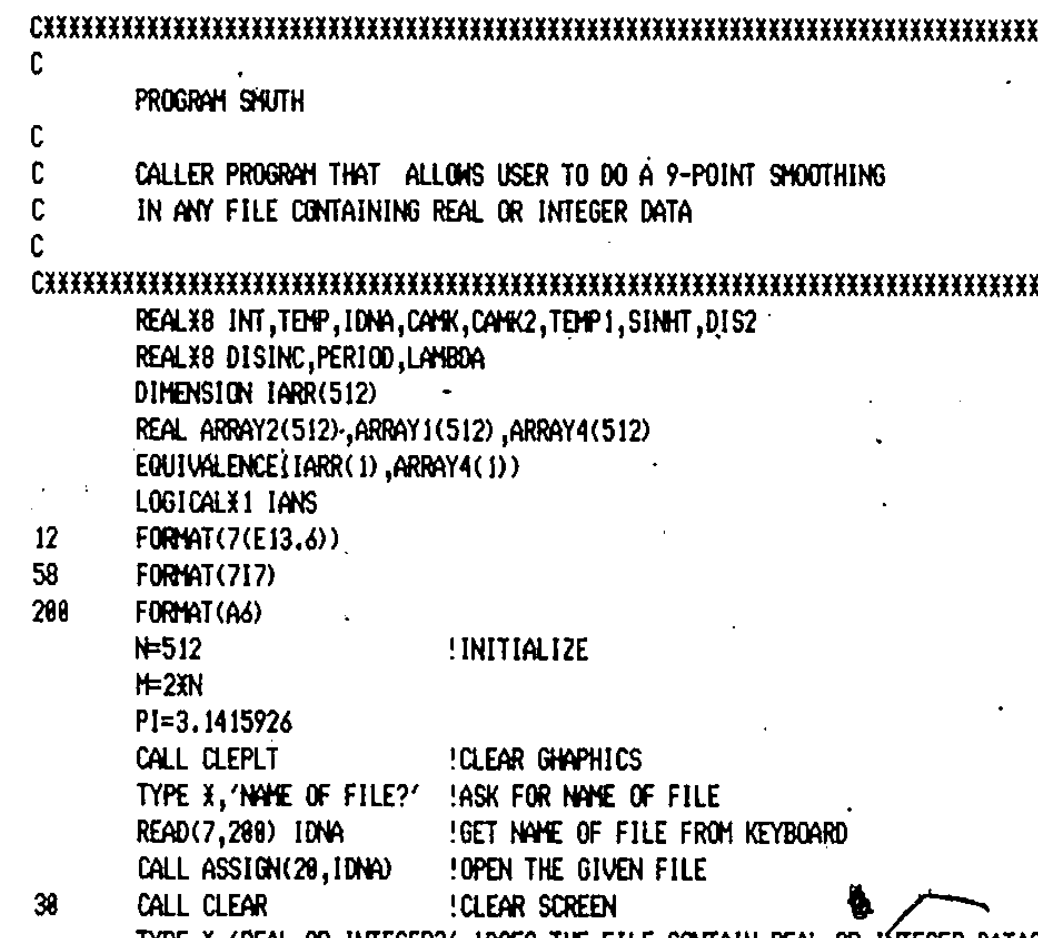

TYPE $X, ' R E A L$ OR INTEGER?' !DOES THE FILE CONTAIN REAL OR INTEGER DATA? CALL INCHAR(IANS) IGET ANSUER FROH KEY'BOARDD

IF(IANS.EQ.' $R^{\prime}$ ) OO TO 32

- IF(IANS.NE.'I') GO TO 38

READ $(28,58)$ (IARR(J), $J=1, N)$ !READ INTEGER DATA

CALL CLEAR ICLEAR. SCREEN

DO $1 \mathrm{~J}=1, \mathrm{~N} \quad$ !CONERT INTEGER DATA INTO REAL

$1 \quad \operatorname{AROAY} 1(J)=F \operatorname{LOAT}($ IARR $(J))$

GO TO 17

32 READ $(28,12)$ (ARPAYI (J), J $=1, N)$ !READ REAL DATA

17 CALL CLOSE(20) !CLOSE FILE

CALL CLEPLT !CLEAR GPAPHIC SCREEN

CALL 9400TH(N,ARRAYI, MH,ARPAY2) !DOES THE SHOOTHING

CALL PLTSIM(ARRAY2,ARRAYJ(4), N-8,0) !PLOT THE SYOOTH \& UNSHOOTH FILES

18

CALL PLTSIM(AARAY2(256), ARPBAY1(268), 252,8) !SHOW DETAIL OF GRAPHS

CALL CLEPLT ICLEAR GPAPHICS

TYPE $X$, 'SATISFIED?' - !DO YOU HISH MORE SHOOTHING?

CALL INCHAR(IANS) !EET ANSWEER

IF(IANS.EQ.' $N$ ') 60 TO 19

997 CALL CLEAR

TYPEX,'DO YOU HISH TO SANE?' !DO YOU HISH TO SAVE RESULTS? CALL INCHAR(IANS) !GET ANSWER

IF(IANS.EQ.'N') 60 TO 999

IF(IANS.NE.' $Y$ ') 60 TO 997

CALL CLEAR

TYPEX, 'WDER HAT NAYE?'

READ (7,208) IDNA

$D 03 N 1,4$

ARPAYI (J) =ARPAY $2(1)$

3 ARPAY $(N-J+1)=A R P A Y 2(504)$

DO $4 \mathrm{~J}=1, \mathrm{~N}-\mathrm{-8}$

$4 \cdot \operatorname{ARPAYI}(J+4)=A R R A Y 2(J)$

!ASK FOR THE NHE OF FILE TO BE CREATED !GET THE NAFE

ISET UP THE DATA INTO PROPER FORY 
CALL ASSIEN(28, IONA)

WRITE $(2 \theta, 12)$ (ARBAYI(J), $=1, N)$ !HRITE THE FILE

CALL CLOSE(29)

G0 TO 999

$19 \quad 002 \vDash 1, \mathrm{~N}-8$

ARPAYI $(J+4)=A$ RPAY $2(J)$

GO TO 17

999 ' CALL CLEPLT

CALL EXIT

END

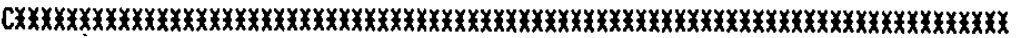

C

C

C

SLBROUINE TO DO 9-POINT SHOOTHING USING LEAST SPLLARES

TECHNIQUES.

CALLER PROGRAY: SWTH

FOR DETAILS SEE REFEREICE 27

DATA LINKAGE:

INPUT-

N NLABER OF RAN DATA POINTS

DATAIN ARRAY CONTAINING N DATA POINTS

OUTPUT-

M NWMEER OF SWOTH DATA POINTS

DATAO ARRAY CONTAINING SMOOTHED. DATA POINTS

C

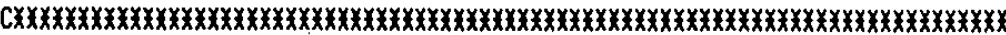

SUBROUT INE SHOOTH(N,DATAIN,M,DATAO)

REAL DATAIN(ND, DATAO(N), NP(9)

$\mathrm{H}=\mathrm{N}-8$

$0018 \mathrm{I}=2,9$

$J=[-1$

is $\quad \operatorname{NP}(\mathrm{I})=$ DATAIN(J)

$00208[=1, M$

$\mathrm{J}=\mathrm{I}+8$

DO $11 \mathrm{~K}=1,8$

$\mathrm{KA}=\mathrm{K}+1$

$11 \quad N(K)=P(K A)$

NP(9)=DATAIN(3)

SUt=59.XNP(5) +54.X(NP(4) +NP(6))+39. $x(N P(3)+N P(7))+14 . x(N P(2)+$

INP(8)) $-21 . x(N P(1)+N P(9))$

DATAO(I) ESLW 231 .

208 CONTINE

RETUPN

ED 


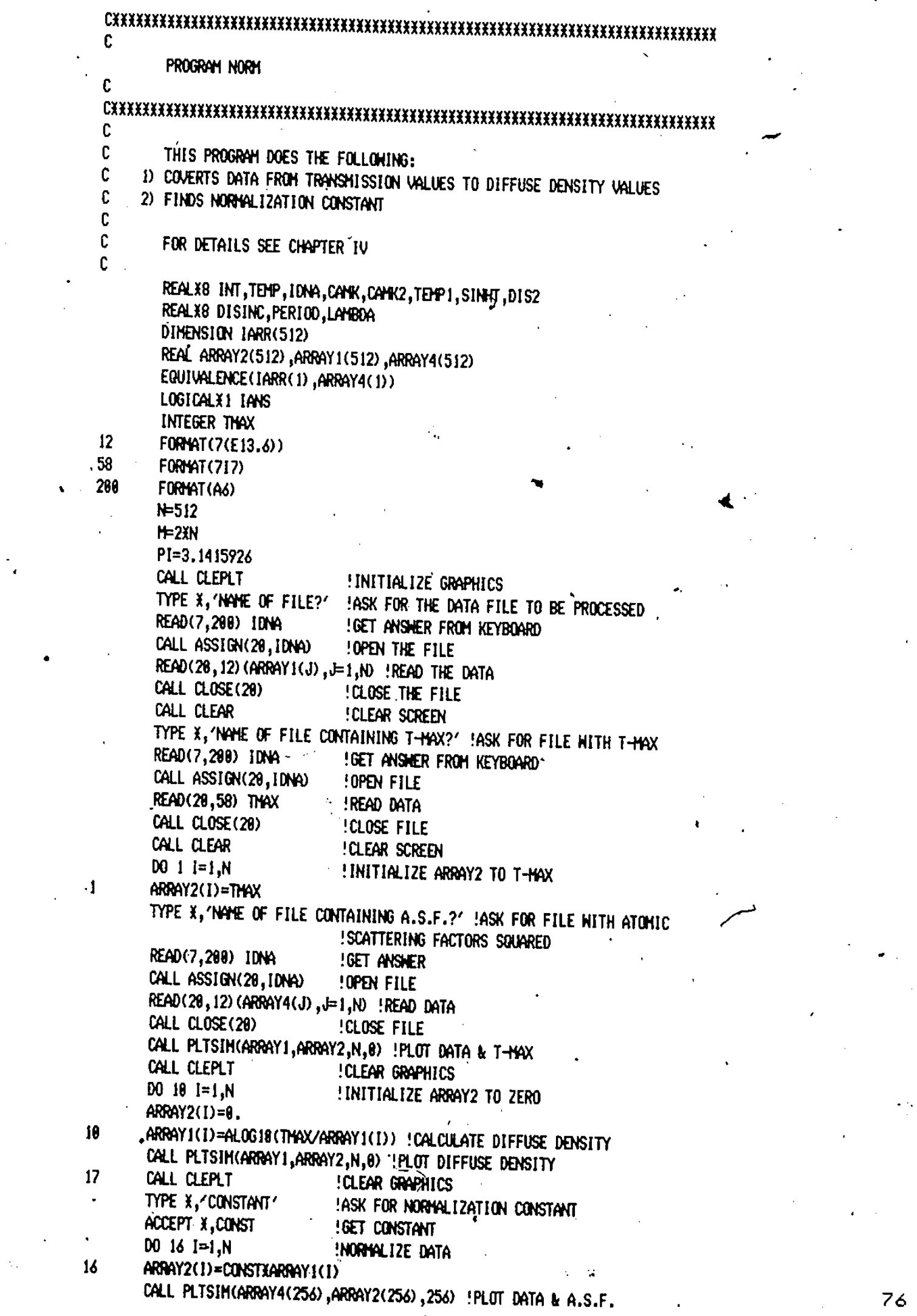


CALL CEPLT

!CLEAR GRAPHICS

TYPE $X, '$ SATISFIED?'

CALL INCHAR(IANS)

!GOOD ENOUCH?

!EET AKSTER

IF(IANS.EQ.' $N^{\prime}$ ) GO TO 17 ! IF NOT GO BACK FOR ANOTHER CONSTANT

IF(IANS.NE.' 'Y') 60 TO 18

997 CALL CLEPT

ICLEAR GRAPHICS

TYPEX,'DO YDU HISH TO SANE?' !SANE DATA?

CALL INCHAR(IANS) !GET ANSHER

IF(IANS.EQ.' $N$ ') 60 TO 999 ! IF NOT 60 TO FINISH

IF(IANS.NE.'Y') 60 TO 997

CALL CLEAR

. !CLEAR SCREEN

TYPEX,' WWER WHAT NAYE?' !ASK FOR NHE OF FILE TO BE MRITTEN INTO

READ(7,288) IONA

CALL ASSION(20,10NA)

WRITE $(28,12)$ CONST

!GET NAYE

!OPEN FILE

!HRITE NORALLIZATION COSTANT

HRITE $(28,12)$ (ARRAYI $(J), J=1, N 0$ !RRITE DATA

999

CALL CLOSE(28). ICLOSE FILE

CALL CLEPLT

CALL EXIT

!CLEAR/GAPHICS

END

!stop

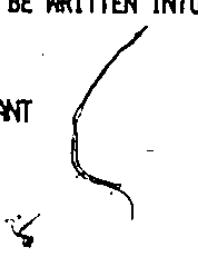




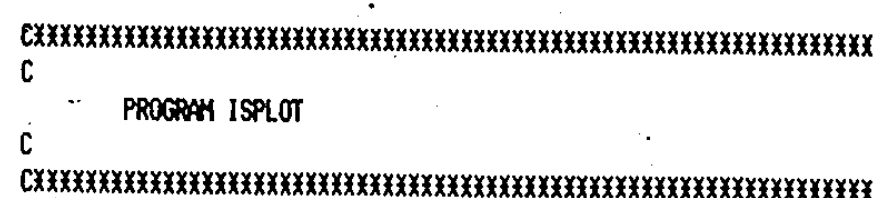

THIS PROGPAY GIUES A CHART RECOROER OUTPUT FOR THE FUNCTION $i(s)$. FROA THIS GRAP THE ERROR FUNCTION EPSALON CAN BE DETERMINED

FOR DETAILS SEE CHAPTER IV SECTION IV<smiles>C1CC[C@@H]2CCC[C@H]2C1</smiles>

REAL ATOFAC(512), ARPAYY ( 1824$)$, HALF (5J2)

REALX8 IONA, CANK, RSTEP,ACCPOT

REALX CAHK2, LAKBDA, PI, DISINC, DIS2, SKAX, RRES, RHAX

LOGICALX! IANS

$\digamma$ COMWONBLOCK/LAMBDA, CAMK, SINC

PI $=3.1415926$

12 FOAAAT (7(E13.6))

58 FORAT(717)

288. FORAT(AS)

291 FORATT' SHAX =',F7.4,/' S-STEP=',F7.4,/' R RESQUUTION=',F7.4,/

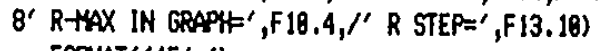

292 FORHT(11F6.1)

283 FORAT(I7)

CALL CLEPLT

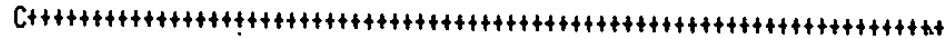

C

C NICKEL DATA

C

$$
\text { C }
$$

CAYH $=258.8$

DISINC $=8.8365 ?$

C

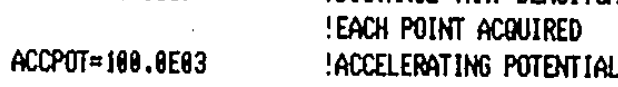

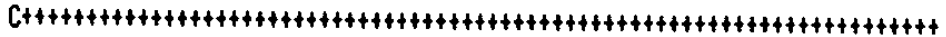
CALL HAMEN(ACCPOT,LAHBCA) !FIND THE HAMELENGH OF THE ELEC. BEAY $1=512$ $H=2 \times N$ IMUPER OF POINTS IN DATA FILE

SWX $=$ SAL (N) IMAXIMUY UALUE OF S IN DATA FILE

RRES $=1.8 /(2.0 \times$ SAAX) - !RESOUUION IN R SPACE

RHAX $=1.8 /(2.0 \times$ SYAL (2)) !HAXIHH WALUE OF $R$

RSTEP=RAX/FLOAT(N-1) IR INCREENT

$33 \operatorname{ARRAY}(J)=0.8$

! INITIALIZE

TYPE $X$, 'EXECUTING ISPLOT PROGRA'

NRITE(5, 201) SHAX, SUAL (2), RRES, RAAX 4, RSTEP

'TYPE $x$, NAYE OF DATA FILE?' !ASK FOR NAYE OF DATA FILE

READ $(7,298)$ IONA IGET NAYE

CALL ASSIGN(28,IONA) !OPEN FILE

READ $(20,12)$ CONST !READ NORHLIZATION CONSTANT

$\operatorname{READ}(20,12)$ (HALF $(J), J=1, N)$ !READ DATA

CALL: CLOSE(28) ICLOSE FILE

C. CALL PLTSIM(HALF, ;ARAGY,N,8) !PLOT DATA

CALL CLEAR - !CLEAR SCREEN

TYPE $X$, NAHE OK FILE CONTAININO A.S.F.' !ASK FOR NAYE OF FILE WITK

C 'ATOHIC SCATTERING FACTORS SQUAPED

- TYPE $x$, 'HAE OF FILE CONTAINING A.S.F.'

READ(7,280) IONA !GET NAE 
CALLL ASSION(20,IONA) !OPEN THE FILE

READ $(28,12)$ (ATOFAC $(J), J 1, N D$ !READ THE A.S.F

CALL CLOSE(28) !CLOSE THE FILE

CALL QLEAR ICLEAR SCREEN

DO $21 \mathrm{~J}=1, N \quad$ !CALCULATE $i(s)$

\section{$S=\operatorname{SNAL}(J)$}

$21 \quad$ HALF $(J)=S X((H A L F(J) \times C O N S T / A T O F A C(J))-1)$

CALL PLTSIM(HALF,ARPAY,N,8) !PLOT IN SCREEN $i(s)$

220 CALL CLEAR

TYPE $x_{\text {, }}$ READY?'

a !CLEAR SCREEN

CALL INCHAR(IANS)

!READY TO USE CHART RECOROER

IF (IANS.NE.' 'Y') GO TO 22 !IF NOR ASK AGAIN

CALL CLEAR

!CLEAR SCREEN

$\stackrel{c}{c}$

CALL OUAINT (HALF,ARPAY,M,N) !OOES QUADERATIC INTERPOLATION IN DATA !SO THAT THE MUEBR OF POINTS PLOTED IN THE ICHART RECOROER IS DOUQAED

CALL PLOTOA(ARPAY,H,1) !PLOT IN CHAR RECOROER UIA D/A

CALL CLEPLT

CALL EXIT

!RING BELL HHEN DONE PLOTING

END !CLEAR GPAPHICS

!STOP

. 


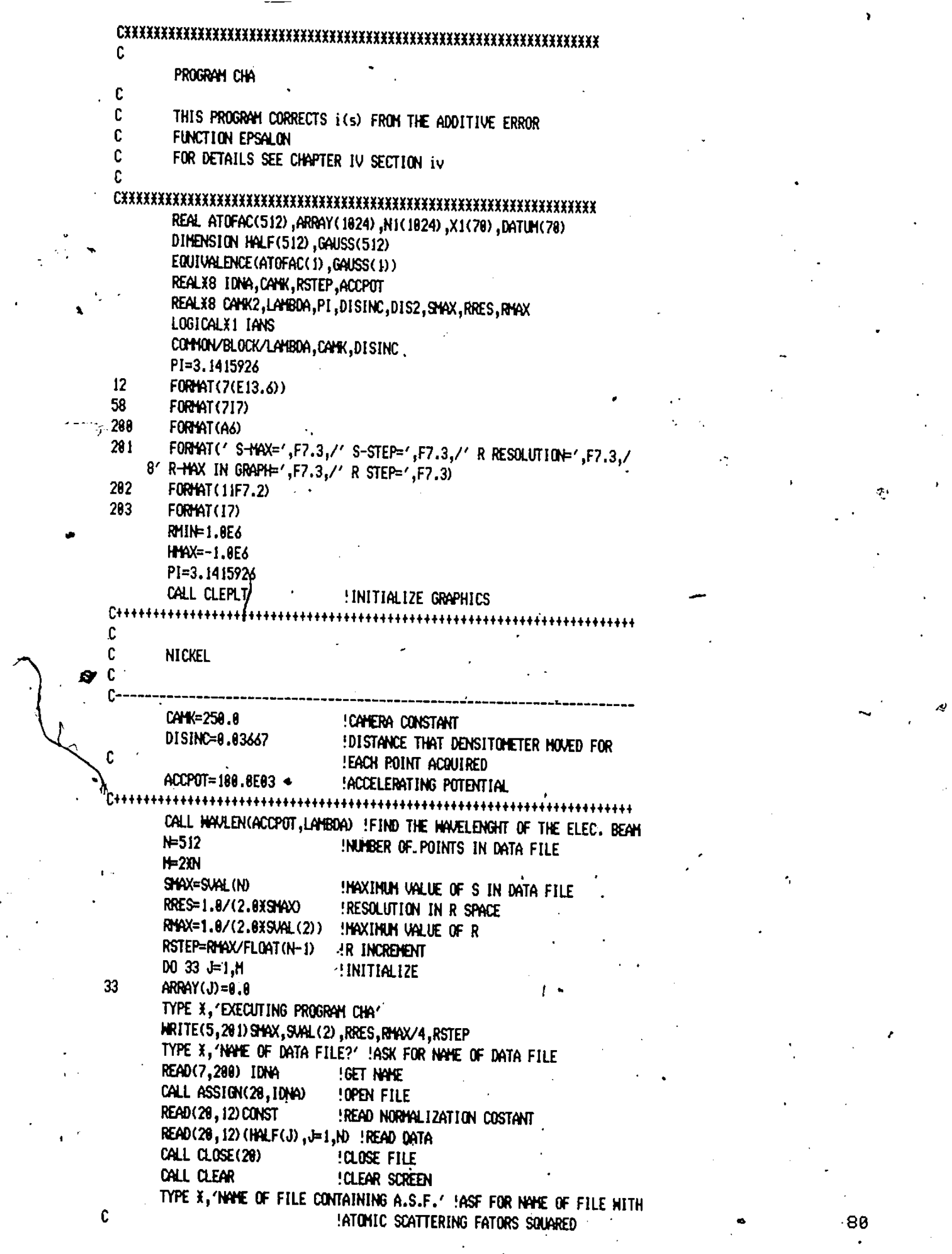




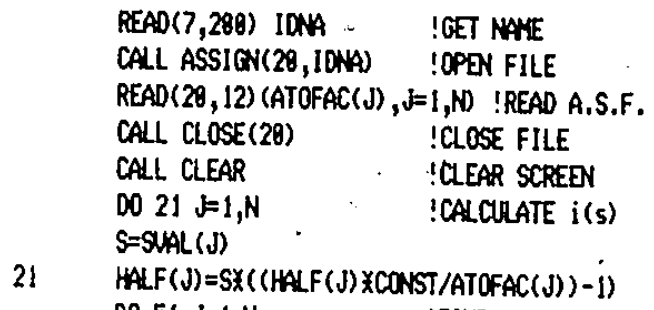




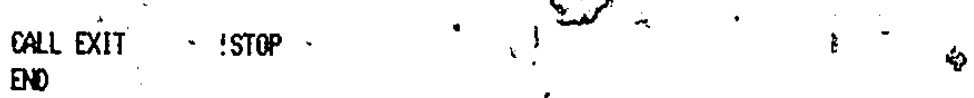

Appendix 2

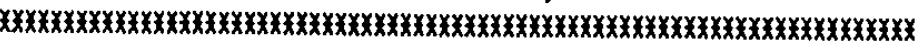

C THIS ROUTINE INTERPOLATES THE ULLLE OF A FUNCTION AT ANY WALUE

- OF THE X-AXIS.

THE FUNCTION MUST BE INPUTED AS A SERIES OF YALUES FOR SPECIFIC WALLES OF $X$

THE PROGPAY USES QLADPATIC INTERPOLATION TO FIND A NEN YSLUE OF

THE FUNCTION BEING CONSIDERED

FOR OETAIIS OF THE QUADRATIC IMTERPOLATION TECHNIOUE USED SEE: E. KREYSZIG,ADUAWCED ENGINEERING HATHEATIICS, CHAPTER 19, PAGE 774

CALLER PROGPAH: CHA

'DATA LINKAGE:

INPUT-

- ARPAY I UALUE OF FUNCTION AT POINTS DEFINED BY XI

$X I$ VALLES OF $X$ FOR WHICH THE FUNCTION HAS A DEFINED VALLUE

M MURBER OF POINTS IN ARRAYI \& XI

$X X$ WALLE OF $X$ FOR WHICH THE WALLE OF THE

OUTPUת - : .FUNCTION IS BEING SEEK

FX INTERPOLATED WALLE OF THE FUNCTION AT POINT XX

C

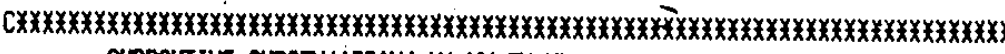

SLBROUTINE CURGEN(ARRAYI,XI, XX,FX,10)

DIMENSION ARRAYI(TD, XI(1)

c

CALL BINSER $(X X, X 1, H, D)$ !USE A BINAPY SEARCH TEONIQUE TO FINO

IF(I.GE.M-1) I=H-2

!THE INTERNAL IN WHICH THE NER POINT FALLS

$X X(B=X I(I)$

$X X 1=X 1(1+1)$

$X \times 2=X 1(1+2)$

$H=(X X 2-X X(\theta) / 2$

$F X \theta=A P P A Y 1(1)$

FXI=APRAY $1(I+1)$

$F X 2=A P P A Y 1(1+2)$

$D F B=F X 1-F X \theta$

OF $J=F \times 2-F \times 1$

$D Z F B=D F J-D F \theta$

$R=(X X-X X \theta) / H$

$F X=F X B+(R \times D F B)+(R X(R-1) \times .5 \times D 2 F B)$

RETURN

END

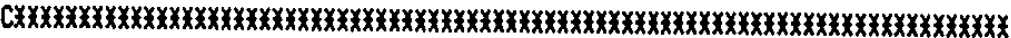

C ROUTINE TO FIND THE INTERAL IN HICK AN, MWBER FALLS IN A

LIST OF GIVEN MUBERS

6

FOR REFERENCES SEE:

D.E. WNTH,'THE ART OF CONPUTER PROCPAHINO VOL.3, SORTING

ANO SEARCHING",PAGES 486/488, ADOISON HESLEY: READING MASS. 1973

CALLER PROGOBAY: CORGEN 
Appendix 2

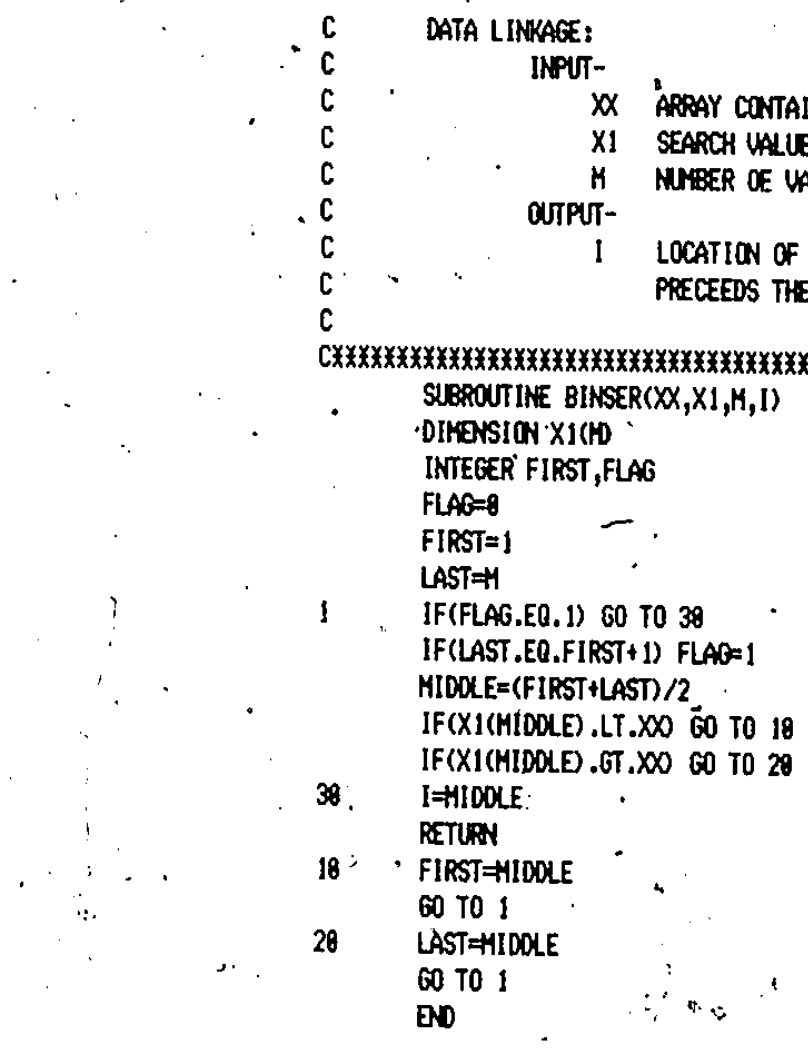




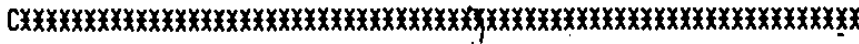

C

- PROGRAY KAP

C THIS PROGPH CORPECTS FOR SYSTEATIC ERRORS CAUSED BY

C ERROAEOUS NORGLIZZATION AND INCORRECT ATCMIC SCATTERING

C FACTORS.

FOR OETAILS SEE CHAPTER IV SECTION ii

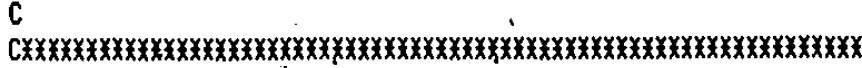

REAL ARPAY(512), NI(1824)

DIMENSION HALF(512), GAUSS(512)

EQUIUALENCE(N1(513), HALL)

REALX8 IONA, CAMK, RSTEP,ACCPOT

REALX8 CATK2, LAYBOA,PI, DISINC,DIS2, GHX, RRES, PAAX

LOSICALXIIANS

COMONBLLOKLLA COA, CAKK,DISINC

$P I=3.1415926$

12 FORATT(7(E13.6))

58 FOPUAT(7I7)

288 FOPATT(AG)

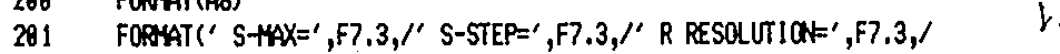

8' R+HAX IN GRAPH'=',F7.3,/' R STEP=',F7.3)

CALL. CLEPLT

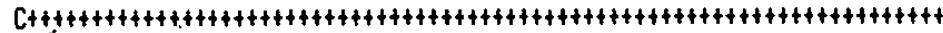

c

c NICXEL

C

$$
\text { c- }
$$

CANK $=259.9$

DISINC $=8.03667$

ACCPOT=180.8E3

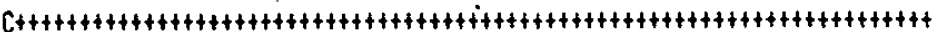

$N=512$

IMUTBER OF POINTS IN DATA FILE

$H=2 \times \mathrm{N}$

CALL HAREN(ACCPOT, LAYBOAA)! FIND HAELENGHT OF ELECTRON BEAH

SHAX=SWAL (N) I !HAXIMH UALUE OF S IN DATA FILE

RRES $=1.8 /(2 . X 94 X) \quad$ !RESOLUTION IN R SPACE -

PHAX $=1.8 /(2$. XSALL (2) $) \quad$ !HAXIHWH UALUE OF $R$

RSTEP-AYAX/FLOAT $(\mathrm{N}-1) \quad ! R$ INCREFENT FOR EACH POINT

!INITIALIZE

$\operatorname{ARRAY}(J)=0.8$

TYPE $X,{ }^{\prime}$ EXECUTING KAP CORRECTION PROCEOURE'

WRITE $(5,291)$ SHAX, SALL (2), RRES, RTAX/4, RSTEP

TYPE $X$, 'NAYE OF DATA FILE?' !ASK FOR NAYE OF DATA FILE

READ(7;,298) IDNA ' !GET NAYE

CALL ASSION(20,IOKA) !OPEN FILE

READ $28 ; 12)$ (HALLF(J), $J=1, N 0$ !READ DATA

$\therefore \quad$ CALL CLOSE(28) !CLOSE FILE

CALL PLTSIM(HALF, ARPAY,N,B) !PLOT INPUT DATA

$75 \quad$ DO $59 \mathrm{~J}=1, \mathrm{~N}$

58. $. A R P A Y(J)=H A L F(J)$

CALL CLEPLT

ISTORE INPUT DATA IN ARRAY

DO $49 I=1, N$

$49 \quad N 1(1)=-H A L F(513-1)$

CALL FORRT (NI M) IDO FOURIER TRANSFORY

!CLEAR GPAPHICS .

!CREATE OOD FUNCTION

CALL PLOT (HAL, N)

!PLOT REOUCED R.D.F: 


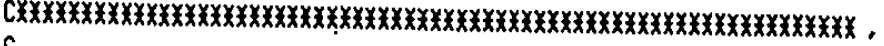
C PROCRAY RDF.

PROGPAY TO GENERATE REDUCED RADIAL' DISTRIBUTION FACTIONS USES THE HAWING FUNCTION AS THE TERIIATION FUMCTION

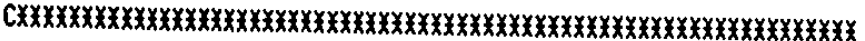
REAL ARRAY(512), N1(1824) DIHENSION HALF(512), GAUSS(512)

EQNIULLENCE (NI(513), HALF)

REALX 8 IONA, CAYK, RSTEP,ACCPOT

REALX8 CAIK2, LAHBDA, PI ,DISINC,DIS2, SYAX, RRES, PAAX LOGICALXI IANS COHMONBLOCKLAMBOA,CAKK,DISINC

$12 \quad$ FORAT(7)

FQNAT(7) (E) 3.6))

FOAATT (717)

$200^{\circ}$ FORAT(A6)

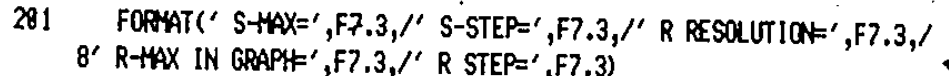
CALL CLEPLT

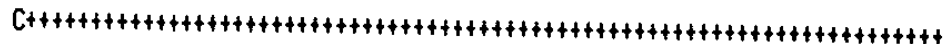
C

C NICKEL

C

C--

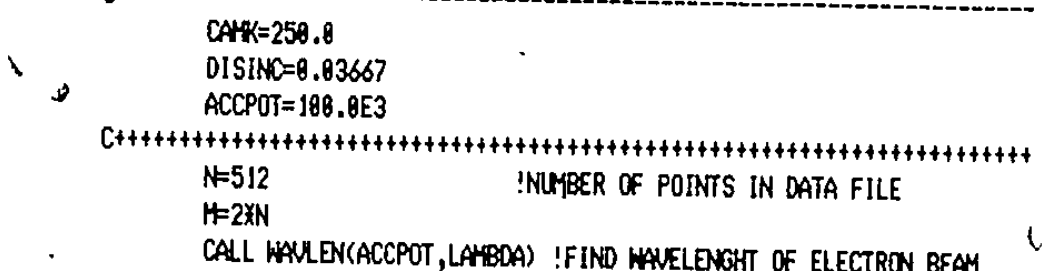

CALL WAULEN(ACCPOT, LA HBDAA) !FIND WAVELENOHT OF ELECTRON BEAY

SHAX $=$ STAL (N) RRES $=1.8 /(2 . X S 44 X)$ !MAXIMUM UALUE OF S IN DATA FILE

?RESOLUTION IN R SPACE

RSTEP $=$ PAAX/FLLAT(N-1) IR INCREMENT FOR EACH POINT

33

$$
0033 \mathrm{~J}=1, \mathrm{~N}
$$
! INITIALIZE

\section{ARAYY $(J)=0.8$}

TYPE $X$, 'CALCULATING ROF FOR NICKEL'

HRITE $(5,281)$ SMAX, SUAL (2), RRES, RYAX 4, RSTEP

TYPE 'X, 'NAYE OF OATA FILE?' !ASK FOR NAYE OF DATA FILE

READ $(7,298)$ IONA !GET NAYE

CALL ASSIGN(20,IONA) !OPEN FILIE

READ $(29,12)$ (HALL (j), J $=1, N)$ !READ DATA, THE $i(s)$ FUNCTION

CALL CLOSE(28) !CLOSE THE FILE

CALL PLTSIM(HALF, ARRAY,N,8) !PLOT TKE DATA

- CALL CLEPLT . !CLEAR GRAPHICS

DO $39^{\circ} i=1$,N ICREATE AN ODD FLNCTION

$30 \quad N I(1)=-H A L F(N+1-1) \quad$ !

$28 D O 28 \mathrm{H}=1, \mathrm{M}$ !MULTIPLY BY TERMINATING FUNCTION

$28 \quad N 1(J)=N 1(J) \times(8.5+8.5 \times \operatorname{COS}(\operatorname{PIXFLOAT}(J-1) / F L O A T(N D))$

CALL FORRT (NI, YD $\quad$ !PERFORY TRANSFORY

92 CALL PLOT (HALF,N) . !PLOT REOUCED ROF $\begin{array}{lll}92 & \text { CALL CLEPLT } & \text { !CLEAR GRAPHICS } \\ & \text { OO 26 } J=1, N & \text { !NORALLIZE } \\ 26 & H A L F(J)=8 . \times P I X H A L F(J) & ! \cdot\end{array}$ 
CALL GLAINT(HALF, GANSS,N,NA) !EXPAND SECTION OF INTEREST TO

C

$\therefore \quad$ - 512 POINTS

CALL PLOTIGAUSS,ND - !PLOT RESULTS

CALL CLEPLT ICLEAR GRAPHICS

TYPEX, 'DO YOU HISH TO SAVE?' !SANE RESULTS?

CALL INCHAR(IANS) I IGET ANSHER

IF(IANS.EQ.' $N^{\prime}$ ) GO TO 899 ! IF NOT GO TO END

IF(IANS.NE.' ' ${ }^{\prime}$ ) GO TO 92

CALL CLEAR . ICLEAR SCREEN

TYPE $\dot{x}$, 'LNOER HHAT NAHE?' !ASK NAYE OF FILE TO BE CREATEO

READ(7,208) IONA IGET. NAHE

CALL ASSIGI(28, IOAA) IOPEN FILE

WRITE $(28,12)$ (GAUSS $(J), J=1, N)$ !WRITE REDUCED RDF"

899

CALL CLCSE(28) \% ?

CALL CLEPLT ICLEAR GRAPHICS

CALL EXIT

!\$TOP

END

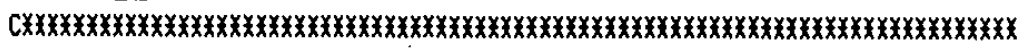

C PROGRAY OLAINT

SUBROUTINE TO DO QUADPATIC INTERPOLATION

CALLER PROGRAHS: ISPLOT,RDF

, LINKAGE:

ARRAY1 - ARRAY CONTAINING CRIGINAL DATA

ARRAY2 - WILL CONTAIN INTERPQLATED DATA

N - DIMENSION OF ARBAY2, NENMYXY

M - DIMENSION OF ARRAYI

FOR REFERENCES SEE - E. KREYSZIG,ADUANCEO ENGINEERING MATHEAMTICS, CHAPTER 19,PAGE 774

C

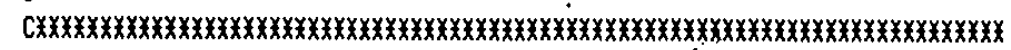

SLBROUI INE OLAINT (ARRAYI,ARRAY2,N, Y)

DIMENSION ARRAYI(HD ,ARPAYZC(N)

NUFANM

$J=8$

$0018 \mathrm{I}=1, M-2$

$x=1-1$

$\mathrm{X}=\mathrm{I}$

$x 2=1+1$

$H=(X 2-X \theta) / 2$

FXP $=A$ ARAYI $(1)$

FXI=ARAPAY $1(1+1)$

EXZ=ARPAY $1(1+2)$

$J=J+1$

$A R P A Y 2(J)=F X B$

$\therefore$ DFE $=F X_{1}-F \times O$

DF $1=F \times 2-F \times 1$

$D 2 F B=0 F 1-D F B$

DO $28 \mathrm{JJ}=1, \mathrm{NLH}-1$

$X=X \theta+F L O A T$ (JJ) $/ F L C A T$ (NLM)

$R=(X-X(\theta) / H$

$F X=F X \theta+(R X D F \theta)+(R X(R-1) X .5 \times 02 F \theta)$

$J=J+1$

28

ARRAY2(J) $=F X$ 
$10^{\circ}:$ CONIINEE

DO $38 \mathrm{I}=1,2$

$J=3+1$

ARRAY2(J)=ARRAY1(M̀-2+1).

DO $48 \mathrm{~J} J=1, \mathrm{NH}-1$

IF(I.EQ . 1$) X=X i+F L O A T(J J) / F L O A K$ A

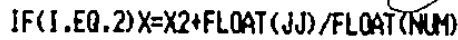

$R=(X-X \theta) / H$

$. F X=F X \theta+(R \times D F \theta)+(R X(R-1) \times .5 \times D 2 F \theta)$

$J=j+1$

$48 \quad \operatorname{ARPAY} 2(j)=F X$

39. CONTINUE

RETUPN

END

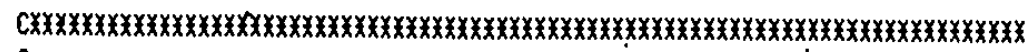

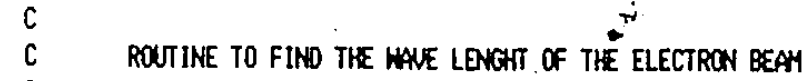

C RUIINE TO FIND THE WUE LENGHT OF THE ELECTRON BEAY

C. CALLER PROGPAHS: ISPLOT,CHA, KAP, RDF

C

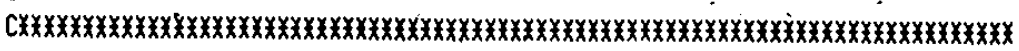

SLEROUTINE WALEN(ACCPOT, LAYBOA)

IPPSICIT REALX $X 8$ (A-2)

LSPEED $=2.998 E 10$

!ELECTRON REST HASS

$E V=1.682 E-12$ ! !EV CONWERSION

'c

PLANK=6.626E-27 $\because \quad$ !PLANK'S CONSTANT

ENEROY=ACCPOTXEV

HOCZ=PAASSX (LSPEEDXX2)

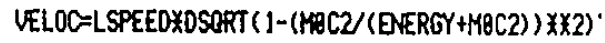

BETHA $1.8 /$ DSORT ( 1 -(UELOC/LSPEED) $X X 2)$

LAMBOAFPLANK (BETHAXPAASSXVELOC)X1.8E8

RETUPN

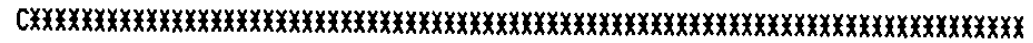

C

C ROUTINE SLAL

c

C DETERMINES THE VALUE OF THE SCATtERING PARATETER S AS A FUNCTION OF

C THE POINT MUBER

C

c

cxx

CALLER PROGBAHS:RDF, CHA, ISPLOT, FIXIT, NORY

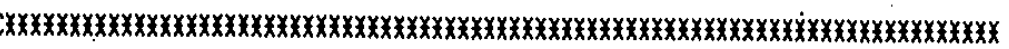
FUNCTION SAAL(I)

IMPLICIT REAL $X 8(A-H, O-Z)$

REALX8 LAWBOA

COMONBLL OCKLLAYBDA, CAMK, DISINC

CATKZ=CAKXCANK

c

$R R=(D I S I N C) \times(1-1)$

RR2=RRXRR

TEMP $1=$ CAHK/OSQRT (PR2+CAK2)

$\operatorname{SINZHT=DSQRT}(8.58 \times(1,-T E 4 P I))$

SWAL $=2 . *(S I N Z H T) /($ LAMBOA $)$

RETURN

!DISTANCE THAT DENSITOKETER HAS

MOUED UP TO THE SPECIFIED POINT

END

!FIND THE SINE OF ANGLE THAT

!CORRESPONDS TO THIS SWALLEST INTERUAL

IFIND VHLLE OF S

!RETLNON 
$F \boxminus F E \Gamma \in R \subset E S$

1) T.J. Chainer, D.A. Thompson and T.K. Worthington, Fall Meating of the Electrochem. Soc., paper \#138

2) G.S. Cargill III, J. Appl. Phys., 41, 12 (1970)

3) T. Yamasaki, H. Izumi and H. Sunada, Scrip. Metall., 15, 177 (1981)

4) J.P. Marton, Ph.D. Thesis, University of Western Ontario

5) I. Kiflawi and M. Schlesinger, J. Electrochem. Soc., 130, 872 . (1983)

6) J.L. Chow, N.E. Hedgecock, M. Schiesinger and J. Rezek, J. Electrochem. Soc., 119, 1614 (1972)

7) J.P. Marton and M. Schlesinger, J. Electroch. Soc., 115, $\therefore \quad 16(1968)$

8). E. Vafaei-Makhsoos, E.L. Thomas and L.E. Toth, Metall. Transe., 9A, 1449 (1978)

9) E. Vafaei-Mạkhsoos, J. Appl. Phys, 51, 12 (1981)

10) F. Zernike and J.A. Prins, Z. Phys., 41, 184 (1927).

11) P: Debye and H. Menke, Physikal. Zeit., 31, 797 (1930)

12) N.S. Gingrich, Rev. Mod. Phys., 15, 90 (1943)

- 13) J. Waser and V. Schomaker, Rev. Mod. Phys., 25, 671 (1953)

14) R. Hosemann and S.N. Bagchi, Direst Analysis of Diffraction by Matter, North Holland Publ.: Amsterdam 1962

15) A. Guinier, X-Ray Diffraction, Chapters 2 and 3, Freeman: San Fransicico 1963

16) B.E. Warren, X-Ray Diffraction, Chapter 10., Addison-Wesley: Readifig, Massachussetts 1969

17) D.8. Dove, Physics of Ihin Eilms, Academic Press, Vol. 7, 1 (1973) 
18) C.N.J. Wagner, Journal of Non-Crystalline Solids, 42, 3 (1980)

19) M. Goldstein, Classical Mechanics, Addison-Wesley: Reading, Mass. 1956

20) J.D. Jackson, Classicial Electrodxnamics, $2^{\text {nd }}$ edition; Wiley and Son: New York 1975

21) Watson, Iheory of Bessel Eunctions $2^{\text {nd }}$ edition, Cambridge 1952

22) N.F. Mott and H.S.W. Massey, the Theory of Atomic collisions

$\therefore \quad 3^{\text {rd }}$ edition, Oxford University Press: New York $1965^{\circ}$

23) see referençe 22 page 89

24) P.A. Doyle and P.S. Turner, Acta Ciryst., A24, 390 (1968)

25) reference 16, pages 121-122

26) G.S. Cargill III, J. Appl. Cryst., 4, 277 197.1

27) A. Savitzky and M.J.E. Golay, Anal. Chem., vol 36, No. 8, $1627(1964)$

28) T.H. James and.G.C. Higgins, Eundamentals of Photooraphic Iheory, John Willey \& Son: London $1948^{\circ}$

29) A. Papoulis, The Eourier Inteoral and its Apolications; MeGraw.Hill: New York 1962

30). E. Oran Brigham, The East Eourier Fansform, Prentice-Hall: Engl ewood, Nẹw Jersey 1974

31) R.J. Bell, Introductary Eourier Iransform Spectroscopiy, Academic'Press: New'York 1972

32) R. Kaplow, S.L. Strong and B.L. Averbach, Phys. Rev., 138 , 1336 (1965)

33) J.F. Graczyk, P. Chaudhari, Phys. Stat. Soli. (b), 58, is 
... (1973)

34) I. Kiflawi and M. Schlesinger, J. Electrochem. Soc , „130, 872 (1983)

35) B.E. Warren, J. Appl. Phys., 12, 375 (19.41)

36) J.P. Marton and M. Schlesinger, f. Electrochem. Soc.., ب15, 16 (1968)

37) N. Feldştein, M. Schlesinger, N.E. Hedgecock and S.L. Chow, J. Electrachem. Soc., 121, $6(1974)$.

38) M. Schelensiger and J.P. Marton, J. Appl. Phys., $\frac{40,}{!} 8$ (1969)

39) J.W. Cooley and J.W. Tuckey, Math. Comp., 19, 297 (1965)

40) D.M. Monro, Appl. Statist., 24, 268 (1975)

41) D.M. Monro, Appl. Statist., 25, 166 (1976) 


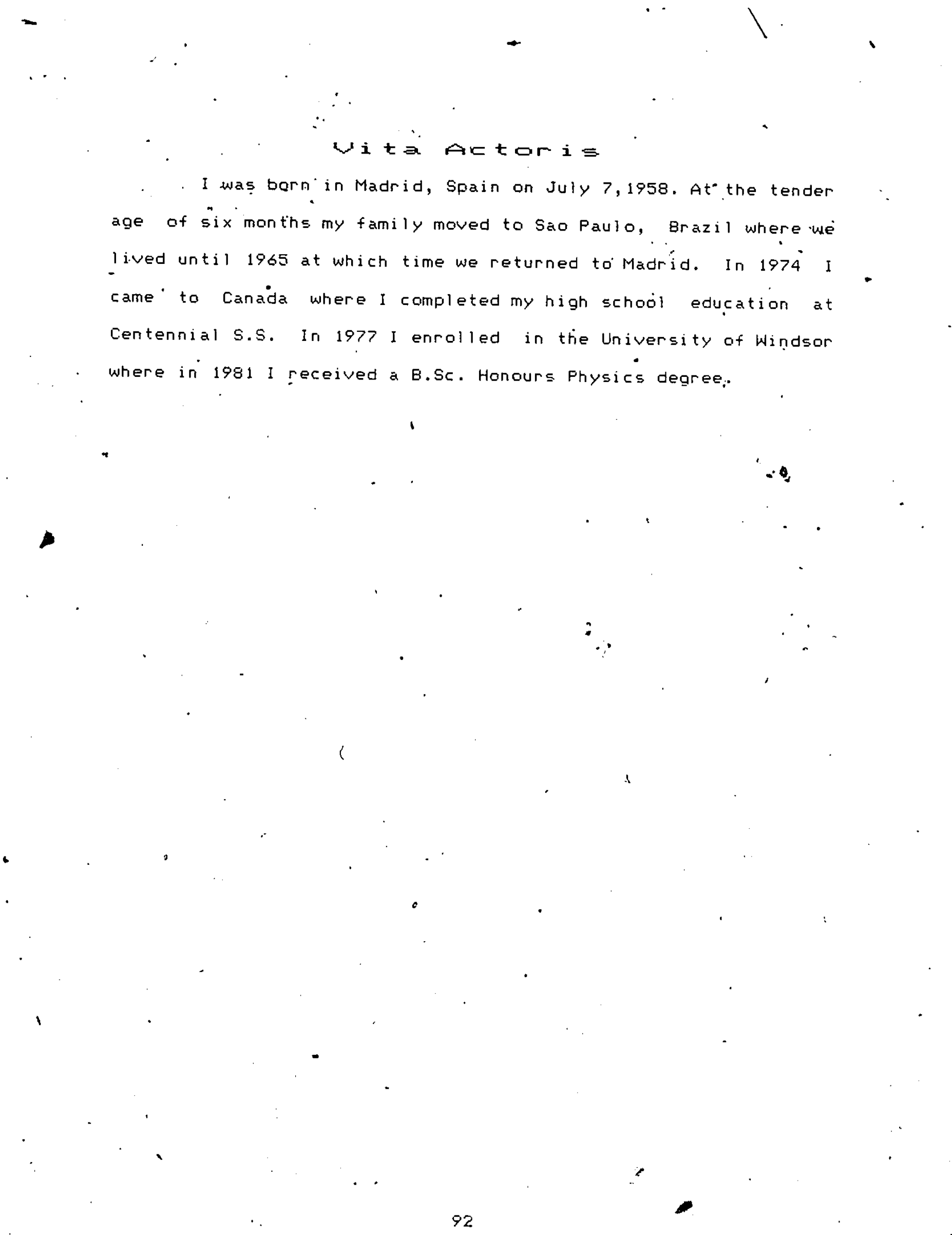

